SANDIA REPORT

SAND96-0729 • UC-721

Unlimited Release

Printed March 1996
RECEIVED

MAY 151996

O S.TI

\title{
Superconducting Technology Program: Sandia 1995 Annual Report
}

\section{E. Peter Roth}

Prepared by

Sandia National Laboratories

Albuquerque, New Mexico 87185 and Livermore, California 94550

for the United States Department of Energy

under Contract DE-AC04-94AL85000

Approved for public release; distribution is unlimited.

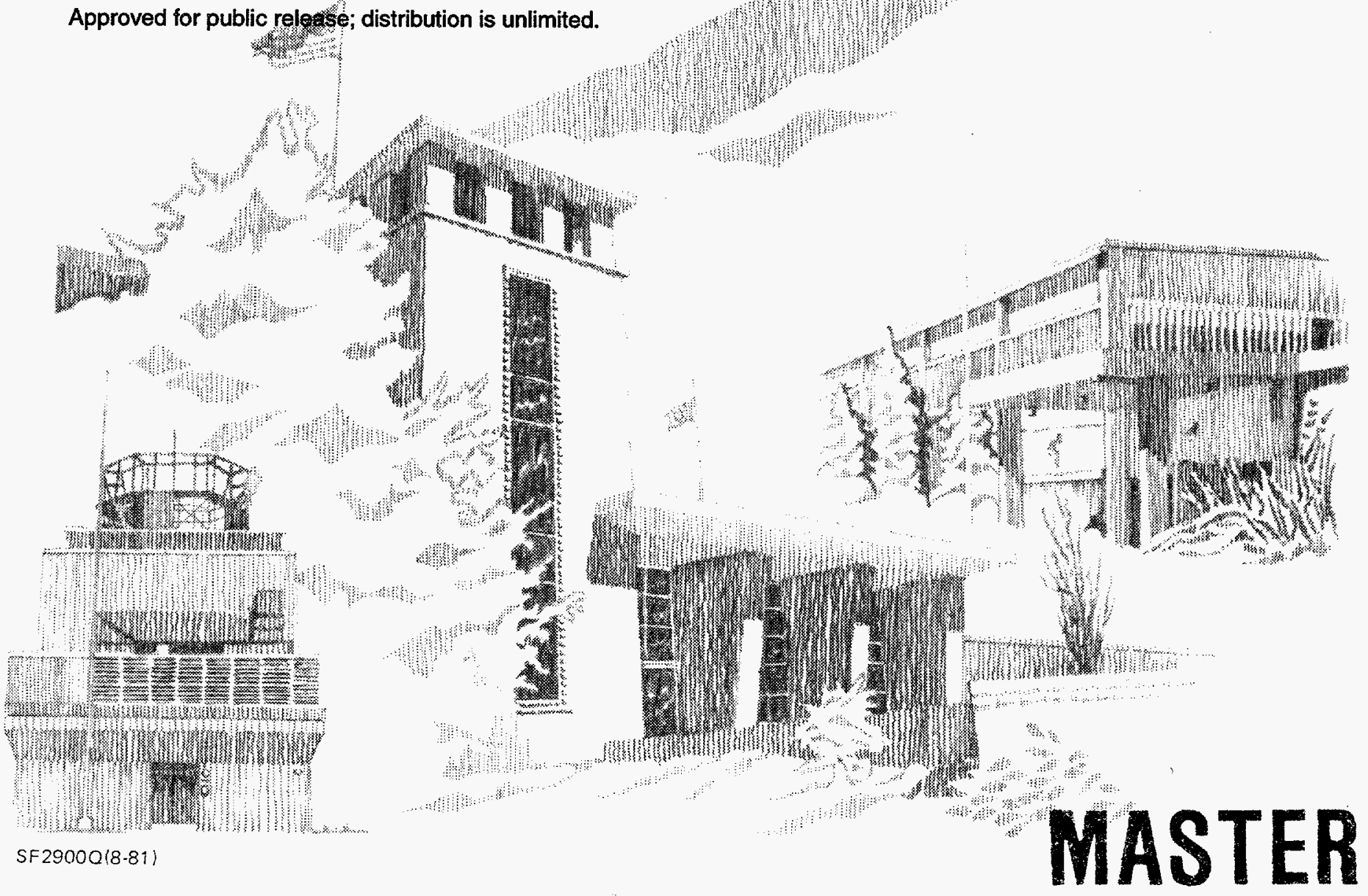

DISTRIBUTION OF THIS DOCUMENT IS UALIMITED 
Issued by Sandia National Laboratories, operated for the United States Department of Energy by Sandia Corporation.

NOTICE: This report was prepared as an account of work sponsored by an agency of the United States Government. Neither the United States Government nor any agency thereof, nor any of their employees, nor any of their contractors, subcontractors, or their employees, makes any warranty, express or implied, or assumes any legal liability or responsibility for the accuracy, completeness, or usefulness of any information, apparatus, product, or process disclosed, or represents that its use would not infringe privately owned rights. Reference herein to any specific commercial product, process, or service by trade name, trademark, manufacturer, or otherwise, does not necessarily constitute or imply its endorsement, recommendation, or favoring by the United States Government, any agency thereof or any of their contractors or subcontractors. The views and opinions expressed herein do not necessarily state or reflect those of the United States Government, any agency thereof or any of their contractors.

Printed in the United States of America. This report has been reproduced directly from the best available copy.

Available to DOE and DOE contractors from

Office of Scientific and Technical Information

PO Box 62

Oak Ridge, TN 37831

Prices available from (615) 576-8401, FTS 626-8401

Available to the public from

National Technical Information Service

US Department of Commerce

5285 Port Royal Rd

Springfield, VA 22161

NTIS price codes

Printed copy: A03

Microfiche copy: A01 


\section{DESCLAMER}

Portions of this document may be illegible in electronic image products. Images are produced from the best available original docament. 
SAND96 - 0729

Distribution

Unlimited Release

Category UC-721

Printed March 1996

\title{
Superconducting Technology Program Sandia 1995 Annual Report
}

\author{
Report prepared by \\ E. Peter Roth \\ Superconductivity Materials \\ and Technology Department \\ Sandia National Laboratories \\ Albuquerque, NM 87185 \\ This report has been prepared for the \\ Advanced Utility Concepts Division \\ Office of Energy Management \\ Energy Efficiency \& Renewable Energy \\ U.S. Department of Energy
}

\begin{abstract}
Sandia's STP program is a thallium-based high-temperature superconductor (HTS) research and development program consisting of efforts in powder synthesis and process development, open-system thick film conductor development, wire and tape fabrication, and HTS motor design. The objective of this work is to develop hightemperature superconducting conductors (wire and tape) capable of meeting requirements for high-power electrical devices of interest to industry. The research efforts currently underway are: 1) Process development and characterization of thallium-based high-temperature superconducting closed system wire and tape, 2) Investigation of the synthesis and processing of thallium-based thick films using twozone processing, and 3 ) Cryogenic design of a $30 \mathrm{~K}$ superconducting motor. This report outlines the research that has been performed during FY95 in each of these areas.
\end{abstract}




\section{CONTENTS}

1 Process Development and Characterization of High-Temperature

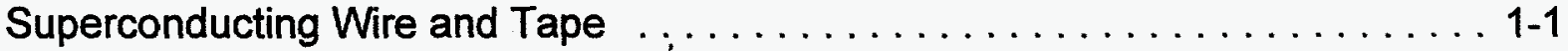

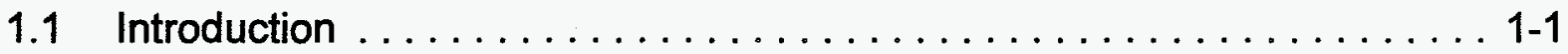

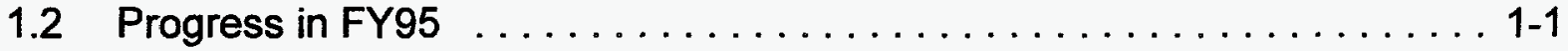

1.2.1 Field Dependence of Critical Current in Pressed Tapes .......... 1-1

1.2.2 Thermal/Mechanical Processing of TI-based Tapes as a Function of Starting Composition ...................... 1-4

1.2.3 Early Time Development of Unreacted Core Tapes . . . . . . . . . . 1-8

1.2.4 SEM/TEM Characterization of the High-Temperature Decomposition of

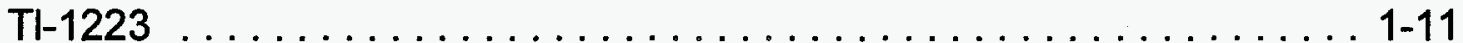

1.2.5 Thallium Level Effects in Ag Tapes . . . . . . . . . . . . . . 1-13

1.2.6 Thermal/Mechanical Processing of Ag/Ag Alloy Sheathed Tapes . . . . 1-17

1.2.7 Stability of Thallium-1223 Phases . . . . . . . . . . . . . . . .

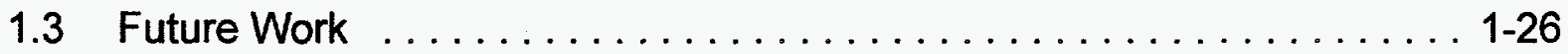

2 Process research on the synthesis of high temperature superconductors $\ldots .2-1$

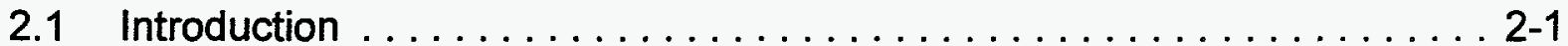

2.2 Progress in FY95 $\ldots \ldots \ldots \ldots \ldots \ldots \ldots \ldots \ldots \ldots \ldots \ldots \ldots \ldots \ldots \ldots \ldots \ldots \ldots .1$

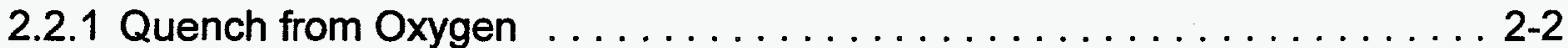

2.2.2 Quench from Argon ............................. 2-3

2.2.3 Quench During Controlled Cool in Oxygen . . . . . . . . . . . 2-8

2.2.4 Development of Segregated Porosity ................. 2-10

2.3 Future Work $\ldots \ldots \ldots \ldots \ldots \ldots \ldots \ldots \ldots \ldots \ldots \ldots \ldots \ldots \ldots \ldots \ldots \ldots .13$

3 Growth of Thick(TI,Pb)-(Ba,Sr)-Ca-Cu-O Superconducting Films Using

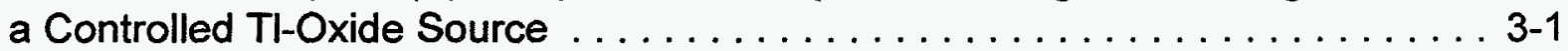

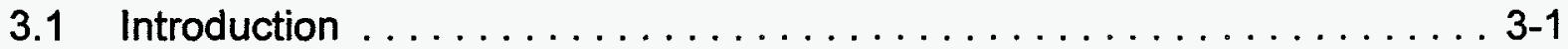

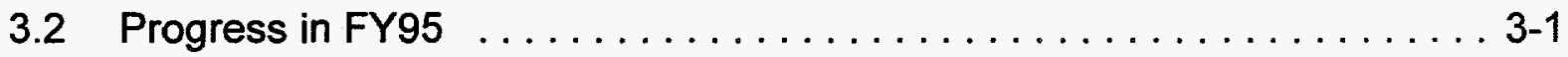

3.2.1 Pb-,Sr-Substituted TI-1223 Films on Ag/Pd Substrates . . . . . . . . . . 3-1

3.2.2 The Effects of TI Content on Doped and Undoped TI-1223 Films on Ag Substrates ............................... 3-2 


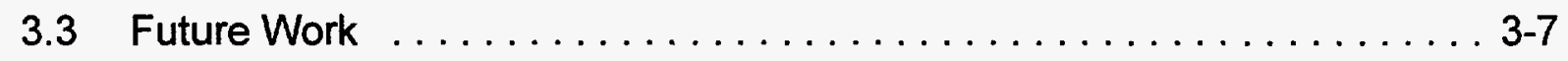

4 Cryogenic Design of a High-Temperature Superconducting (HTS) Motor . . . . 4-1

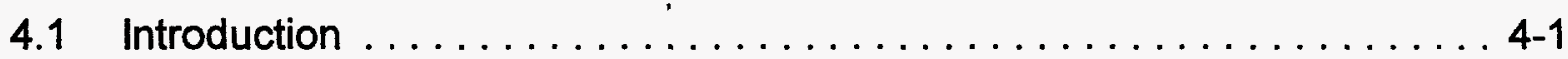

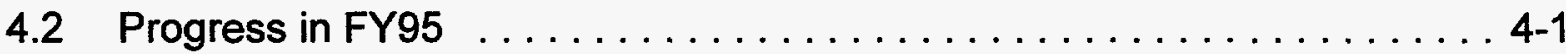

4.3 Future Work $\ldots \ldots \ldots \ldots \ldots \ldots \ldots \ldots \ldots \ldots \ldots \ldots \ldots \ldots \ldots \ldots \ldots \ldots \ldots, 2$ 


\section{FIGURES}

1-1 An optical micrograph of a non-pressed/annealed tape. . . . . . . . . . . 1-2

1-2 An optical micrograph of a pressed/annealed tape. . . . . . . . . . . . . 1-2

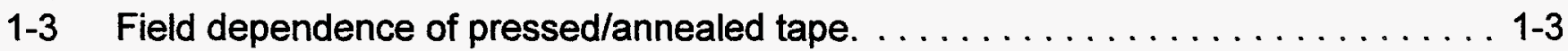

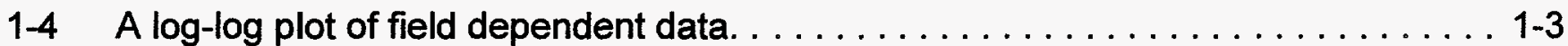

1-5 Temperature dependence of critical current as a function of magnetic field. . . . . 1-3

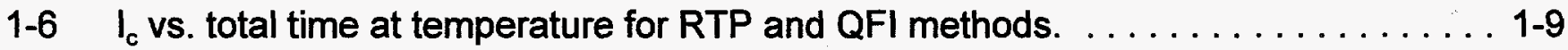

1-7 Meissner data for RTP tapes processed for 5, 10 and 20 min ......... 1-10

1-8 Shielding data for RTP tapes processed for 5,10 and 20 min ......... 1-10

1-9 Tl-1223 Ag Tape, RTP $910^{\circ} \mathrm{C} / 40$ sec/Ar . . . . . . . . . . . . . . . . 1-12

1-10 TI-1223 Ag Tape, RTP $910^{\circ} \mathrm{C} / 40$ sec/Ar; $880^{\circ} \mathrm{C} / 8 \mathrm{hr} / \mathrm{O}_{2}$ Anneal . . . . . . . . . . . 1-12

1-11a DTA data for Ag tape of "Hitachi" composition with $\mathrm{TI}_{0.6}$ (TW066). . . . . . . 1-14

1-11b DTA data for Ag tape of "Hitachi" composition with $\mathrm{TI}_{0.7}$ (TW067) . . . . . . . . 1-14

1-11c DTA data for Ag tape of "Hitachi" composition with $\mathrm{TI}_{0.8}$ (TW068). . . . . . . . 1-14

1-11d DTA data for Ag tape of "Hitachi" composition with $\mathrm{TI}_{0.5}$ using $\mathrm{Tl}_{2} \mathrm{Ba}_{2} \mathrm{O}_{5}$ (TW039). . 1-14

1-12 SEM micrographs of tapes after one and four press/anneal cycles . . . . . . 1-21

1-13 The effects of $\mathrm{P}\left(\mathrm{Tl}_{2} \mathrm{O}\right)$ on samples with $\mathrm{Ba}: \mathrm{Ca}: \mathrm{Cu}$ ratios of $2: 2: 3 \ldots \ldots \ldots \ldots$ 1-25

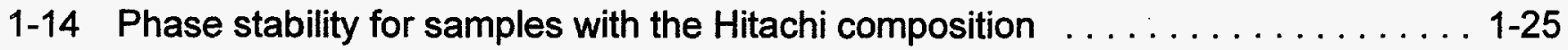

2-1 Meissner (left) and low-field shielding (right) data for tape samples before quenching and after quenching from $920^{\circ} \mathrm{C}$ with holds at temperature of $5 \mathrm{~min}$.

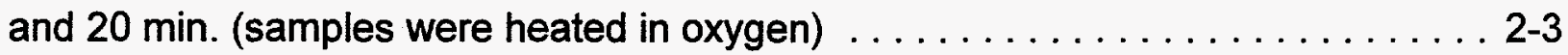

2-2 Backscattered electron photomicrographs of polished cross sections of tape samples that were quenched from $920^{\circ} \mathrm{C}$ after holds at temperature of $5 \mathrm{~min}$.

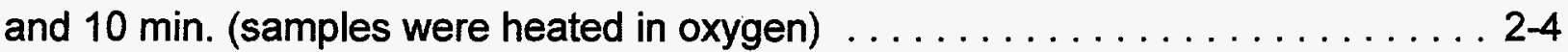

2-3 Backscattered electron photomicrographs of polished cross sections of tape samples that were quenched from oxygen and argon atmospheres after holds of

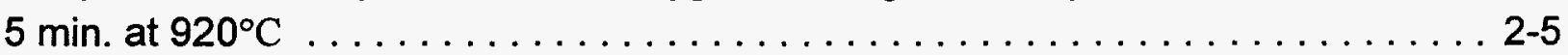

2-4 Secondary electron photomicrographs and elemental maps of a polished cross section of a tape sample that was quenched from an argon atmosphere after a

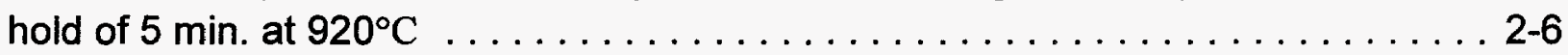

2-5 Secondary electron photomicrographs and elemental maps of a polished cross section of a tape sample that was quenched from an argon atmosphere after a

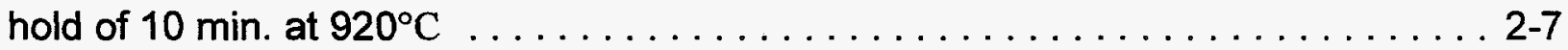

2-6 Backscattered electron photomicrographs and strontium elemental maps of polished cross sections of tape samples that were quenched from an argon atmosphere after holds of $5 \mathrm{~min}$. (left) and $10 \mathrm{~min}$. (right) at $920^{\circ} \mathrm{C} \ldots \ldots \ldots 2-8$ 
2-7 BES photomicrographs of tapes that were quenched from an oxygen atmosphere after cooling from $920^{\circ} \mathrm{C}$ to $915^{\circ} \mathrm{C}$ (top), $910^{\circ} \mathrm{C}$ (middle), and $870^{\circ} \mathrm{C}$ (bottom) at $4^{\circ} \mathrm{C} / \mathrm{min}$.; samples held for $10 \mathrm{~min}$. in argon at $920^{\circ} \mathrm{C}$ prior to cooling . . . . . . . . . 2-9

2-8 Meissner data for samples quenched during stages 2 and 3 of the processing cycle. Data for points 1 and 2 are for samples quenched after $5 \mathrm{~min}$. and $10 \mathrm{~min}$. at $920^{\circ} \mathrm{C}$ in argon, respectively, while points $3-6$ are for samples quenched after the atmosphere switch to oxygen and initiation of the controlled cool at $4^{\circ} \mathrm{C} / \mathrm{hr}$ ( point $3=$ quenched at $915^{\circ} \mathrm{C}$, point $4=$ quenched at $910^{\circ} \mathrm{C}$, point $5=$ quenched at $900^{\circ} \mathrm{C}$, and point $6=$ quenched at $\left.890^{\circ} \mathrm{C}\right) \ldots \ldots \ldots \ldots \ldots \ldots \ldots \ldots \ldots \ldots \ldots .11$

2-9 Low-field shielding data for samples quenched during stages 2 and 3 of the processing cycle. Data for points 1 and 2 are for samples quenched after $5 \mathrm{~min}$. and $10 \mathrm{~min}$. at $920^{\circ} \mathrm{C}$ in argon, respectively, while points $3-6$ are for samples quenched after the atmosphere switch to oxygen and initiation of the controlled cool at $4^{\circ} \mathrm{C} / \mathrm{hr}$ ( point $3=$ quenched at $915^{\circ} \mathrm{C}$, point $4=$ quenched at $910^{\circ} \mathrm{C}$, point $5=$ quenched at $900^{\circ} \mathrm{C}$, and point $6=$ quenched at $890^{\circ} \mathrm{C}$ )

2-10 Series of backscattered electron photomicrograph montages of polished cross sections of quenched wire samples $\ldots \ldots \ldots \ldots \ldots \ldots \ldots \ldots \ldots \ldots \ldots \ldots \ldots \ldots \ldots \ldots \ldots .12$

3-1 Time/Temperature profile for flow-through two-zone furnace $\ldots \ldots \ldots \ldots \ldots$ 3-3

3-2 X-ray diffraction patterns for $940^{\circ} \mathrm{C} / 770^{\circ} \mathrm{C}, 925^{\circ} \mathrm{C} / 770^{\circ} \mathrm{C}$ and $915^{\circ} \mathrm{C} / 760^{\circ} \mathrm{C}$ two-zone $\mathrm{Pb}$-, Sr-doped Tl-based thick film on $\mathrm{Ag} / \mathrm{Pd}$.

3-3 Nominal $\left(\mathrm{Tl}_{0.5} \mathrm{~Pb}_{0.5}\right)\left(\mathrm{Sr}_{0.8} \mathrm{Ba}_{0.2}\right)_{2} \mathrm{Ca}_{2} \mathrm{Cu}_{3} \mathrm{O}_{x}: \mathrm{Ag}_{0.37}$ composition showing interaction

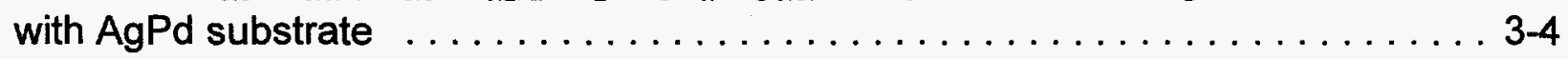

3-4 Nominal $\left(\mathrm{TI}_{0.5} \mathrm{~Pb}_{0.5}\right)\left(\mathrm{Sr}_{0.8} \mathrm{Ba}_{0.2}\right)_{2} \mathrm{Ca}_{2} \mathrm{Cu}_{3} \mathrm{O}_{x}$ composition showing interaction with $\mathrm{AgPd}$ substrate leading to aligned grain structure $\ldots \ldots \ldots \ldots \ldots \ldots \ldots \ldots \ldots \ldots$

3-5 Transition temperature of TI-1223 films as a function of TI content . . . . . . 3-5

3-6 Transport currents for TBCCO TI-1223 films on Ag substrates . . . . . . . . 3-5

3-7 Critical current densities for Tl-1223 films on Ag substrates . . . . . . . . 3-6

3-8 SEM micrograph of undoped TI-1223 thick film on $\mathrm{Ag} \ldots \ldots \ldots \ldots \ldots \ldots . . \ldots \ldots$

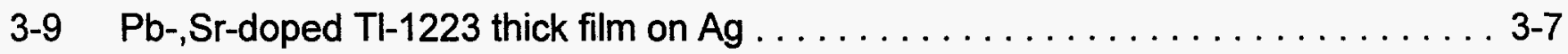

4-1 Reliance Electric/Sandia Design Team with HTS Motor ............. 4-1

4-2 Simplified geometry of Reliance Electric cryogenic motor $\ldots \ldots \ldots \ldots \ldots \ldots$ 4-2 


\section{TABLES}

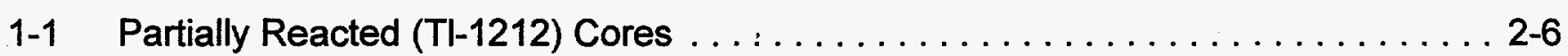

1-2 Fully Reacted TI-1223 Cores . . . . . . . . . . . . . . .

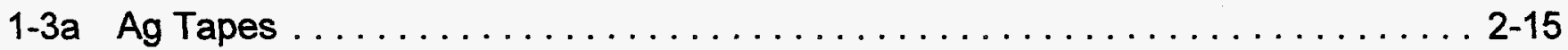

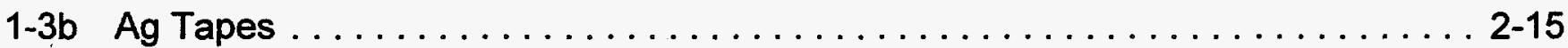

1-3c Ag Tapes .................................. 2-16

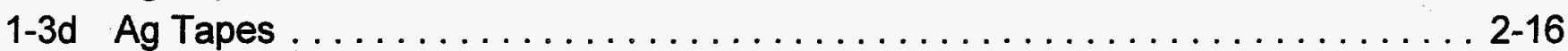

1-4a Ag Alloy Sheath Tapes ......................... 2-18

1-4b Ag Sheath Tapes ................................. 2-19

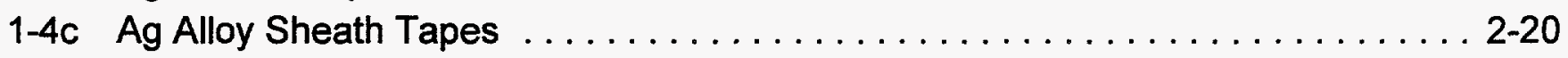




\title{
CONTRIBUTORS
}

\author{
Sandia Contributors to the \\ Superconducting Technology Program \\ for Electric Energy Systems
}

Program Manager

E. Peter Roth

Ceramic Synthesis

James A. Voigt

Diana L. Lamppa

Ceramic Processing

Steve Lockwood

David M. Toupal

Advanced Materials/Magnetic

Characterization

Eugene L. Venturini

Advanced Materials/Phase Diagrams

Terence L. Aselage

Stuart B. Van Deusen
Advanced Materials/Thick Film

Michael P. Siegal

Donald L. Overmyer

Advanced Materials/Electron

Microscopy

Paula P. Newcomer

Advanced Materials/X-ray Diffraction

Bruno Morosin

Roberto G. Dunn

Superconducting Materials/Transport

Properties

Frank Chavez

Thermal \& Fluid Modeling

Ronald C. Dykhuizen 
1 Process Development and Characterization of High-temperature Superconducting Wire and Tape

\subsection{Introduction}

The objective of this project is to develop high-temperature superconducting wire capable of meeting the requirements for high-power electrical devices of interest to industry. Primary interest has been to develop materials and processes which can lead to the practical production of wires which can carry high currents in the presence of typical operating magnetic fields at liquid nitrogen temperature or higher, although lower temperature operation is considered for special applications. The thalliumbased single layer system is considered the only viable material for operation in moderate magnetic fields at $77 \mathrm{~K}$. In particular, the $\mathrm{Pb}$ - and Sr-substituted system is believed to have the best performance in magnetic field (high irreversibiltiy line) and most readily results in the desired $\mathrm{Tl}-1223$ phase. During the last year we have continued to devote our research efforts exclusively in this system, developing techniques for conductor fabrication and processing with our industrial and National Lab partners. Studies of closed system conductors prepared by the Powder-in-Tube (PIT) method centered on thermal/mechanical processing to try to obtain densified, aligned grains with strong link conduction paths. Almost 300 samples were measured during the several programs designed to investigate various aspects of tape processing and microstructural development. These experimental programs are described in more detail in the following sections.

\subsection{Progress in FY95}

\subsubsection{Field Dependence of Critical Current in Pressed Tapes}

Thermal processing of tapes prepared by Powder-in-Tube (PIT) leads to the development of a very porous, sparsely connected grain structure with weak-link grain boundaries resulting in low critical currents and poor performance in magnetic field. The tape microstructure and performance can be improved significantly by combining thermal and mechanical processing steps. 
We have been characterizing $\mathrm{Tl}-1223$ tapes processed at Intermagnetics General Corporation (IGC) prepared from precursor powders produced at Sandia using our coprecipitation process. These tapes have nominal Hitachi composition cores, $\left(\mathrm{Tl}_{0.5} \mathrm{~Pb}_{0.5}\right)\left(\mathrm{Sr}_{0.8} \mathrm{Ba}_{0.2}\right)_{2} \mathrm{Ca}_{2} \mathrm{Cu}_{3} \mathrm{O}_{\mathrm{x}}$, and have been processed through a series of uniaxial pressings and heat treatments. The pressings have greatly reduced core cracks and porosity as shown in Figures 1-1 and 1-2. Figure 1-1 shows a tape that had not undergone any pressings but was thermally processed at $860^{\circ} \mathrm{C}$ for 8 hours (similar thermal processing as the pressed tape shown in Figure 1-2). The unpressed tape had a $J_{c}$ of only $1,000 \mathrm{~A} \mathrm{~cm}^{2}$ while the pressed tape had a $J_{c}$ of $8,000 \mathrm{~A} / \mathrm{cm}^{2}$. Measurements were made as a function of temperature down to $8 \mathrm{~K}$ and fields up to 0.2 Tesla. The critical current vs. field data are shown in Figure 1-3. The data show that the dominant current is weak-link limited, but that a strong link component is present. Figure 1-4 shows a log-log plot of the data which indicates that at the higher fields the strong link component is less field dependent, deviating from the approximate $B^{-0.7}$ behavior seen at lower fields. The temperature dependencies of $J_{c}$ for the different applied fields are shown in Figure 1-5 which shows that the low-field, weak-link dominated critical current is strongly temperature dependent while the higher-field, strong-link current is much less dependent on temperature. The critical current of 1.5 amps at 0.2 Tesla for the pressed tape is approximately eight times higher than that seen for similar tapes which had only undergone thermal treatments.

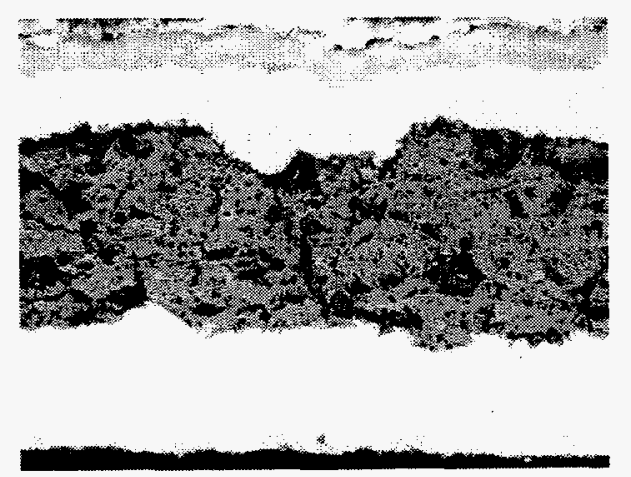

Figure 1-1. An optical micrograph of a non-pressed/annealed tape.

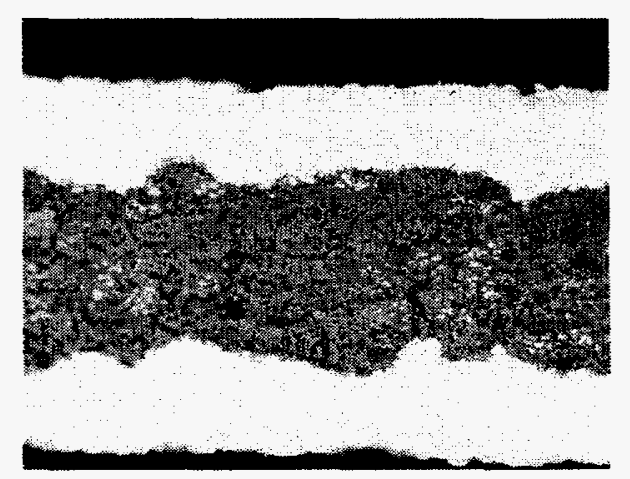

Figure 1-2. An optical micrograph of a pressed/annealed tape. 


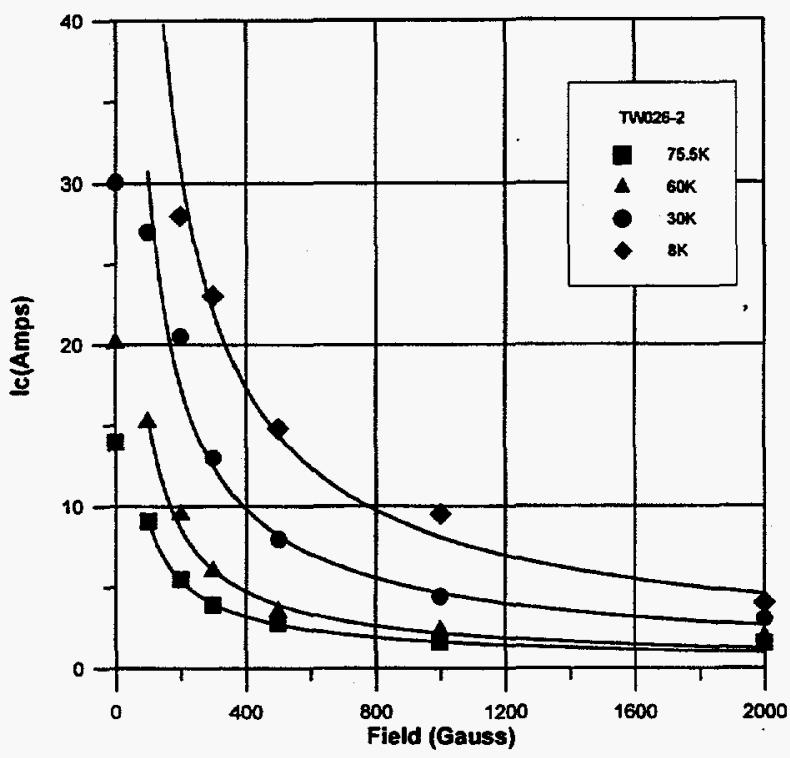

Figure 1-3. Field dependence of field pressed/annealed tape.

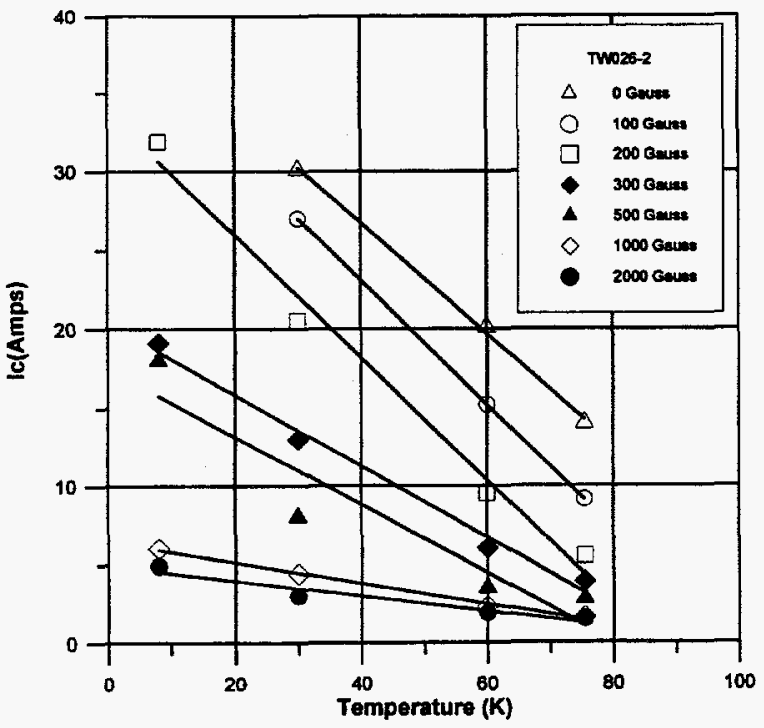

Figure 1-5. Temperature dependence of critical current as a function of magnetic field.

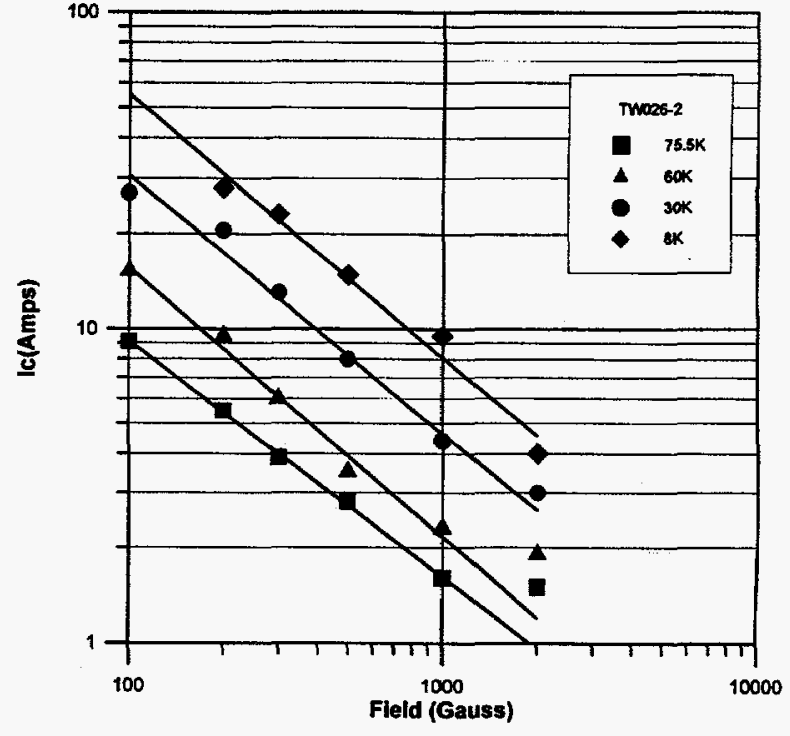

Figure 1-4. A log-log plot of dependent data. 


\subsubsection{Thermal/Mechanical Processing of TI-based Tapes as a Function of Starting Composition}

Improvement in $\mathrm{J}_{c}(0)$ and the strong-linked $\mathrm{J}_{\mathrm{c}}$ component in the Tl-1223 system depends on achieving improvement in densification, intergrain contact, and reduction of secondary phases. We initiated a study of microstructural development in the $\left(\mathrm{Tl}_{0.5} \mathrm{~Pb}_{0.5}\right)\left(\mathrm{Sr}_{0.8} \mathrm{Ba}_{0.2}\right)_{2} \mathrm{Ca}_{2} \mathrm{Cu}_{3} \mathrm{O}_{\mathrm{x}}$ superconductor as a function of thermal annealing, Rapid Thermal Processing (RTP), and isostatic pressing. Tapes were prepared at IGC using unreacted chemprep powders from Sandia and then thermally reacted at different temperatures to produce two starting compositions: fully reacted powder ( $\mathrm{Tl}$ 1223); partially reacted powder (mostly TI-1212). The thermodynamic driving forces are different for each powder composition and should result in different reaction paths toward the final microstructure. The Rapid Thermal Processing (RTP) is performed using a computer controlled quartz lamp system that allows rapid and precise temperature control of the tape samples. RTP is intended to produce controlled melting of the grains, thus improving the intergranular strong links. The RTP process was performed in an oxygen atmosphere and all tapes were given a final anneal at $860^{\circ} \mathrm{C} / 3 \mathrm{hr} / \mathrm{O}_{2}$. The experimental plan is shown below:
a. Press (200 kpsi - 40klb):
b. Press,
RTP: $--920 \mathrm{C} / 20 \mathrm{~s} / \mathrm{O}_{2}$
anneal: $860 \mathrm{C} / 3 \mathrm{hr} / \mathrm{O}_{2}$
$-910 \mathrm{C} / 20 \mathrm{~s} / \mathrm{O}_{2}$
c. No Press,
RTP: $--920 \mathrm{C} / 20 \mathrm{~s} / \mathrm{O}_{2}$ $-910 \mathrm{C} / 20 \mathrm{~s} / \mathrm{O}_{2}$
d. No Press:
anneal:

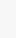
u
"
$\wedge$ Cycle 4 times

Total: 48 samples Measurements: Transport, Meissner, SEM

Table 1-1 shows the data for the partially reacted core tapes while Table 1-2 shows the data for the fully reacted core tapes. The data in any box, from top to bottom, show the results of the sequential processing steps. The values in parentheses are the results measured at 0.02 Tesla. Patterns can readily be seen in these data. 
Pressing after two cycles and above results in significant improvement in the critical current. SEM micrographs show that the pressed/annealed samples have a smaller, more dense grain structure than seen for the annealed only samples. However, after four cycles, only relatively moderate increases were being obtained. Although all samples were primarily TI-1223 after the first $860^{\circ} \mathrm{C} / 3 \mathrm{hr}$ anneal, regardless of starting composition or process step, the starting TI-1212 material resulted in much smaller TI1223 grains and more secondary phases such as ( $\mathrm{Sr}, \mathrm{Ca})-\mathrm{Cu}-\mathrm{O}$. The RTP step had little effect on the Tl-1223 material and resulted in degraded performance for the TI1212 material. Apparently the initial transient melt of the TI-1212 results in an irreversible (at $860^{\circ} \mathrm{C}$ ) degradation to a much greater extent than seen for the fully reacted TI-1233 material. The $\mathrm{I}_{\mathrm{c}}$ values obtained for both types of starting compositions are significantly less than has been obtained using the completely unreacted powder composition ( $>20$ amps at IGC). 
Table 1-1. Partially Reacted (TI-1212) Cores

\begin{tabular}{|c|c|c|c|}
\hline Sample/Cycle & Process & Ic(Amps) & $\mathrm{Tc}(\mathrm{K})$ \\
\hline A1 & Press & 1.0 & 108 \\
\hline A3 & Anneal: $860 \mathrm{C} / 3 \mathrm{hr} / \mathrm{O} 2$ & 3.5 & 111 \\
\hline A2 & & $6.2(0.6)$ & 113 \\
\hline A4 & & $6.1(0.5)$ & 112 \\
\hline B4920 & Press & 0.0 & 94 \\
\hline B3920 & RTP: $920 \mathrm{C} / 20 \mathrm{~s} / \mathrm{O} 2$ & 1.3 & 112 \\
\hline B1920 & Anneal: $860 \mathrm{C} / 3 \mathrm{hr} / \mathrm{O} 2$ & $2.3(0.2)$ & 112 \\
\hline B2920 & & 1.2 & 113 \\
\hline B3910 & Press & 0.0 & 107 \\
\hline B1910 & RTP: $910 \mathrm{C} / 20 \mathrm{~s} / \mathrm{O} 2$ & 0.5 & 109 \\
\hline B2910 & Anneal: $860 \mathrm{C} / 3 \mathrm{hr} / \mathrm{O} 2$ & $4.0(0.4)$ & 113 \\
\hline B4910 & & 0.4 & 112 \\
\hline C1920 & No Press & 0.0 & 54 \\
\hline $\mathrm{C} 2920$ & RTP: $920 \mathrm{C} / 20 \mathrm{~s} / \mathrm{O} 2$ & 1.5 & 113 \\
\hline C3920 & Anneal: $860 \mathrm{C} / 3 \mathrm{hr} / 02$ & $\ldots$ & $\ldots$ \\
\hline C4920 & & $--{ }^{*}$ & $-{ }^{*}$ * \\
\hline C1910 & No Press & 0.0 & 104 \\
\hline C2910 & RTP: $910 \mathrm{C} / 20 \mathrm{~s} / \mathrm{O} 2$ & 0.9 & 104 \\
\hline C3910 & Anneal: $860 \mathrm{C} / 3 \mathrm{hr} / \mathrm{O} 2$ & 1.4 & 111 \\
\hline C4910 & & 1.1 & 112 \\
\hline D4 & & 1.0 & 107 \\
\hline D3 & No Press & 2.6 & 111 \\
\hline D2 & Anneal: $860 \mathrm{C} / 3 \mathrm{hr} / \mathrm{O} 2$ & 3.0 & 111 \\
\hline D1 & & 0.2 & 111 \\
\hline
\end{tabular}

*Tape Damaged ( ) $-I_{c}$ at 200 Gauss 
Table 1-2. Fully Reacted TI-1223 Cores

\begin{tabular}{||c|c|c|c||}
\hline Sample/Cycle & Process & IC(Amps) & Tc(K) \\
\hline A1 & Press & 2.7 & 110 \\
A3 & Anneal: 860C/3hr/O2 & $4.0(0.3)$ & 112 \\
A4 & & $5.7(0.6)$ & 112 \\
A2 & & $6.4(0.9)$ & 111 \\
\hline B1920 & Press & 2.4 & 112 \\
B3920 & RTP: 920C/20s/O2 & $4.3(0.3)$ & 112 \\
B4920 & Anneal: 860C/3hr/O2 & $4.9(0.5)$ & 107 \\
B2920 & & $5.9(0.8)$ & 115 \\
\hline B1910 & Press & 2.5 & 107 \\
B2910 & RTP: 910C/20s/O2 & $4.8(0.3)$ & 113 \\
B3910 & Anneal: 860C/3hr/O2 & $5.3(0.5)$ & 114 \\
B4910 & & $5.5(0.8)$ & 112 \\
\hline C1920 & No Press & 2.1 & 107 \\
C2920 & RTP: 920C/20s/O2 & 1.9 & 111 \\
C3920 & Anneal: 860C/3hr/O2 & 1.0 & 110 \\
C4920 & & 0.8 & 110 \\
\hline C1910 & No Press & 1.9 & 107 \\
C2910 & RTP: 910C/20s/O2 & 1.1 & 114 \\
C3910 & Anneal: 860C/3hr/O2 & 2.0 & 115 \\
C4910 & & 1.3 & 115 \\
\hline D1 & & 2.5 & 114 \\
D2 & No Press & 2.4 & 111 \\
D4 & Anneal: 860C/3hr/O2 & $2.8(0.2)$ & 115 \\
D3 & & $2.9(0.2)$ & 115 \\
\hline & & & \\
\hline
\end{tabular}

( ) $-I_{c}$ at 200 Gauss 


\subsubsection{Early Time Development of Unreacted Core Tapes}

Pressing has been shown to be essential to achieve higher critical current and densification. However, the ultimate current levels are apparently very sensitive to the initial processing step in conversion of the unreacted core tapes. Tapes produced using Sandia's powder in collaboration with IGC have achieved currents over 20 amps, but rapid initial thermal heating rates were important. We have studied the initial phase development of the unreacted core as a function of time in our Rapid Thermal Processing (RTP) system. Unreacted Hitachi composition tapes with 10 wt\% Ag were given 5 minutes at $860^{\circ} \mathrm{C}\left(\mathrm{O}_{2}\right.$ atm $)$ using the RTP system. The tapes were then pressed starting at $200 \mathrm{kpsi}$. This cycle was repeated six times using increasing pressure levels up to $500 \mathrm{kpsi}$. At each step, a sample was removed and annealed at $860^{\circ} \mathrm{C}$ for one hour $\left(\mathrm{O}_{2} \mathrm{~atm}\right)$. The last sample $(500 \mathrm{kpsi})$ was given an additional $2.5 \mathrm{hr} / 860^{\circ} \mathrm{C}$ anneal (no press step) and then a $200 \mathrm{kpsi}$ press and a $3 \mathrm{hr} / 860^{\circ} \mathrm{C}$ anneal. Figure 1-6 shows the data for this series of press/anneals along with data for another tape that had undergone a press/anneal process. This additional tape was initially inserted directly into the $860^{\circ} \mathrm{C}$ furnace to achieve rapid heating of the unreacted core to the processing temperature. This quick furnace insertion (QFI) method does not have as rapid a heating rate as the RTP method but gives superior results compared to slow heating to the process temperature used previously for these type of tapes. This tape was given a 3 hour anneal at $860^{\circ} \mathrm{C}$ following each press for 3 cycles (total 10 hours at temperature). The data show that time at temperature is not the most significant factor in determining higher $\mathrm{I}_{\mathrm{c}}$, but increasing pressure results in a near linear increase in $I_{c}$ up to approximately $400 \mathrm{kpsi}$. The two tapes processed at a maximum pressure of $400 \mathrm{kpsi}$ had nearly equal $\mathrm{I}_{\mathrm{c}} \mathrm{s}$ although one tape had seen 10 hours at temperature and the other only 1.5 hours. This suggests that the most important microstructural development that determines ultimate levels for $I_{c}$ occur within the first few minutes at temperature. Above $400 \mathrm{kpsi}$ the $I_{c}$ degraded sharply. SEM micrographs show that silver from the sheath can be included into cracks which develop after pressing, thus reducing the cross sectional area of the tape. Further annealing without pressing only further degraded the tape, probably resulting from loss of grain interconnects as the grains continued to grow. Another press/anneal cycle apparently was able to restore the grain interconnectivity. The strong link component of $I_{c}$ tracked the zero field values although averaging 


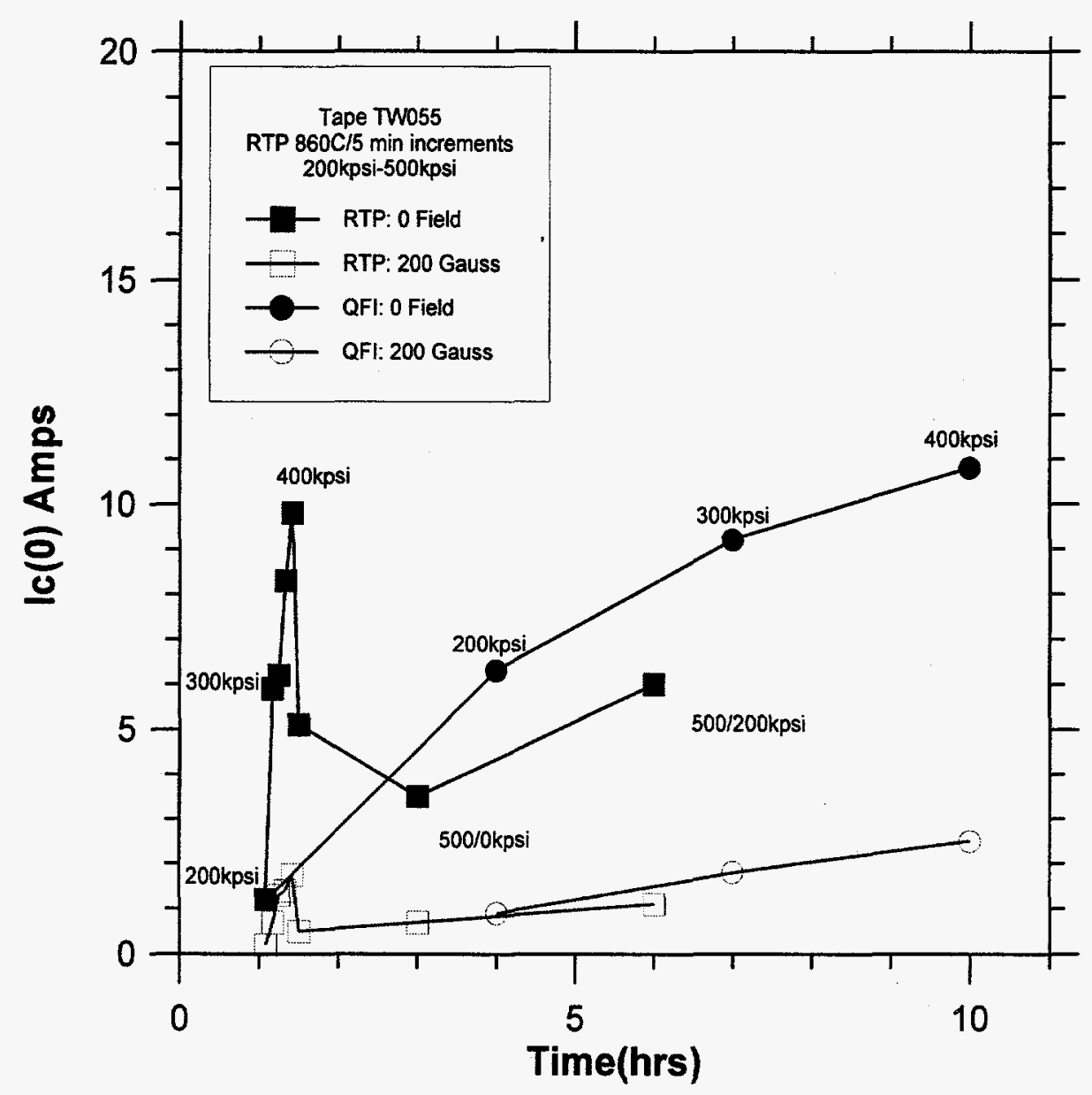

Figure 1-6. $I_{c}$ vs. total time at temperature for RTP and QFI methods.

about $17 \%$ of the total current.

Phase development of the fully unreacted core was also studied as a function of time using magnetization techniques. Tapes were heated in an oxygen atmosphere to $860^{\circ} \mathrm{C}$ in $5 \mathrm{sec}$ and held for times of 5,10 , and 20 minutes. Due to "pillowing" after the first cycle, all tapes were pressed before further processing. Figure 1-7 shows magnetization data for the 5,10 and 20 min samples. The data show that the first superconducting phase formed is predominately Tl-1212 even after only 5 minutes at temperature. Smaller amounts of a $105 \mathrm{~K}$ phase, probably TI-1223, were also present. The initial pressing suppresses the TI-1212 phase, but further time at 


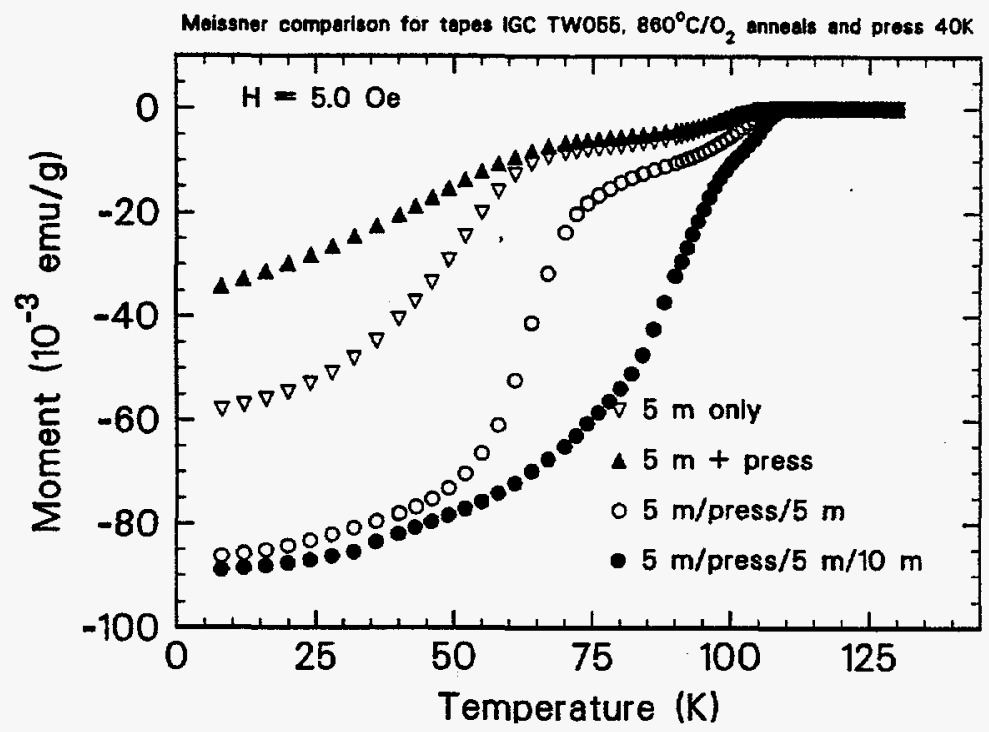

Figure 1-7. Meissner data for RTP tapes processed for 5, 10 and $20 \mathrm{~min}$.

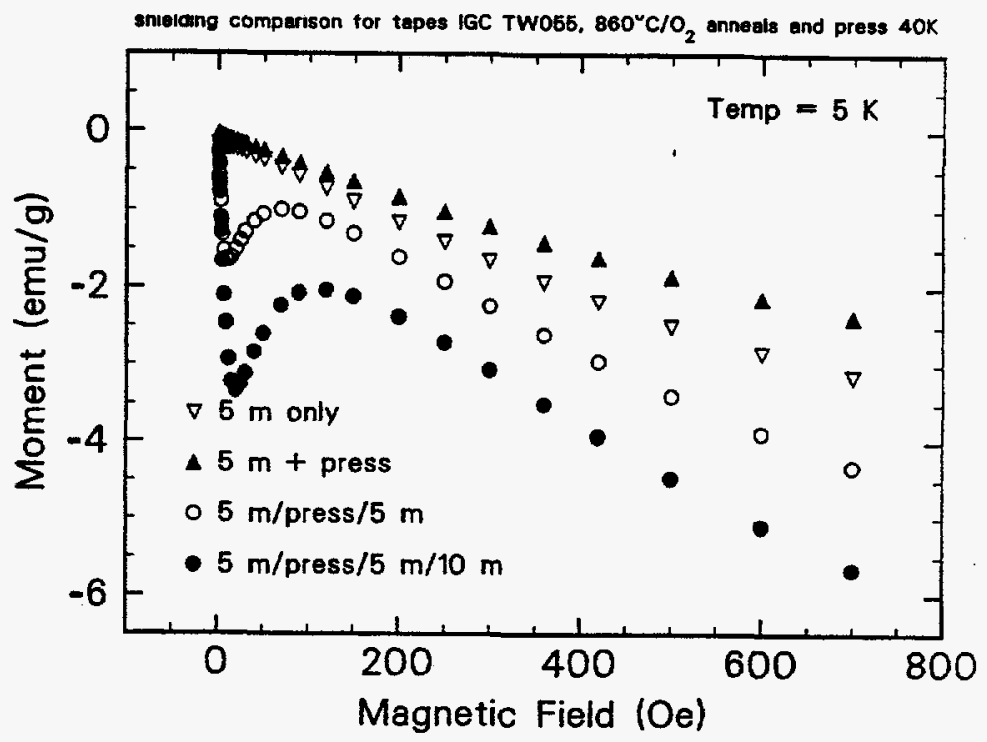

Figure 1-8. Shielding data for RTP tapes processed for 5,10 and $20 \mathrm{~min}$. 
temperature results in further development of the TI-1212 phase which then progresses in time toward a fully TI-1223 material. Figure 1-8 shows that the intergranular connections form after 10 minutes and increase with time at temperature. Apparently $\mathrm{TI}-1212$ is an unavoidable phase in the eventual development toward the TI-1223.

\subsubsection{SEM/TEM Characterization of the High-Temperature Decomposition of TI-1223}

Rapid Thermal Processing (RTP) has been used to produce melt interactions in the $\mathrm{Pb}-\mathrm{Sr}$-doped $\mathrm{Tl}-1223$ superconductors. Tapes with enhanced $(\mathrm{TI}, \mathrm{Pb})$ and $(\mathrm{Ca}, \mathrm{Cu})$ levels, $\left(\mathrm{Tl}_{0.5} \mathrm{~Pb}_{0.5}\right)_{1.15}\left(\mathrm{Sr}_{0.8} \mathrm{Ba}_{0.2}\right)_{2} \mathrm{Ca}_{2.1} \mathrm{Cu}_{3.15} \mathrm{O}_{\mathrm{x}}$, were prepared from Sandia chemprep powders at IGC. The cores were first converted into the 1223 state by processing at $900^{\circ} \mathrm{C}$ for $2 \mathrm{hr}$ in $\mathrm{O}_{2}$ and then RTPed in Argon for $40 \mathrm{sec}$ at $880^{\circ} \mathrm{C}, 890^{\circ} \mathrm{C}, 900^{\circ} \mathrm{C}$, and $910^{\circ} \mathrm{C}$. After the RTP step, the tapes were annealed at $860^{\circ} \mathrm{C}$ for 8 hours. SEM and TEM analysis were performed at the New Mexico Institute of Mining and Technology by Y. Tu and Prof. Y. Gao. These RTP experiments were repeated without the final $860^{\circ} \mathrm{C}$ anneal to identify the decomposition phases that existed during the RTP step. The SEM and TEM micrographs showed that the decomposition products were the same as seen for the annealed samples, namely $\mathrm{Tl}-1212$, Sr-Ca-Cu-O and $\mathrm{Ba}-\mathrm{Pb}-\mathrm{O}$. No intermediate melt phases were observed. As can be seen in Figure 1-9, decomposed $\mathrm{Tl}-1223$ was finely intermixed with the secondary phases. After the $860^{\circ} \mathrm{C}$ anneal, the $\mathrm{Tl}-1223$ grains were more clearly defined, as shown in Figure 1-10, and the secondary phases had segregated into larger homogeneous regions. Higher critical current levels measured in these tapes have been associated with the longer, blocky grain structures as seen in these figures. However, the secondary phases need to be reduced and a more densified core structure obtained. 

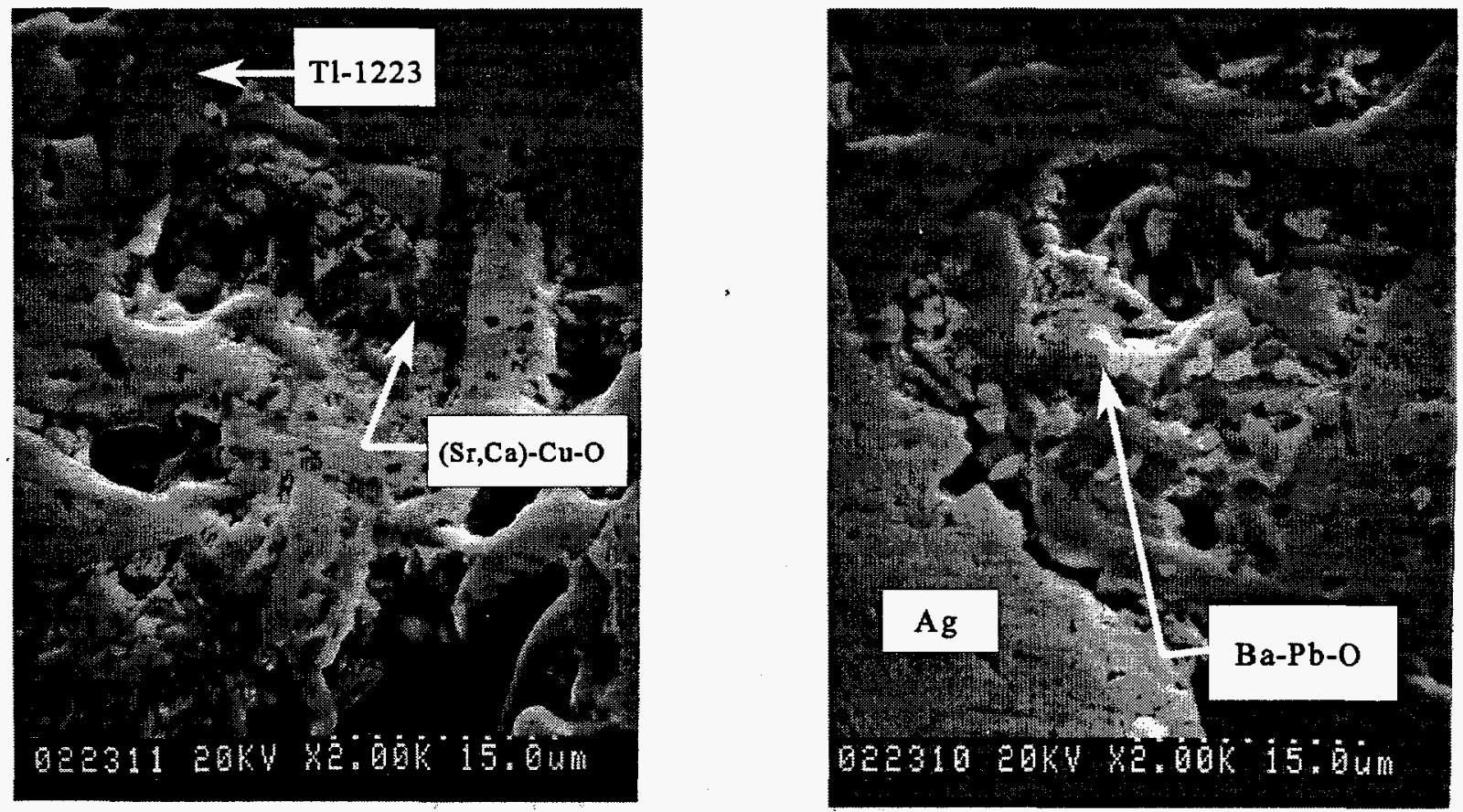

Figure 1-9. $\mathrm{Tl}-1223 \mathrm{Ag}$ Tape, RTP $910^{\circ} \mathrm{C} / 40 \mathrm{sec} / \mathrm{Ar}$.
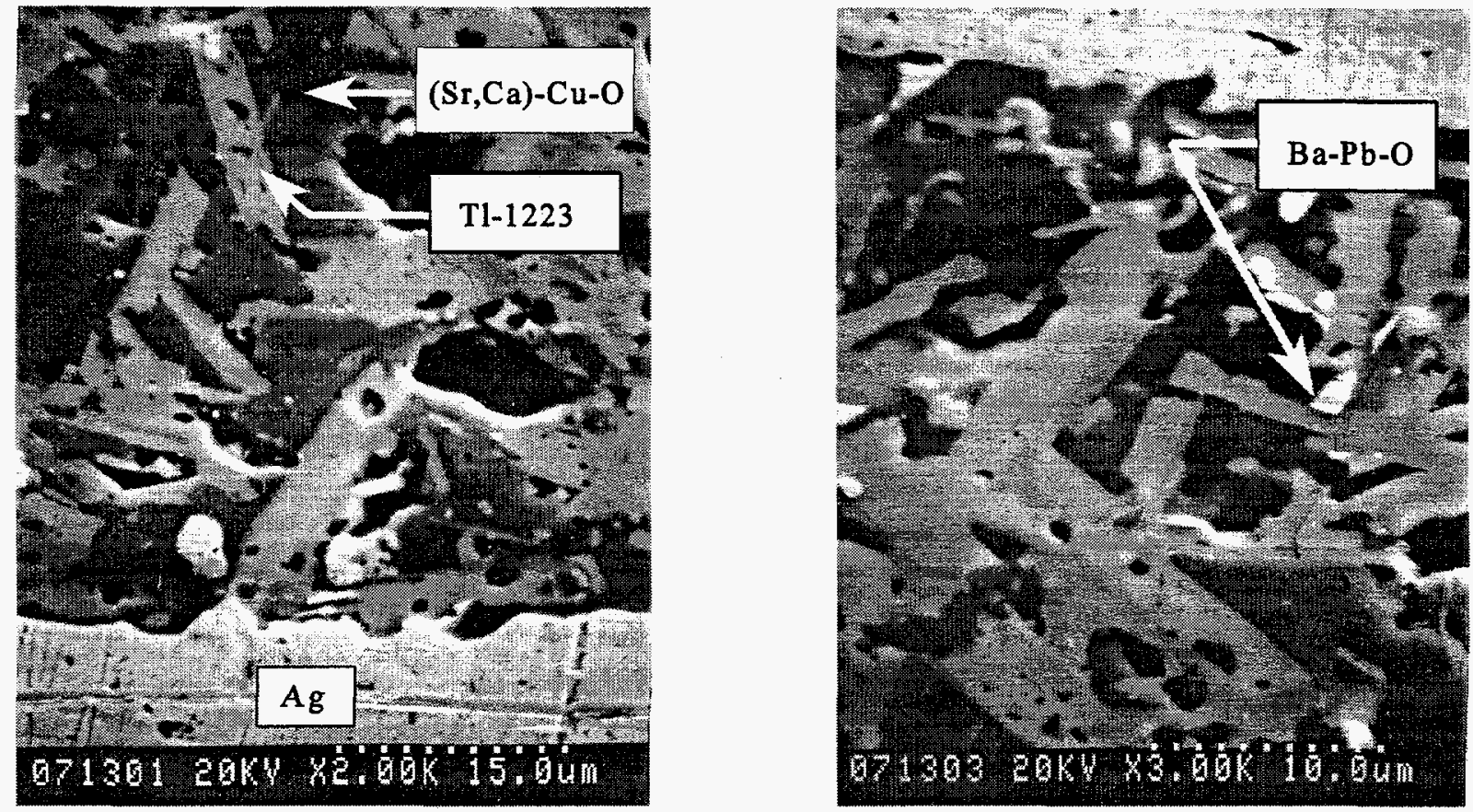

Figure 1-10. TI-1223 Ag Tape, RTP $910^{\circ} \mathrm{C} / 40 \mathrm{sec} / \mathrm{Ar} ; 880^{\circ} \mathrm{C} / 8 \mathrm{hr} / \mathrm{O}_{2}$ Anneal. 


\subsubsection{Thallium Level Effects in Ag Tapes}

Our previous work had shown that increased TI levels resulted in larger TI-1223 grain structures which might be more amenable to orientation by thermal/mechanical processing. Tl level in the starting powder composition therefore was studied to determine the effects on the early phase development in Ag-clad tapes. Three compositions were prepared based on the nominal "Hitachi" composition, $\left(\mathrm{Tl}_{0.5} \mathrm{~Pb}_{0.5}\right)\left(\mathrm{Sr}_{0.8} \mathrm{Ba}_{0.2}\right)_{2} \mathrm{Ca}_{2} \mathrm{Cu}_{3} \mathrm{O}_{x}$, but with $\mathrm{Tl}$ levels of $\mathrm{Tl}_{0.6}, \mathrm{Tl}_{0.7}$ and $\mathrm{Tl}_{0.8}$. These powders were processed into Ag-clad tapes by IGC with designations TW066, TW067 and TW068 respectively. In addition, a $\mathrm{TI}_{0.5}$ level starting powder using a $\mathrm{TI}$ substitution compound, $\mathrm{Tl}_{2} \mathrm{Ba}_{2} \mathrm{O}_{5}$, instead of $\mathrm{Tl}_{2} \mathrm{O}_{3}$, was prepared (designation TW039). The TI substitution compound was chosen to have a higher decomposition temperature, thus delaying the evolution of $\mathrm{Tl}_{2} \mathrm{O}$ and the formation of the superconducting phases. DTA analysis was performed on all tapes to determine possible processing temperatures. The tapes were cut into small pieces and sealed under $\mathrm{O}_{2}$ in gold capsules to prevent thallium loss. Figures 1-11a thru 1-11d show the DTA curves for these tapes. All thallium compositions showed an initial melt in the $870^{\circ} \mathrm{C}-873^{\circ} \mathrm{C}$ range while the $\mathrm{Tl}_{0.6}$ composition had a second endotherm at $886^{\circ} \mathrm{C}$. The $\mathrm{Tl}_{2} \mathrm{Ba}_{2} \mathrm{O}_{5}$ composition had a single higher endotherm at $884^{\circ} \mathrm{C}$. The large melt event at $928^{\circ} \mathrm{C}$ was the $\mathrm{Ag}$ sheath material. The tapes were processed by rapidly heating the unreacted tapes to $860^{\circ} \mathrm{C}$ by Quick Furnace Insertion (QFI) for various time periods then quenching to room temperature. This temperature was chosen to be below the first melt events seen in these tapes. The tapes were then pressed at a pressure of $300 \mathrm{kpsi}$ and annealed at $860^{\circ} \mathrm{C}$ for 1 hour. The tapes were given several cycles of press $1860^{\circ} \mathrm{C}$ anneals to see how the different stoichiometries affected microstructure development and transport behavior. Tables 1-3a thru 1-3d show the resulting transport data obtained for the processed tapes. The data show that the highest critical currents were obtained for the compositions closest to the $\mathrm{TI}_{0.5}$ level. Also observed was the fast reaction time to achieve these higher currents as seen previously with other TI-based compositions. Extended processing only introduces cracking and "sausaging" into the core. This study showed that there was no significant advantage in increasing $\mathrm{Tl}$ level or using a TI source with higher decomposition temperature. 


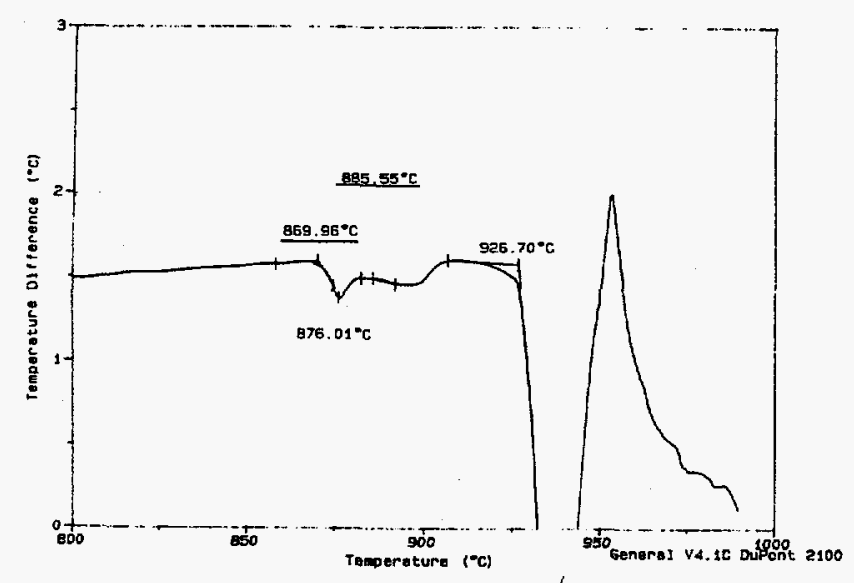

Figure 1-11a. DTA data for Ag tape, "Hitachi" composition with $\mathrm{TI}_{0.6}$ (TW066).

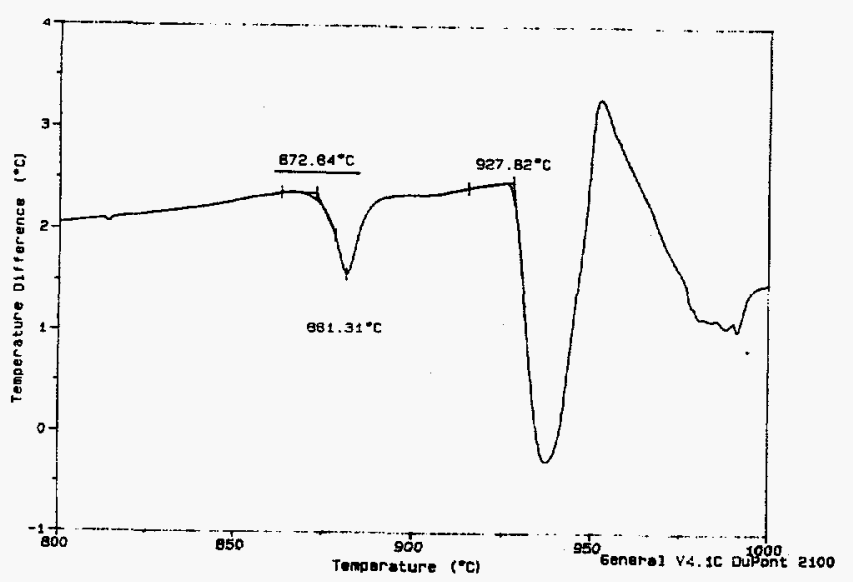

Figure 1-11c. DTA data for Ag tape, "Hitachi" composition with $\mathrm{Tl}_{0.8}$ (TW068).

$\mathrm{Tl}_{2} \mathrm{Ba}_{2} \mathrm{O}_{5}$ (TW039).

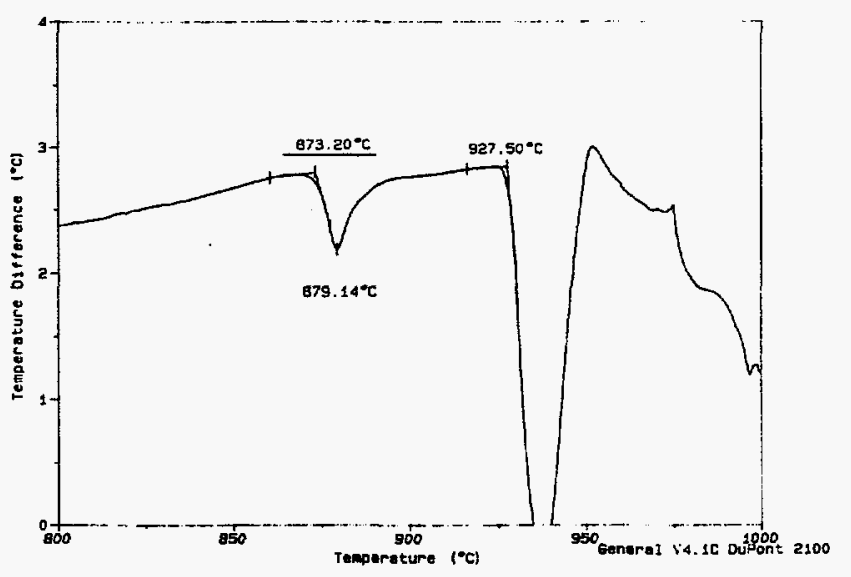

Figure 1-11b. DTA data for Ag tape, "Hitachi" composition with $\mathrm{TI}_{0.7}$ (TW067).

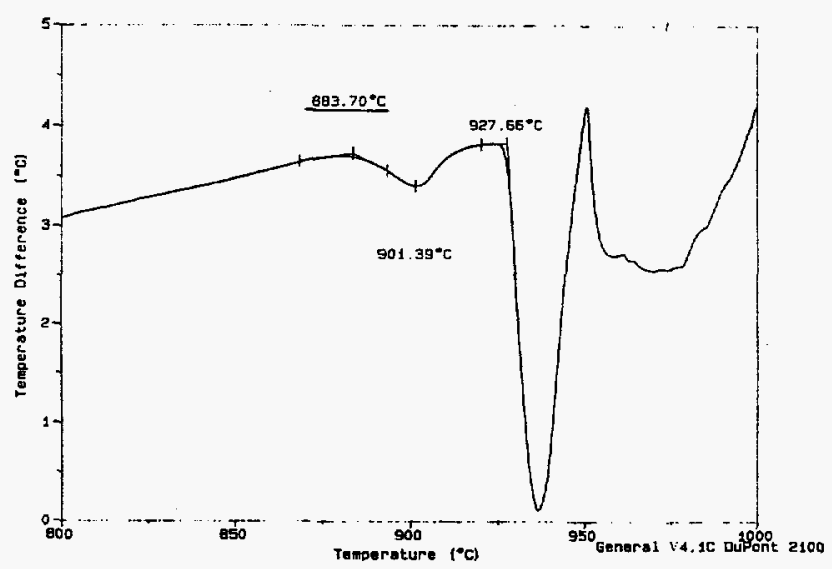

Figure 1-11d. DTA data for $\mathrm{Ag}$ tape, "Hitachi" composition with $\mathrm{Tl}_{0.5}$ using 
Table 1-3a. Ag Tapes

\begin{tabular}{|c|c|c|c|}
\hline \multicolumn{4}{|c|}{ TW066: TI/Pb $=0.6: 0.5$} \\
\hline & $860 \mathrm{C} / 1 \mathrm{hr}$ & $\begin{array}{c}300 \mathrm{kpsi} \text { Press } \\
\text { /860C/1hr }\end{array}$ & $\begin{array}{c}300 \mathrm{kpsi} \text { Press } \\
/ 860 \mathrm{C} / 1 \mathrm{hr}\end{array}$ \\
\hline $\begin{array}{c}\text { QFl:860C/10min } \\
300 \text { kpsi Press } \\
\text { (Total time: } 10 \mathrm{~min} \text { ) }\end{array}$ & $\begin{array}{c}\mathrm{Tc} \sim 85 \mathrm{~K} \\
\mathrm{lc}=0\end{array}$ & $\begin{array}{c}\text { Tc }=106 \mathrm{~K} \\
\mathrm{Ic}=0.4 \mathrm{~A} \\
(0 \mathrm{~A})\end{array}$ & $\begin{aligned} & T c=107 \mathrm{~K} \\
& \mathrm{Ic}=2.0 \mathrm{~A} \\
&(0.2 \mathrm{~A})\end{aligned}$ \\
\hline $\begin{array}{l}\text { QFI: } 860 \mathrm{C} / 10 \mathrm{~min} \\
300 \mathrm{kpsi} \text { Press } \\
\text { (Total time: } 20 \mathrm{~min} \text { ) }\end{array}$ & $\begin{aligned} T c & =108 \mathrm{~K} \\
\mathrm{Ic} & =4.8 \mathrm{~A} \\
& (0.5 \mathrm{~A})\end{aligned}$ & $\begin{array}{c}\mathrm{Tc}=106 \mathrm{~K} \\
\mathrm{Ic}=1.4 \mathrm{~A} \\
(0.1 \mathrm{~A})\end{array}$ & $\begin{aligned} & \mathrm{Tc}=109 \mathrm{~K} \\
& \mathrm{Ic}=5.0 \mathrm{~A} \\
&(0.7 \mathrm{~A})\end{aligned}$ \\
\hline $\begin{array}{l}\text { QFI } 860 \mathrm{C} / 10 \mathrm{~min} \\
300 \mathrm{kpsi} \text { Press } \\
\text { (Total time: } 30 \mathrm{~min})\end{array}$ & $\begin{aligned} T c & =106 \mathrm{~K} \\
\mathrm{Ic} & =1.4 \mathrm{~A}\end{aligned}$ & $\begin{aligned} & \mathrm{Tc}=108 \mathrm{~K} \\
& \mathrm{Ic}=1.9 \mathrm{a} \\
&(0.3 \mathrm{~A})\end{aligned}$ & $\begin{array}{c}\mathrm{Tc}=109 \mathrm{~K} \\
\mathrm{Ic}=0.9 \mathrm{~A} \\
(0.1 \mathrm{~A})\end{array}$ \\
\hline
\end{tabular}

Table 1-3b. Ag Tapes

\begin{tabular}{|c|c|c|c|}
\hline \multicolumn{4}{|c|}{ TW067: $\mathrm{TI} / \mathrm{Pb}=0.7 / 0.5$} \\
\hline & $860 \mathrm{C} / 1 \mathrm{hr}$ & $\begin{array}{l}300 \mathrm{kpsi} \\
\text { Press } \\
/ 860 \mathrm{C} / 1 \mathrm{hr}\end{array}$ & $\begin{array}{c}300 \mathrm{kpsi} \text { Press } \\
\quad / 860 \mathrm{C} / 1 \mathrm{hr}\end{array}$ \\
\hline $\begin{array}{l}\text { QFI: } 860 \mathrm{C} / 10 \mathrm{~min} \\
300 \text { kpsi Press } \\
\text { (Total time: } 10 \mathrm{~min} \text { ) }\end{array}$ & $\begin{aligned} T c & =107 \mathrm{~K} \\
\mathrm{Ic} & =1.6 \mathrm{~A}\end{aligned}$ & $\begin{array}{c}\mathrm{Tc}=108 \mathrm{~K} \\
\mathrm{Ic}=2.1 \mathrm{~A} \\
(0.3 \mathrm{~A})\end{array}$ & $\begin{aligned} & T c=110 \mathrm{~K} \\
& \mathrm{Ic}=3.4 \mathrm{~A} \\
&(0.5 \mathrm{~A})\end{aligned}$ \\
\hline $\begin{array}{l}\text { QFI: } 860 \mathrm{C} / 10 \mathrm{~min} \\
300 \mathrm{kpsi} \text { Press } \\
\text { (Total time: } 20 \mathrm{~min} \text { ) }\end{array}$ & $\begin{aligned} \mathrm{Tc} & =104 \mathrm{~K} \\
\mathrm{Ic} & =0.2 \mathrm{~A}\end{aligned}$ & $\begin{array}{c}T c=106 \mathrm{~K} \\
\mathrm{Ic}=1.1 \mathrm{~A} \\
(0.2 \mathrm{~A})\end{array}$ & $\begin{array}{c}T c=109 \mathrm{~K} \\
\mathrm{Ic}=0.8 \mathrm{~A} \\
(0.1 \mathrm{~A})\end{array}$ \\
\hline $\begin{array}{l}\text { QFI: } 860 \mathrm{C} / 10 \mathrm{~min} \\
300 \mathrm{kpsi} \text { Press } \\
\text { (Total time: } 30 \mathrm{~min} \text { ) }\end{array}$ & $\begin{aligned} \mathrm{Tc} & =90 \mathrm{~K} \\
\mathrm{Ic} & =0 \mathrm{~A}\end{aligned}$ & $\begin{array}{c}T c=105 \mathrm{~K} \\
\mathrm{Ic}=1.3 \mathrm{~A} \\
(0.2 \mathrm{~A})\end{array}$ & $\begin{aligned} & \mathrm{Tc}=109 \mathrm{~K} \\
& \mathrm{Ic}=1.3 \mathrm{~A} \\
&(0.2 \mathrm{~A})\end{aligned}$ \\
\hline
\end{tabular}


Table 1-3c. Ag Tapes

\begin{tabular}{|c|c|c|c|}
\hline \multicolumn{4}{|c|}{ TW068: $\mathrm{TI} / \mathrm{Pb}=0.8 / 0.5$} \\
\hline & $860 \mathrm{C} / 1 \mathrm{hr}$ & $\begin{array}{l}300 \mathrm{kpsi} \\
\text { Press } \\
/ 860 \mathrm{C} / 1 \mathrm{hr}\end{array}$ & $\begin{array}{c}300 \text { kpsi Press } \\
\text { /860C/1hr }\end{array}$ \\
\hline $\begin{array}{l}\text { QFI: } 860 \mathrm{C} / 10 \mathrm{~min} \\
300 \mathrm{kpsi} \text { Press } \\
\text { (Total time: } 10 \mathrm{~min} \text { ) }\end{array}$ & $\begin{aligned} T c & =104 K \\
I c & =0.8 A\end{aligned}$ & $\begin{array}{c}\mathrm{Tc}=106 \mathrm{~K} \\
\mathrm{Ic}=1.7 \mathrm{~A} \\
(0.2 \mathrm{~A})\end{array}$ & $\begin{aligned} & \mathrm{Tc}=106 \mathrm{~K} \\
& \mathrm{Ic}=3.4 \mathrm{~A} \\
&(0.3 \mathrm{~A})\end{aligned}$ \\
\hline $\begin{array}{l}\text { QFI: } 860 \mathrm{C} / 10 \mathrm{~min} \\
300 \mathrm{kpsi} \text { Press } \\
\text { (Total time: } 20 \mathrm{~min} \text { ) }\end{array}$ & $\begin{aligned} T c & =102 K \\
I c & =1.3 A\end{aligned}$ & $\begin{aligned} & \mathrm{Tc}=105 \mathrm{~K} \\
& \mathrm{Ic}=2.5 \mathrm{~A} \\
&(0.2 \mathrm{~A})\end{aligned}$ & $\begin{aligned} & \mathrm{Tc}=108 \mathrm{~K} \\
& \mathrm{Ic}=2.4 \mathrm{~A} \\
&(0.4 \mathrm{~A})\end{aligned}$ \\
\hline $\begin{array}{l}\text { QFI: } 860 \mathrm{C} / 10 \mathrm{~min} \\
300 \mathrm{kpsi} \text { Press } \\
\text { (Total time: } 30 \mathrm{~min} \text { ) }\end{array}$ & $\begin{array}{c}T c=103 \mathrm{~K} \\
\mathrm{Ic}=2.1 \mathrm{~A} \\
(0.2 \mathrm{~A})\end{array}$ & $\begin{array}{c}T c=105 \mathrm{~K} \\
\mathrm{Ic}=0 \mathrm{~A} \\
(0.0 \mathrm{~A})\end{array}$ & $\begin{aligned} & \mathrm{Tc}=108 \mathrm{~K} \\
& \mathrm{Ic}=0.7 \mathrm{~A} \\
&(0.2 \mathrm{~A})\end{aligned}$ \\
\hline
\end{tabular}

Table 1-3d. Ag Tapes

\begin{tabular}{|c|c|c|c|}
\hline \multicolumn{4}{|c|}{ TW039: $\mathrm{Tl} / \mathrm{Pb}=0.5 / 0.5$} \\
\hline & $860 \mathrm{C} / 1 \mathrm{hr}$ & $\begin{array}{c}300 \mathrm{kpsi} \text { Press } \\
/ 860 \mathrm{C} / 1 \mathrm{hr}\end{array}$ & $\begin{array}{c}300 \mathrm{kpsi} \text { Press } \\
/ 860 \mathrm{C} / 1 \mathrm{hr}\end{array}$ \\
\hline $\begin{array}{l}\text { QFI: } 860 \mathrm{C} / 10 \mathrm{~min} \\
300 \mathrm{kpsi} \text { Press } \\
\text { (Total time: } 10 \mathrm{~min} \text { ) }\end{array}$ & $\begin{aligned} T c & =106 \mathrm{~K} \\
\mathrm{Ic} & =1.2 \mathrm{~A}\end{aligned}$ & $\begin{array}{c}T c=107 \mathrm{~K} \\
\mathrm{Ic}=1.9 \mathrm{~A} \\
(0.2 \mathrm{~A})\end{array}$ & $\begin{array}{c}T c=110 \mathrm{~K} \\
\mathrm{Ic}=2.7 \mathrm{~A} \\
(0.3 \mathrm{~A})\end{array}$ \\
\hline $\begin{array}{l}\text { QFI: } 860 \mathrm{C} / 10 \mathrm{~min} \\
300 \mathrm{kpsi} \text { Press } \\
\text { (Total time: } 20 \mathrm{~min} \text { ) }\end{array}$ & $\begin{aligned} T c & =106 \mathrm{~K} \\
\mathrm{Ic} & =1.4 \mathrm{~A}\end{aligned}$ & $\begin{array}{c}\mathrm{Tc}=110 \mathrm{~K} \\
\mathrm{Ic}=6.1 \mathrm{~A} \\
(0.9 \mathrm{~A})\end{array}$ & $\begin{array}{c}\mathrm{Tc}=107 \mathrm{~K} \\
\mathrm{Ic}=1.5 \mathrm{~A} \\
(0.1 \mathrm{~A})\end{array}$ \\
\hline $\begin{array}{l}\text { QFI: } 860 \mathrm{C} / 10 \mathrm{~min} \\
300 \mathrm{kpsi} \text { Press } \\
\text { (Total time: } 30 \mathrm{~min} \text { ) }\end{array}$ & $\begin{array}{l}T c=106 \mathrm{~K} \\
\mathrm{Ic}=1.5 \mathrm{~A}\end{array}$ & $\begin{array}{c}\mathrm{Tc}=108 \mathrm{~K} \\
\mathrm{Ic}=1.3 \mathrm{~A} \\
(0.2 \mathrm{~A})\end{array}$ & $\begin{aligned} & T c=108 \mathrm{~K} \\
& \mathrm{Ic}=1.4 \mathrm{~A} \\
&(0.1 \mathrm{~A})\end{aligned}$ \\
\hline
\end{tabular}




\subsubsection{Thermal/Mechanical Processing of AglAg Alloy Sheathed Tapes}

TI-1223 tapes have been produced using two sheath materials: pure $\mathrm{Ag}$ and a harder Ag alloy produced at LANL. Two tape thicknesses (4mil and $10 \mathrm{mil}$ ) were produced in a collaborative effort with Los Alamos using Sandia chemprep powder of composition $\left(\mathrm{TI}_{0.5} \mathrm{~Pb}_{0.5}\right)\left(\mathrm{Sr}_{0.8} \mathrm{Ba}_{0.2}\right)_{2} \mathrm{Ca}_{2} \mathrm{Cu}_{3} \mathrm{O}_{\mathrm{x}}$. The tapes were subjected to a series of thermal/mechanical cycles to determine microstructural development and the stability of the $\mathrm{Ag} /$ superconductor interface. The tapes were initially given a series of short heat treatments $(15 \mathrm{~min})$ at $875^{\circ} \mathrm{C}$ followed by a uniaxial press starting at $200 \mathrm{kpsi}$ and going up to $375 \mathrm{kpsi}$. These initial heat/press cycles were intended to take advantage of the rapid kinetics in this system while maintaining a dense core structure. Tapes from each step of the initial press/anneals were then subjected to standard press/ anneal cycles $\left(875^{\circ} \mathrm{C} / 2 \mathrm{hr}\right)$. The transport properties at each intermediate processing step were measured and select tapes were chosen for SEM analysis. Tables 1-4a thru 1-4c summarize the transport data. Ic and $\mathrm{Jc}$ values were taken at $75 \mathrm{~K}$ and in self field. (The Ic data in brackets were taken at 200 gauss).

Figure 1-12 shows the comparison of the SEM micrographs of the tapes after one and four anneal/press cycles.

The results of these processing steps show that the harder Ag alloy sheath did not result in improved transport properties. The average transport $\mathrm{Jc}$ for the $4 \mathrm{mil} \mathrm{Ag}$ alloy tapes was $7,100 \mathrm{~A} / \mathrm{cm}^{2}$ compared to $9,400 \mathrm{~A} / \mathrm{cm}^{2}$ for the $4 \mathrm{mil} \mathrm{Ag}$ tapes. However, the $\mathrm{Ag}$ alloy sheath tapes did show a smaller spread in Ic values than did the $\mathrm{Ag}$ sheathed tapes. Also observed was a lower average $\mathrm{Jc}\left(5,200 \mathrm{~A} / \mathrm{cm}^{2}\right)$ for the 10 mil tapes compared to the $4 \mathrm{mil}$ tapes. A much higher level of transverse cracks were seen in the 10mil tapes. SEM analysis showed an increase in density and coarsening of the grain structure with longer press/anneal times, but no large increase in transport values. In fact, the most processed tapes usually showed a decrease in transport current. The increasing brittle nature of the processed cores results in a limit on improvements from further processing steps. No sign of grain alignment was observed from the combined press/anneal cycles and the cores still showed significant porosity. Smaller core thickness and/or larger grain structures may result in mechanical constraint of the grains resulting in some texture. 
Table 1-4a. Ag Alloy Sheath Tapes

\begin{tabular}{|c|c|c|c|}
\hline \multicolumn{4}{|c|}{ Thickness: 4mil } \\
\hline & $\begin{array}{c}\text { Bake: } \\
875 \mathrm{C} / 2 \mathrm{hr}\end{array}$ & $\begin{array}{l}\text { Press: } 300 \mathrm{kpsi} \\
\text { Slow: } 875 \mathrm{C} / 3 \mathrm{hr}\end{array}$ & $\begin{array}{l}\text { Press: } 375 \mathrm{kpsi} \\
\text { Slow: } 875 \mathrm{C} / 3 \mathrm{hr}\end{array}$ \\
\hline $\begin{array}{l}15 \text { min Anneal/Press } \\
\text { Cycles }\end{array}$ & $\operatorname{Tc}_{\mathrm{Jc}} \mathrm{Ic}$ & $\operatorname{Tc}_{\mathrm{Jc}} \mathrm{Ic}$ & $\mathrm{Jc}_{\mathrm{Jc}}^{\mathrm{lc}}$ \\
\hline $\begin{array}{l}875 \mathrm{C} / 15 \mathrm{~min} / \text { Press } \\
200 \mathrm{kpsi} \\
\text { (Total: } 15 \mathrm{~min} \text { ) }\end{array}$ & $\begin{array}{c}\mathrm{TC}=113 \mathrm{~K} \\
\mathrm{Ic}=2.6 \mathrm{~A}(0.2) \\
\mathrm{Jc}=5900 \mathrm{~A} / \mathrm{cm}^{2} \\
\text { Total } 2 \mathrm{hr} 15 \mathrm{~min}\end{array}$ & $\begin{array}{c}\mathrm{Tc}=114 \mathrm{~K} \\
\mathrm{Ic}=3.2 \mathrm{~A}(0.3) \\
\mathrm{Jc}=7200 \mathrm{~A} / \mathrm{cm}^{2} \\
\text { Total } 5 \mathrm{hr} 15 \mathrm{~min}\end{array}$ & $\begin{array}{c}\mathrm{Tc}=117 \mathrm{~K} \\
\mathrm{Ic}=4.0 \mathrm{~A}(0.7) \\
\mathrm{Jc}=9000 \mathrm{~A} / \mathrm{cm}^{2} \\
\text { Total: } 8 \mathrm{hr} 15 \mathrm{~min}\end{array}$ \\
\hline $\begin{array}{l}875 \mathrm{C} / 15 \mathrm{~min} / \text { Press } \\
300 \mathrm{kpsi} \\
\text { (Total: } 30 \mathrm{~min} \text { ) }\end{array}$ & $\begin{array}{c}\mathrm{TC}=113 \mathrm{~K} \\
\mathrm{IC}=3.2 \mathrm{~A}(0.3) \\
\mathrm{Jc}=7200 \mathrm{~A} / \mathrm{cm}^{2} \\
\text { Total: } 2 \mathrm{hr} 30 \mathrm{~min}\end{array}$ & $\begin{array}{c}\mathrm{TC}=116 \mathrm{~K} \\
\mathrm{Ic}=2.2 \mathrm{~A}(0.2) \\
\mathrm{Jc}=5000 \mathrm{~A} / \mathrm{cm}^{2} \\
\text { Total } 5 \mathrm{hr} 30 \mathrm{~min}\end{array}$ & $\begin{array}{c}\mathrm{Tc}=116 \mathrm{~K} \\
\mathrm{Ic}=3.4 \mathrm{~A}(0.4) \\
\mathrm{Jc}=7700 \mathrm{~A} / \mathrm{cm}^{2} \\
\text { Total: } 8 \mathrm{hr} 30 \mathrm{~min}\end{array}$ \\
\hline $\begin{array}{l}875 \mathrm{C} / 15 \mathrm{~min} / \text { Press } \\
375 \mathrm{kpsi} \\
\text { (Total: } 45 \mathrm{~min} \text { ) }\end{array}$ & $\begin{array}{c}\mathrm{Tc}=114 \mathrm{~K} \\
\mathrm{Ic}=3.5 \mathrm{~A}(0.3) \\
\mathrm{Jc}=7900 \mathrm{Avcm}{ }^{2} \\
\text { Total } 2 \mathrm{hr} 45 \mathrm{~min}\end{array}$ & $\begin{array}{c}T \mathrm{c}=117 \mathrm{~K} \\
\mathrm{Ic}=3.0 \mathrm{~A}(0.3) \\
\mathrm{Jc}=6800 \mathrm{~A} / \mathrm{cm}^{2} \\
\text { Total } 5 \mathrm{hr} 45 \mathrm{~min}\end{array}$ & $\begin{array}{c}T c=118 \mathrm{~K} \\
\mathrm{Ic}=2.9 \mathrm{~A}(0.5 \mathrm{~A}) \\
\mathrm{Jc}=6500 \mathrm{~A} / \mathrm{cm}^{2} \\
\text { Total: } 8 \mathrm{hr} 45 \mathrm{~min}\end{array}$ \\
\hline
\end{tabular}


Table 1-4b. Ag Sheath Tapes

\begin{tabular}{|c|c|c|c|}
\hline \multicolumn{4}{|c|}{ Thickness: $4 \mathrm{mil}$} \\
\hline & $\begin{array}{l}\text { Bake: } \\
875 \mathrm{C} / 2 \mathrm{hr}\end{array}$ & $\begin{array}{l}\text { Press: } 300 \mathrm{kpsi} \\
\text { Slow: } 875 \mathrm{C} / 3 \mathrm{hr}\end{array}$ & $\begin{array}{l}\text { Press: } 375 \mathrm{kpsi} \\
\text { Slow: } 875 \mathrm{C} / 3 \mathrm{hr}\end{array}$ \\
\hline $\begin{array}{l}15 \text { min Anneal/Press } \\
\text { Cycles }\end{array}$ & $\operatorname{Jc}_{\mathrm{Jc}}$ Ic & $\operatorname{Jc}^{\mathrm{Jc}}$ Ic & $\underset{\mathrm{Jc}}{\mathrm{Tc}}$ \\
\hline $\begin{array}{l}875 \mathrm{C} / 15 \mathrm{~min} / \text { Press } \\
200 \mathrm{kpsi} \\
\text { (Total: } 15 \mathrm{~min} \text { ) }\end{array}$ & $\begin{array}{c}\mathrm{Tc}=112 \mathrm{~K} \\
\mathrm{Ic}=2.1 \mathrm{~A}(0.1) \\
\mathrm{Jc}=6500 \mathrm{~A} / \mathrm{cm}^{2} \\
\text { Total: } 2 \mathrm{hr} 15 \mathrm{~min}\end{array}$ & $\begin{array}{c}\mathrm{Tc}=114 \mathrm{~K} \\
\mathrm{Ic}=3.5 \mathrm{~A}(0.5) \\
\mathrm{Jc}=10700 \mathrm{~A} / \mathrm{cm}^{2} \\
\text { Total } 5 \mathrm{hr} 15 \mathrm{~min}\end{array}$ & $\begin{array}{c}\mathrm{Tc}=117 \mathrm{~K} \\
\mathrm{lc}=1.0 \mathrm{~A} \\
\mathrm{Jc}=3100 \mathrm{~A} / \mathrm{cm}^{2} \\
\text { Total }: 8 \mathrm{hr} 15 \mathrm{~min}\end{array}$ \\
\hline $\begin{array}{l}875 \mathrm{C} / 15 \mathrm{~min} / \text { Press } \\
300 \mathrm{kpsi} \\
\text { (Total: } 30 \mathrm{~min} \text { ) }\end{array}$ & $\begin{array}{c}\mathrm{Tc}=113 \mathrm{~K} \\
\mathrm{Ic}=3.4 \mathrm{~A}(0.4) \\
\mathrm{Jc}=10500 \mathrm{~A} / \mathrm{cm}^{2} \\
\text { Total } 2 \mathrm{hr} 30 \mathrm{~min}\end{array}$ & $\begin{array}{c}\mathrm{TC}=116 \mathrm{~K} \\
\mathrm{IC}=4.3 \mathrm{~A}(0) \\
\mathrm{Jc}=13200 \mathrm{~A} / \mathrm{cm}^{2} \\
\text { Total: } 5 \mathrm{hr} 30 \mathrm{~min}\end{array}$ & $\begin{array}{c}\mathrm{Tc}=117 \mathrm{~K} \\
\mathrm{Ic}=4.5 \mathrm{~A}(1.0 \mathrm{~A}) \\
\mathrm{Jc}=13900 \mathrm{~A} / \mathrm{cm}^{2} \\
\text { Total } 8 \mathrm{hr} 30 \mathrm{~min}\end{array}$ \\
\hline $\begin{array}{l}875 \mathrm{C} / 15 \mathrm{~min} / \text { Press } \\
375 \mathrm{kpsi} \\
\text { (Total: } 45 \mathrm{~min} \text { ) }\end{array}$ & $\begin{array}{c}\mathrm{Tc}=117 \mathrm{~K} \\
\mathrm{Ic}=1.0 \mathrm{~A}(0) \\
\mathrm{Jc}=3100 \mathrm{Acm} \mathrm{cm}^{2} \\
\text { Total: } 2 \mathrm{hr} 45 \mathrm{~min}\end{array}$ & $\begin{array}{c}\mathrm{Tc}=115 \mathrm{~K} \\
\mathrm{Ic}=3.7 \mathrm{~A}(0.6) \\
\mathrm{Jc}=11400 \mathrm{~A} / \mathrm{cm}^{2} \\
\text { Total: } 5 \mathrm{hr} 45 \mathrm{~min}\end{array}$ & $\begin{array}{c}\mathrm{Tc}=118 \mathrm{~K} \\
\mathrm{Ic}=3.0 \mathrm{~A} \\
\mathrm{Jc}=9200 \mathrm{~A} / \mathrm{cm}^{2} \\
\text { Total: } 8 \mathrm{hr} 45 \mathrm{~min}\end{array}$ \\
\hline
\end{tabular}


Table 1-4c. Ag Alloy Sheath Tapes

\begin{tabular}{|c|c|c|c|}
\hline \multicolumn{4}{|c|}{ Thickness: 10mil } \\
\hline : & $\begin{array}{c}\text { Bake: } \\
875 \mathrm{C} / 2 \mathrm{hr}\end{array}$ & $\begin{array}{l}\text { Press: } 300 \mathrm{kpsi} \\
\text { Slow: } 875 \mathrm{C} / 3 \mathrm{hr}\end{array}$ & $\begin{array}{l}\text { Press: } 375 \mathrm{kpsi} \\
\text { Slow: } 875 \mathrm{C} / 3 \mathrm{hr}\end{array}$ \\
\hline $\begin{array}{l}15 \text { min Press/Anneal } \\
\text { Cycles }\end{array}$ & $\operatorname{Tc}_{\mathrm{Jc}} \mathrm{Ic}$ & $\operatorname{Tc}_{\mathrm{JC}} \mathrm{Ic}$ & $\operatorname{Jc}^{\text {Jc }}$ \\
\hline $\begin{array}{l}875 \mathrm{C} / 15 \mathrm{~min} / \text { Press } \\
200 \mathrm{kpsi} \\
\text { (Total: } 15 \mathrm{~min} \text { ) }\end{array}$ & $\begin{array}{c}\mathrm{TC}=112 \mathrm{~K} \\
\mathrm{IC}=4.7 \mathrm{~A}(0.5) \\
\mathrm{JC}=5500 \mathrm{~A} / \mathrm{cm}^{2} \\
\text { Total: } 2 \mathrm{hr} 15 \mathrm{~min}\end{array}$ & $\begin{array}{c}\mathrm{Tc}=112 \mathrm{~K} \\
\mathrm{Ic}=4.0 \mathrm{~A}(0.8) \\
\mathrm{Jc}=4700 \mathrm{~A} / \mathrm{cm}^{2} \\
\text { Total } 5 \mathrm{hr} 15 \mathrm{~min}\end{array}$ & $\begin{array}{c}\mathrm{Tc}=113 \mathrm{~K} \\
\mathrm{Ic}=6.3 \mathrm{~A}(1.5) \\
\mathrm{Jc}=7300 \mathrm{~A} / \mathrm{cm}^{2} \\
\text { Total } 8 \mathrm{hr} 15 \mathrm{~min}\end{array}$ \\
\hline $\begin{array}{l}875 \mathrm{C} / 15 \mathrm{~min} / \text { Press } \\
300 \mathrm{kpsi} \\
\text { (Total: } 30 \mathrm{~min} \text { ) }\end{array}$ & $\begin{array}{c}\mathrm{TC}=113 \mathrm{~K} \\
\mathrm{Ic}=4.0 \mathrm{~A}(0.6) \\
\mathrm{Jc}=4700 \mathrm{~A} / \mathrm{cm}^{2} \\
\text { Total } 2 \mathrm{hr} 30 \mathrm{~min}\end{array}$ & $\begin{array}{c}\mathrm{Tc}=112 \mathrm{~K} \\
\mathrm{Ic}=4.0 \mathrm{~A}(0.8) \\
\mathrm{Jc}=4700 \mathrm{~A} / \mathrm{cm}^{2} \\
\text { Total } 5 \mathrm{hr} 30 \mathrm{~min}\end{array}$ & $\begin{array}{c}\mathrm{Tc}=118 \mathrm{~K} \\
\mathrm{lc}=3.4 \mathrm{~A}(0.5) \\
\mathrm{Jc}=4000 \mathrm{~A} / \mathrm{cm}^{2} \\
\text { Total } 8 \mathrm{hr} 30 \mathrm{~min}\end{array}$ \\
\hline $\begin{array}{l}875 \mathrm{C} / 15 \mathrm{~min} / \text { Press } \\
375 \mathrm{kpsi} \\
\text { (Total: } 45 \mathrm{~min} \text { ) }\end{array}$ & $\begin{array}{c}\mathrm{TC}=112 \mathrm{~K} \\
\mathrm{IC}=5.6 \mathrm{~A}(1.1) \\
\mathrm{Jc}=6500 \mathrm{~A} / \mathrm{cm}^{2} \\
\text { Total: } 2 \mathrm{hr} 45 \mathrm{~min}\end{array}$ & Total:5hr45min & Total:8hr45min \\
\hline
\end{tabular}


4 mil Ag

Sheath

4 mil Ag

Alloy Sheath

$10 \mathrm{mil} \mathrm{Ag}$ Alloy Sheath
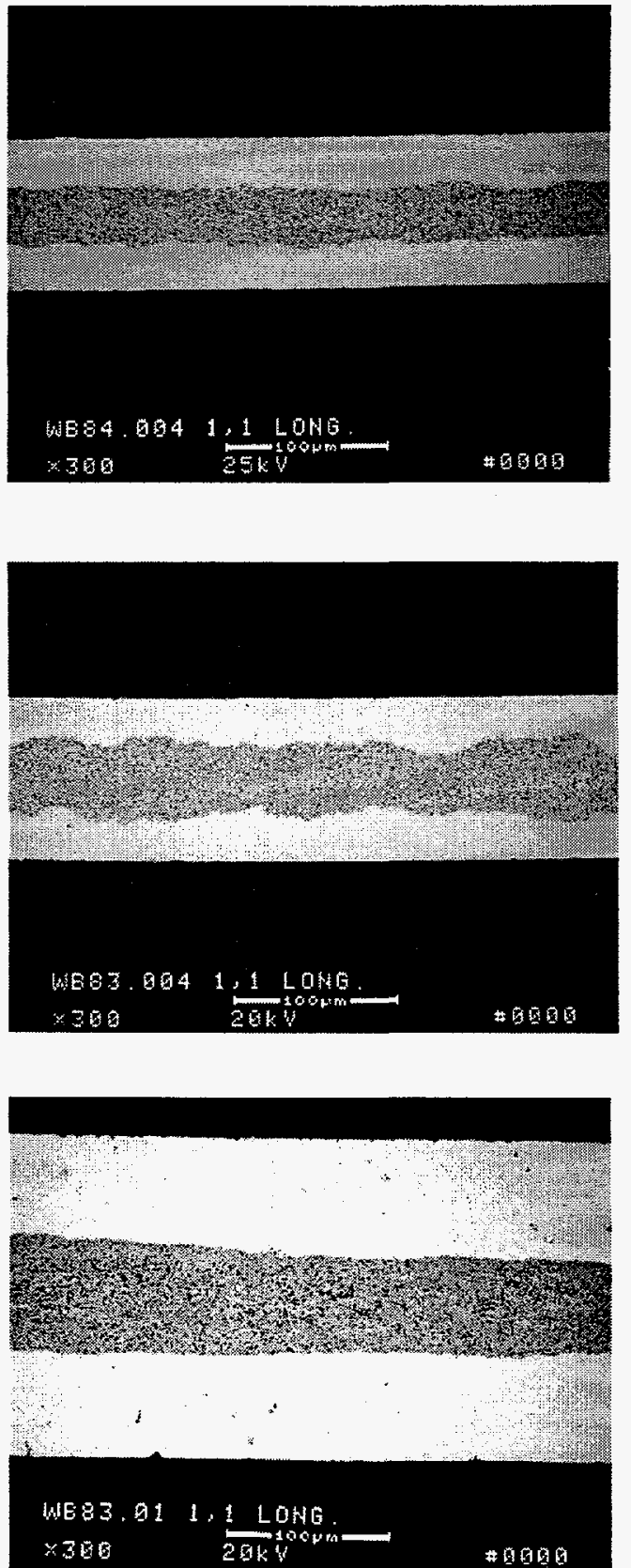

One Press/Anneal Cycle
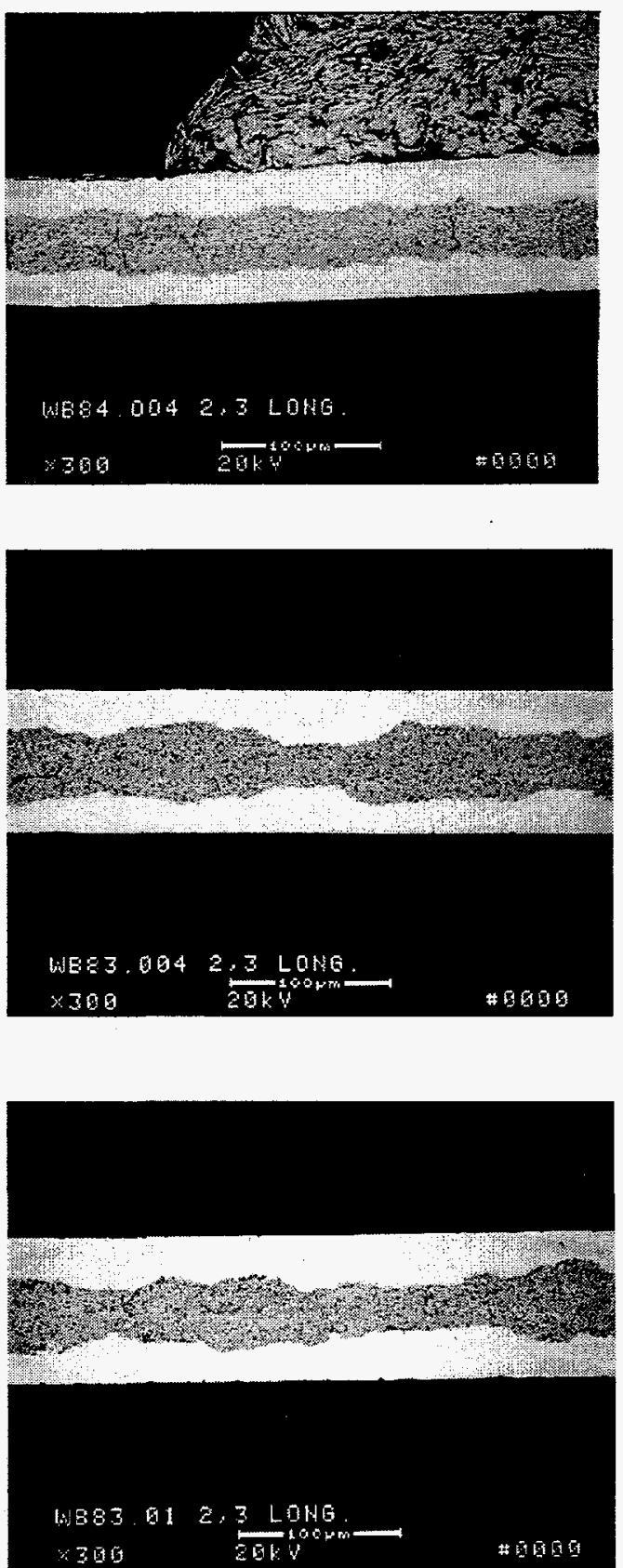

Four Press/Anneal Cycles

Figure 1-12. SEM micrographs of tapes after one and four press/anneal cycles. 


\subsubsection{Stability of Thallium-1223 Phases}

Efforts to utilize thallium cuprate superconductors in bulk wire applications have focused on the so-called 1223 phase, $\mathrm{TIBa}_{2} \mathrm{Ca}_{2} \mathrm{Cu}_{3} \mathrm{O}_{9}$, and structurally similar materials. The partial substitution of $\mathrm{Pb}$ for $\mathrm{Tl}$ and of $\mathrm{Sr}$ for $\mathrm{Ba}$ were reported by Doi and coworkers at Hitachi to enhance the formation of the 1223 phase. Based on this report, a large amount of effort has been devoted to producing wires based on the "Hitachi" composition, $\left(\mathrm{TI}_{0.5} \mathrm{~Pb}_{0.5}\right)\left(\mathrm{Sr}_{1.6} \mathrm{Ba}_{0.4}\right) \mathrm{Ca}_{2} \mathrm{Cu}_{3} \mathrm{O}_{9}$. Phases with double TI-O layers (e.g. $\mathrm{Tl}_{2} \mathrm{Ba}_{2} \mathrm{CaCu}_{2} \mathrm{O}_{8}, \mathrm{Tl}_{2} \mathrm{Ba}_{2} \mathrm{Ca}_{2} \mathrm{Cu}_{3} \mathrm{O}_{10}$ ) have not been reported in bulk materials with this composition. In addition, the formation of 1223 competes with the formation of a phase or phases with the $\mathrm{TIBa}_{2} \mathrm{CaCu}_{2} \mathrm{O}_{7}(1212)$ structure. This competition appears to be sensitively governed by the conditions used in processing the bulk material. We have endeavored to understand whether these observations arise from thermodynamic origins. In particular, we have extended our prior study of phase equilibria in the unsubstituted TI-Ba-Ca-Cu-O system to materials with the Hitachi composition. These studies have addressed three questions: 1) does a thermodynamic boundary between the 1212 and 1223 phases exist which might explain the sensitivity of phase formation to process conditions?,2) does the substitution of $\mathrm{Pb}$ and/or $\mathrm{Sr}$ prohibit the formation of phases with double TI-O layers?, and 3) what role, if any, do liquids play in the thermodynamic stability of the 1223 phase?

The thermodynamic variables that must be controlled to establish an equilibrium state in this system include the sample temperature, the oxygen partial pressure, $\mathrm{P}\left(\mathrm{O}_{2}\right)$, the partial pressure of thallous oxide, $\mathrm{P}\left(\mathrm{Tl}_{2} \mathrm{O}\right)$, and the independent ratios of nonvolatile cations in the sample. Our prior studies of the unsubstituted TI-Ba-Ca-Cu-O system demonstrated that control of $\mathrm{P}\left(\mathrm{Tl}_{2} \mathrm{O}\right)$ is crucial in establishing phase equilibria. Changes in $\mathrm{P}\left(\mathrm{Tl}_{2} \mathrm{O}\right)$ alone can reversibly drive phase changes from one crystal structure to another. Figure 1-13 illustrates these effects of $\mathrm{P}\left(\mathrm{Tl}_{2} \mathrm{O}\right)$ on samples with $\mathrm{Ba}: \mathrm{Ca}: \mathrm{Cu}$ ratios of 2:2:3. Relatively small increases in $\mathrm{P}\left(\mathrm{Tl}_{2} \mathrm{O}\right)$ produce a succession of dominant equilibrium phases: TI-free phases $\rightarrow 1223 \rightarrow 2223 \rightarrow 2212 \rightarrow$ TI-rich phases. By analogy, we anticipated that a boundary in $\mathrm{P}\left(\mathrm{Tl}_{2} \mathrm{O}\right)$ between the 1223 (low-P $\left(\mathrm{Tl}_{2} \mathrm{O}\right)$ ) and 1212 (high $\mathrm{P}\left(\mathrm{Tl}_{2} \mathrm{O}\right)$ ) phases might be found in samples with the Hitachi composition. Such a boundary would explain the formation of 1212 in wires 
as being related to an excessive activity of thallium oxide. Furthermore, by increasing $\mathrm{P}\left(\mathrm{Tl}_{2} \mathrm{O}\right)$ to the highest values possible in our system, we explored whether any phases with double TI-O layers might exist in samples with the Hitachi composition.

We have combined our chemically prepared samples having well defined stoichiometries with our capability to perform extended high-temperature anneals in our two-zone furnace to establish independent control of each of the thermodynamic variables in the system. Our early work demonstrated that $\mathrm{Pb}$ could be considered a non-volatile cation for our purposes. Therefore, each of the independent cation ratios in the sample except those involving $\mathrm{TI}$ were fixed at the Hitachi ratios by the composition of the chemically prepared starting materials. Based on our observation that phases with single TI-O layers in unsubstituted TI-Ba-Ca-Cu oxides are less stable with decreasing $P\left(O_{2}\right)$ (see Figure 1-13), we have focused our attention on atmospheres of pure $\mathrm{O}_{2}$. The effect of a liquid's presence on phase stability was assessed by determining the phase relations at sample temperatures $920^{\circ} \mathrm{C}$ and $870^{\circ} \mathrm{C}$. The former temperature is above and the latter below the onset of melting determined by our DTA measurements.

The results of our phase stability experiments for samples with the Hitachi composition are illustrated in Figure 1-14. Note that the abscissa in Figure 1-14 is the sample temperature; here $\mathrm{P}\left(\mathrm{O}_{2}\right)$ is held constant at $0.8 \mathrm{~atm}$. In Figure 1-13, the abscissa is the oxygen partial pressure. In both cases, the ordinate is the partial pressure of $\mathrm{Tl}_{2} \mathrm{O}$. The temperature of the source zone required to produce the corresponding value of $P\left(T_{2} \mathrm{O}\right)$ at the experimental $P\left(\mathrm{O}_{2}\right)$ are shown on the right sides of Figures 1-13 and1-14.

Above a minimum value of $\mathrm{P}\left(\mathrm{Tl}_{2} \mathrm{O}\right)$ of about $10^{-3}$ atm, Figure 1-14 shows the Hitachicomposition 1223 phase to be the stable superconducting phase over the entire range of $\mathrm{P}\left(\mathrm{Tl}_{2} \mathrm{O}\right)$ accessible in our two-zone system. No evidence of the 1212 phase or of any phase with a double TI-O layer was found at any value of $\mathrm{P}\left(\mathrm{Tl}_{2} \mathrm{O}\right)$ or at either sample temperature in our studies. The upper bound depicted in Figure 1-14 represents our experimental limit, not a thermodynamic boundary. Contrasting Figures 1-13 and 1-14 illustrates the greatly enhanced relative stability of the 1223 phase produced by $\mathrm{Pb}$ and $\mathrm{Sr}$ substitutions (Hitachi composition). 
Sample temperature did not have a major effect on the experimental outcome. The powder x-ray diffraction patterns of samples annealed at $920^{\circ} \mathrm{C}$ (in the presence of a liquid phase) had reflections of only the 1223 phase, whereas the patterns of samples annealed at $870^{\circ} \mathrm{C}$ (in the absence of a liquid) had small amounts of a $\mathrm{BaPbO}_{3}$ impurity. In both cases, the $\mathrm{T}_{\mathrm{c}}$ of the sample decreased with increasing $\mathrm{P}\left(\mathrm{Tl}_{2} \mathrm{O}\right)$. The observation of 1223 at both $870^{\circ} \mathrm{C}$ and $920^{\circ} \mathrm{C}$ suggests that a liquid phase is not required for this phase to be stable. Additionally, 1223 was formed at $870^{\circ} \mathrm{C}$ from a sample comprising a mixture of $1212, \mathrm{Ca}_{2} \mathrm{PbO}_{4}$, and other oxides by an 8 day anneal under $\mathrm{P}\left(\mathrm{Tl}_{2} \mathrm{O}\right)$ of $9 \times 10^{-3} \mathrm{~atm}$. This experiment confirms that a liquid phase is not required to form 1223 .

The results of our two-zone experiments disprove the operating hypothesis that a boundary between 1223 and 1212 would be found at some $P\left(\mathrm{Tl}_{2} \mathrm{O}\right)$ in samples with the Hitachi composition. In the course of the experiments, however, we did develop information that led to a proposed mechanism by which the 1212 phase is observed in wires and tapes. The initial observation was based on mixing $\mathrm{Tl}_{2} \mathrm{O}_{3}$ with our chemically prepared precursors and heating for several hours at various temperatures. 1212 was observed only when the sample temperature was low $\left(<830^{\circ} \mathrm{C}\right) \cdot \mathrm{Ca}_{2} \mathrm{PbO}_{4}$ was also present in large amount with this 1212 . Upon heating samples at higher temperatures, both the 1212 and the $\mathrm{Ca}_{2} \mathrm{PbO}_{4}$ disappear, and only 1223 results. This observation suggested that the availability of $\mathrm{Pb}$ for incorporation into the superconductor drives the formation of 1223. A two-zone equilibration experiment using a sample of composition $\left(\mathrm{Sr}_{1.6} \mathrm{Ba}_{0.4}\right) \mathrm{Ca}_{2} \mathrm{Cu}_{3} \mathrm{O}_{x}$, i.e. the Hitachi composition minus $\mathrm{Pb}$, and a $\mathrm{P}\left(\mathrm{Tl}_{2} \mathrm{O}\right)$ of $1.2 \times 10^{-2}$ atm produced the 1212 phase along with calcium cuprates required to balance the stoichiometry. Under otherwise identical conditions, samples of the Hitachi composition with $\mathrm{Pb}$ produce the 1223 phase. From this evidence, we infer that the observation of 1212 at low temperatures in bulk materials of the Hitachi composition results from the lack of available $\mathrm{Pb}$, the $\mathrm{Pb}$ being tied up in stable alkaline earth plumbates. With increasing temperature (and time at temperature), these plumbates are decomposed and 1223 is produced. We note that 1212 can also be formed by the incongruent melting of the 1223 phase at high temperatures. We have not yet explored this temperature range. 


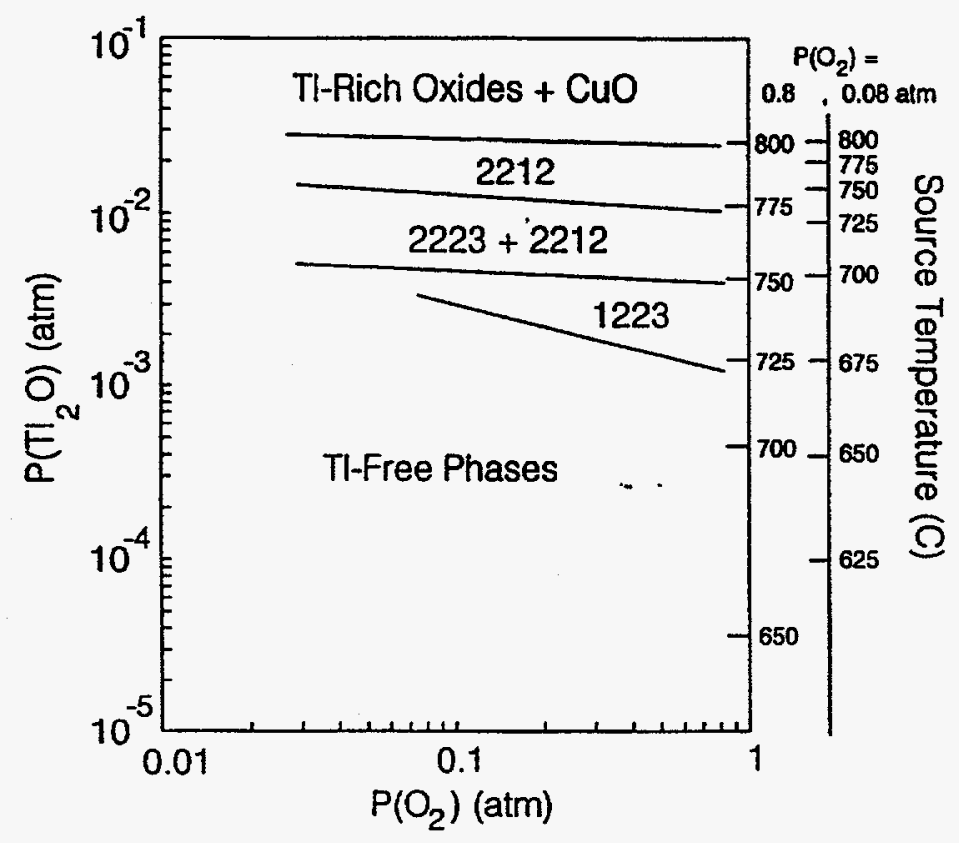

Figure 1-13. The effects of $\mathrm{P}\left(\mathrm{Tl}_{2} \mathrm{O}\right)$ on samples with $\mathrm{Ba}: \mathrm{Ca}: \mathrm{Cu}$ ratios of 2:2:3.

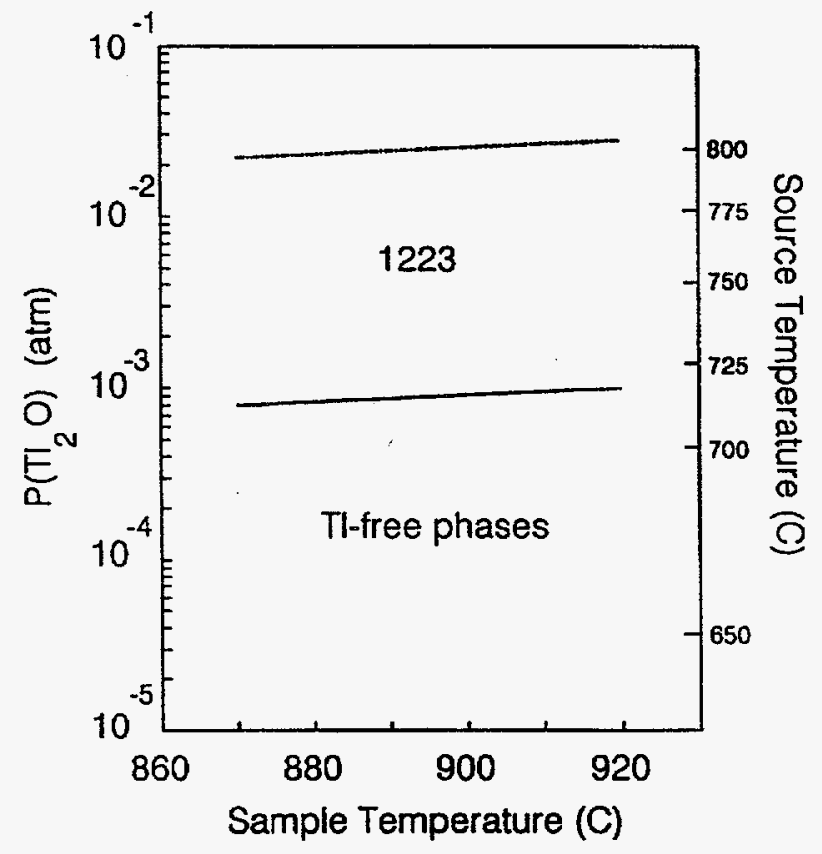

Figure 1-14. Phase stability for samples with the Hitachi composition. 


\subsection{Future Work}

Thermal/mechanical processing of PIT tapes has achieved current densities up $2 \times 10^{4}$ $\mathrm{A} / \mathrm{cm}^{2}$, but advancement beyond that value has not been achieved despite concentrated effort by several groups over the last year. In addition, the PIT tapes have not shown the performance in field that has been seen in the open system tapes. However, improvements may be obtained if longer, aligned grain structures could be grown without the porosity seen up to now. It is possible that $\mathrm{Sr}$ deficient tapes may result in less porosity and that a combination of atmosphere, temperature gradient processing may allow the growth of extended grain structures. We will be preparing powders with reduced $\mathrm{Sr}$ composition for production into tapes at IGC. These tapes will be heated in a quench furnace system as described previously to identify the shifts in compositional development during high temperature processing. These results will be used to develop a processing schedule for gradient processing of long length tapes. We are constructing a special pull through furnace that will allow both atmosphere and temperature gradient processing and we will begin initial processing studies during the coming year. 
2 Process research on the synthesis of high temperature superconductors

\subsection{Introduction}

The development of high temperature superconducting wires with properties suitable for high-power electrical applications requires an extensive understanding of the processing/property relationships of the superconducting material. It is the goal of this project to develop such understanding for the TI-based class of high temperature superconductors. Specifically, we have focused on the $\mathrm{Pb}$ - and $\mathrm{Sr}$-substituted $\mathrm{TIBa}_{2} \mathrm{Ca}_{2} \mathrm{Cu}_{3} \mathrm{O}_{x}$ phase, $\mathrm{Tl}-1223$, because of its high irreversibility line and the ease of formation of the desired TI-1223 structure.

In previous work, we have developed and patented an aqueous coprecipitation process for the preparation of superconductor precursor powders. We have continued to use this process to prepare superconductor powders with a variety of stoichiometries and used the powders to investigate the effect of stoichiometry on the synthesis, processing, and properties of TI-1223. We also have used the coprecipitated powders to support our in-house processing studies and several collaborations dealing with wire development. As part of our continuing effort to understand the role of liquids in the phase development of TI-1223, this year we have carried out a series of quench experiments in collaboration with Intermagnetics General Corp. (IGC) and E. Hellstrom, University of Wisconsin-Madison.

\subsection{Progress in FY95}

Much of our wire development work has focused on the TI-1223 stoichiometry as developed by Hitachi which is $\left(\mathrm{TI}_{0.5} \mathrm{~Pb}_{0.5}\right)\left(\mathrm{Sr}_{0.8} \mathrm{Ba}_{0.2}\right)_{2} \mathrm{Ca}_{2} \mathrm{Cu}_{3} \mathrm{O}_{\mathrm{x}}$. Although this formulation provides a wide stability window for the TI-1223 phase, it does not lend itself to texture development in wire configurations when conventional thermal processing approaches are used. Because of this problem, alternative processing methods such as melt and gradient processing are being considered. Recently IGC has shown evidence of regions of highly aligned TI-1223 grains in wire samples that have been processed using the melt processing technique. These encouraging results have been somewhat tempered by the fact that between the regions of aligned 
TI-1223 grains are regions of concentrated porosity which act as barriers to current flow. In order to understand how both the regions of aligned TI-1223 and the regions of current-inhibiting porous regions are formed, we initiated a series of quench experiments.

The quench experiments were performed using tape samples that were prepared with unreacted powder cores with stoichiometries of $\left(\mathrm{TI}_{0.6} \mathrm{~Pb}_{0.5}\right)\left(\mathrm{Sr}_{0.8} \mathrm{Ba}_{0.2}\right)_{2} \mathrm{Ca}_{2} \mathrm{Cu}_{3} \mathrm{O}_{\mathrm{X}}$ and $\left(\mathrm{TI}_{0.8} \mathrm{~Pb}_{0.5}\right)\left(\mathrm{Sr}_{0.8} \mathrm{Ba}_{0.2}\right)_{2} \mathrm{Ca}_{2} \mathrm{Cu}_{3} \mathrm{O}_{\mathrm{x}}$. Prior to the quench experiments, the cores of the tape samples were fully converted to the TI-1223 phase and pressed. Conditions for the quench experiments were selected based on the results of processing studies performed at IGC. The basic thermal processing scheme developed by IGC consists of three steps: 1) Heat the samples to just below the melting point of the silver sheath in either air or oxygen $\left.\left(\approx 920^{\circ} \mathrm{C}\right) ; 2\right)$ Switch the processing atmosphere to argon to induce melting in the superconducting core and hold for between 5 and $10 \mathrm{~min}$.; and 3) Recrystallize the melted core by switching back to oxygen in combination with cooling the sample at a controlled rate. Using $E$. Hellstrom's quench furnace system, samples were quenched at different times in the various steps of the melt-regrowth process and the resulting samples characterized. The results of these experiments are discussed in the following sections. Results were similar for the $\mathrm{TI}=0.6$ and the $\mathrm{Tl}=0.8$ series of samples, so only the results of the $\mathrm{TI}=0.8$ samples are presented.

\subsubsection{Quench from Oxygen}

The initial series of quench experiments were performed to determine whether the first step in the process altered the core microstructure significantly. For these experiments, samples were heated to $920^{\circ} \mathrm{C}$ in oxygen and quenched after holds of 5 , 10,15 , and $20 \mathrm{~min}$. The results of this study provide a good contrast to the dramatic effect switching to argon has on inducing core melting (discussed in the next section). The Meissner and low-field shielding data for the starting material, the $5 \mathrm{~min}$. and the 20 min. samples, are shown in Figure 2-1. The Meissner data show a slight sharpening of the superconducting transition with time held at $920^{\circ} \mathrm{C}$ indicating the possibility of some residual TI-1212 being converted to TI-1223. The low-field 

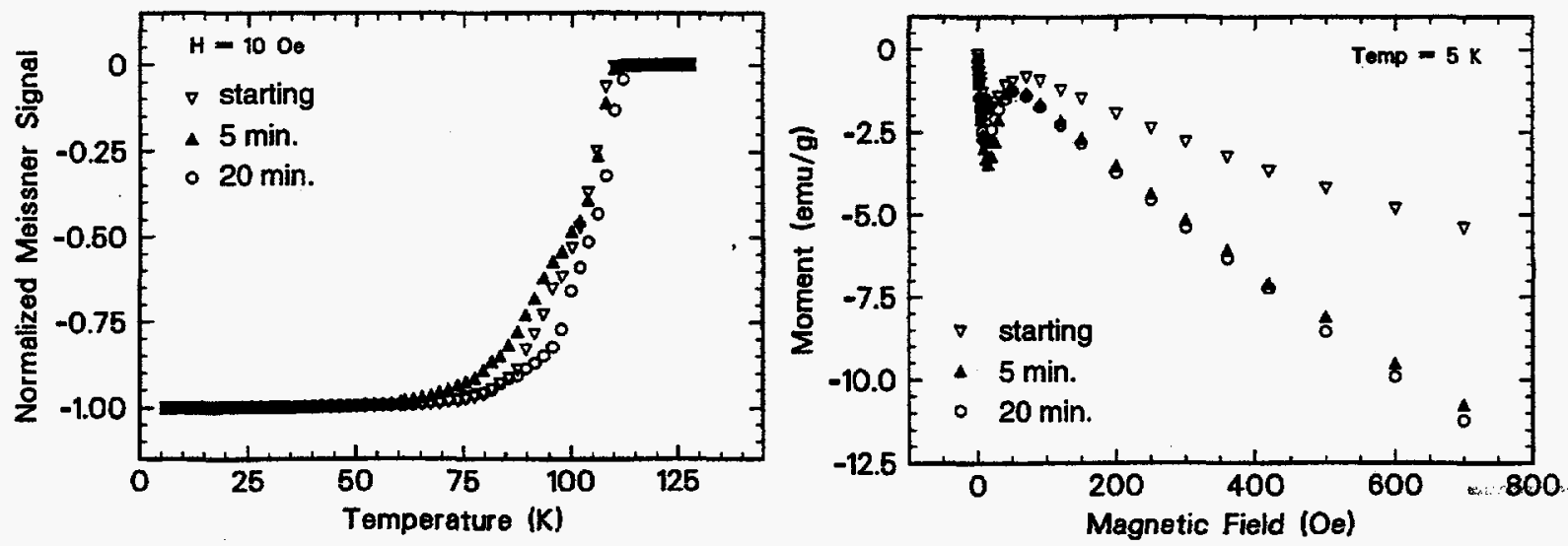

Figure 2-1. Meissner (left) and low-field shielding (right) data for tape samples before quenching and after quenching from $920^{\circ} \mathrm{C}$ with holds at temperature of $5 \mathrm{~min}$. and 20 min. (samples were heated in oxygen).

shielding data for the three samples show that there is some limited improvement in Figure 2-2 compares the microstructures of the $5 \mathrm{~min}$. and $20 \mathrm{~min}$. samples. The figure shows the typical microstructure for $\mathrm{Pb}$-,Sr-substituted Tl-1223 (Hitachi formulation) when very little melting has occurred during phase formation. The TI1223 phase is present in the form of thin, unaligned platelets with sizes in the long dimension on the order of $10 \mu \mathrm{m}$. From the results presented, it is concluded that there are no obvious changes in the microstructure or phase assemblage of the sample superconducting cores during the first step of the melt-regrowth process.

\subsubsection{Quench from Argon}

The fact that the melting point of Tl-1223 is a strong function of the oxygen partial pressure is used in this step to generate a liquid from which the TI-1223 can be regrown. In this step, switching from oxygen or air to argon causes the Tl-1223 to decompose to form significant quantities of liquid. To investigate this step in the process, samples were heated in air to $920^{\circ} \mathrm{C}$. With the temperature at $920^{\circ} \mathrm{C}$, the processing atmosphere was switched to argon and samples were quenched after holds of 5 and 10 minutes. 

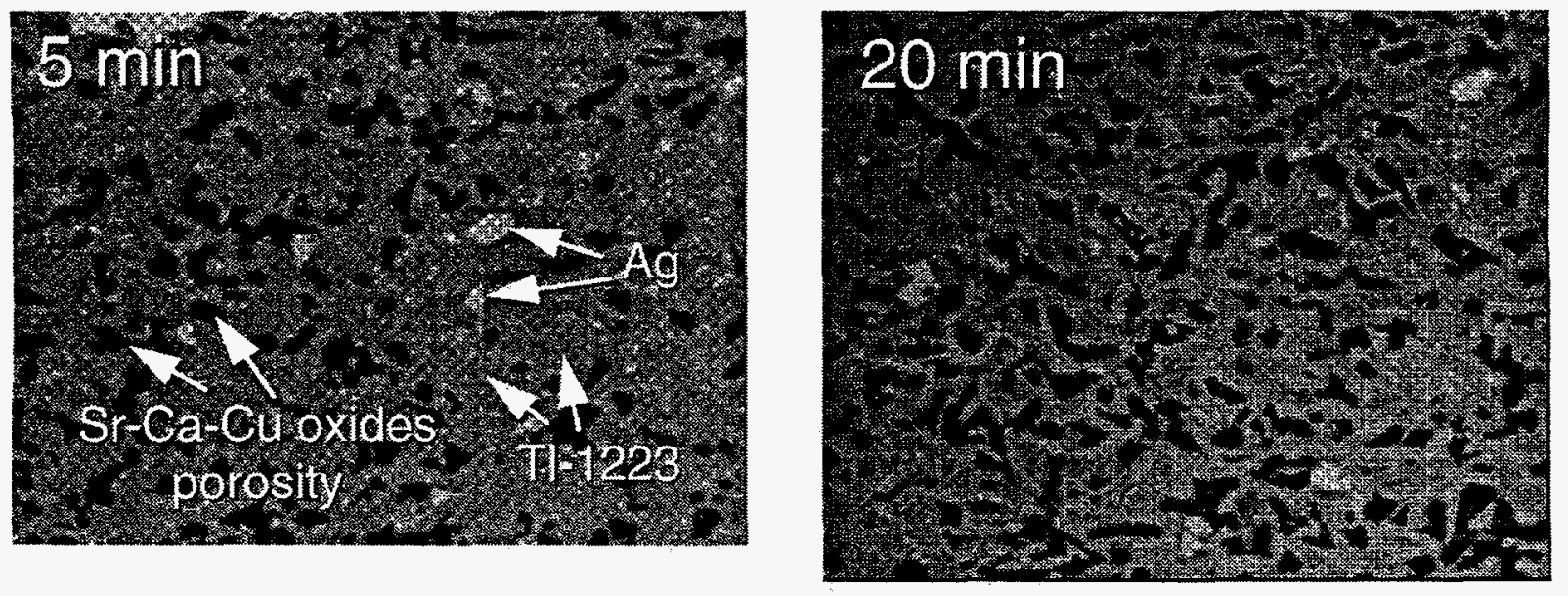

\section{$25 \mu \mathrm{m}$}

Figure 2-2. Backscattered electron photomicrographs of polished cross sections of tape samples that were quenched from $920^{\circ} \mathrm{C}$ after holds at temperature of $5 \mathrm{~min}$. and $10 \mathrm{~min}$. (samples were heated in oxygen).

Figure 2-3 compares the phase assemblages of samples quenched from oxygen and argon after holds of $5 \mathrm{~min}$. at $920^{\circ} \mathrm{C}$. The figure shows backscattered electron photomicrographs of polished cross sections of these samples. The micrographs show the dramatic effect that processing in an argon atmosphere has as compared to oxygen. The figure shows evidence of the formation of a Ag-containing liquid and segregation of $\mathrm{Sr}-\mathrm{Ca}-\mathrm{Cu}$ oxides.

The elemental distribution for the $5 \mathrm{~min}$. sample quenched from argon is shown in Figure 2-4 which contains the elemental maps obtained using an electron microprobe. The figure also contains a secondary electron photomicrograph to help distinguish porosity. The sample section shown in the figure contains both a Ag-rich liquid region (left) and a Sr-Ca-Cu oxide region (right). The Ca map shows that a large fraction of the $\mathrm{Ca}$ has segregated into $\mathrm{CaO}$ spherical islands that are relatively uniformly distributed throughout the entire sample. $\mathrm{TI}, \mathrm{Pb}$, and $\mathrm{Ba}$ are much more concentrated in the Ag-rich region, while the $\mathrm{Cu}$ and $\mathrm{Sr}$ are more concentrated in the other region. The strontium that is in the Ag-rich region is present as part of Tl-1212 grains. 


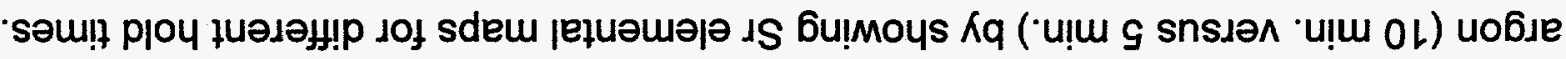

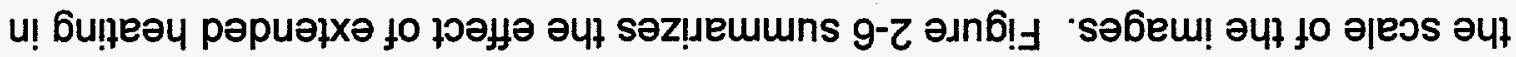

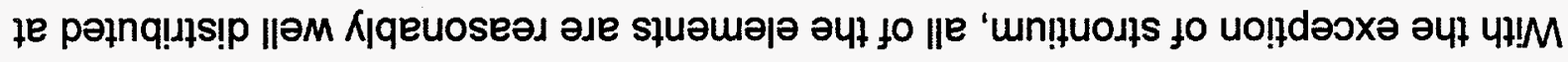

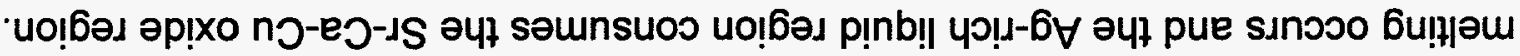

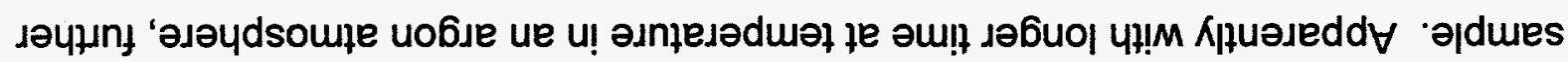

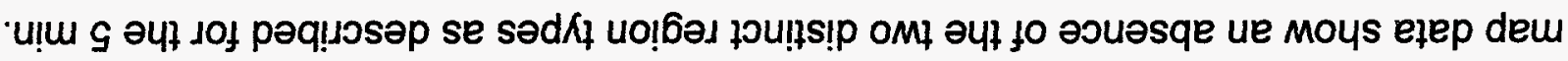

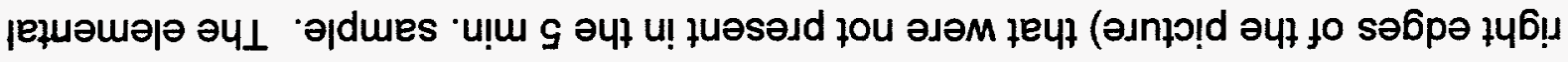

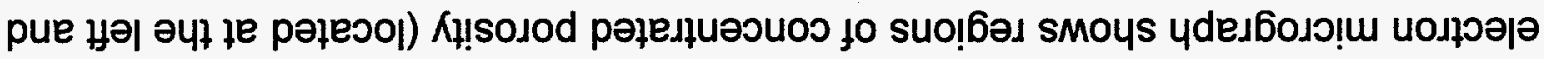

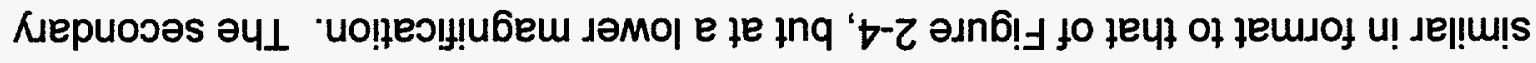

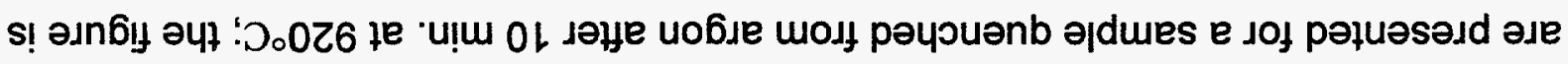

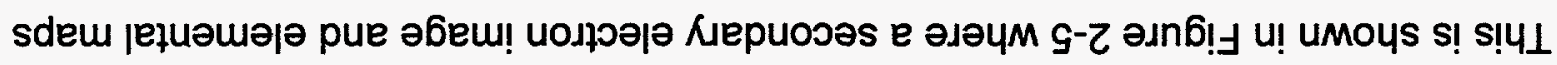

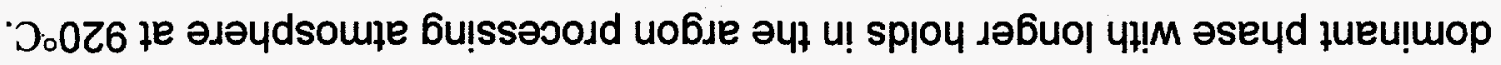
әцा sәmo⿰ə⿱

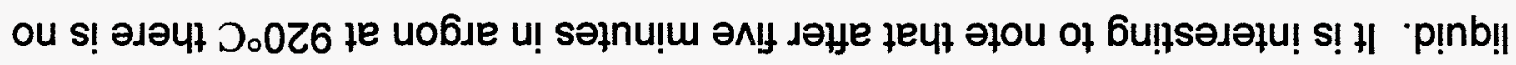

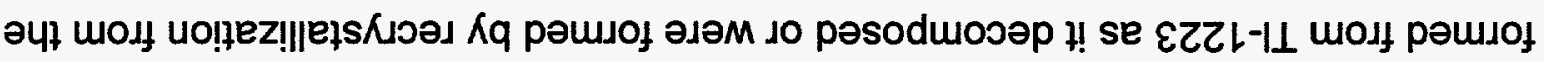

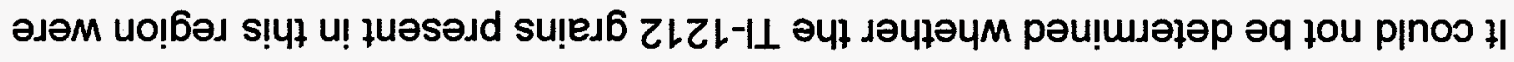

'Do0Z6 le u!̣ g

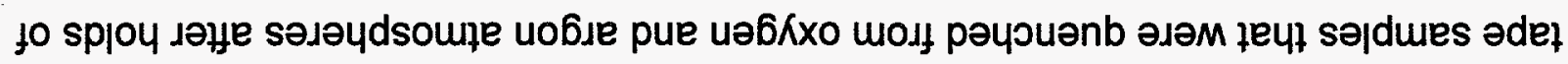

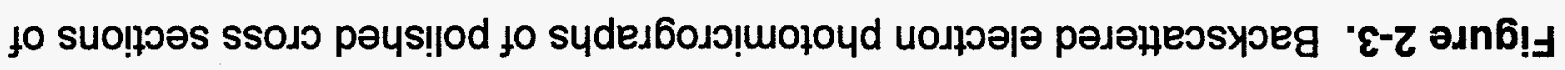
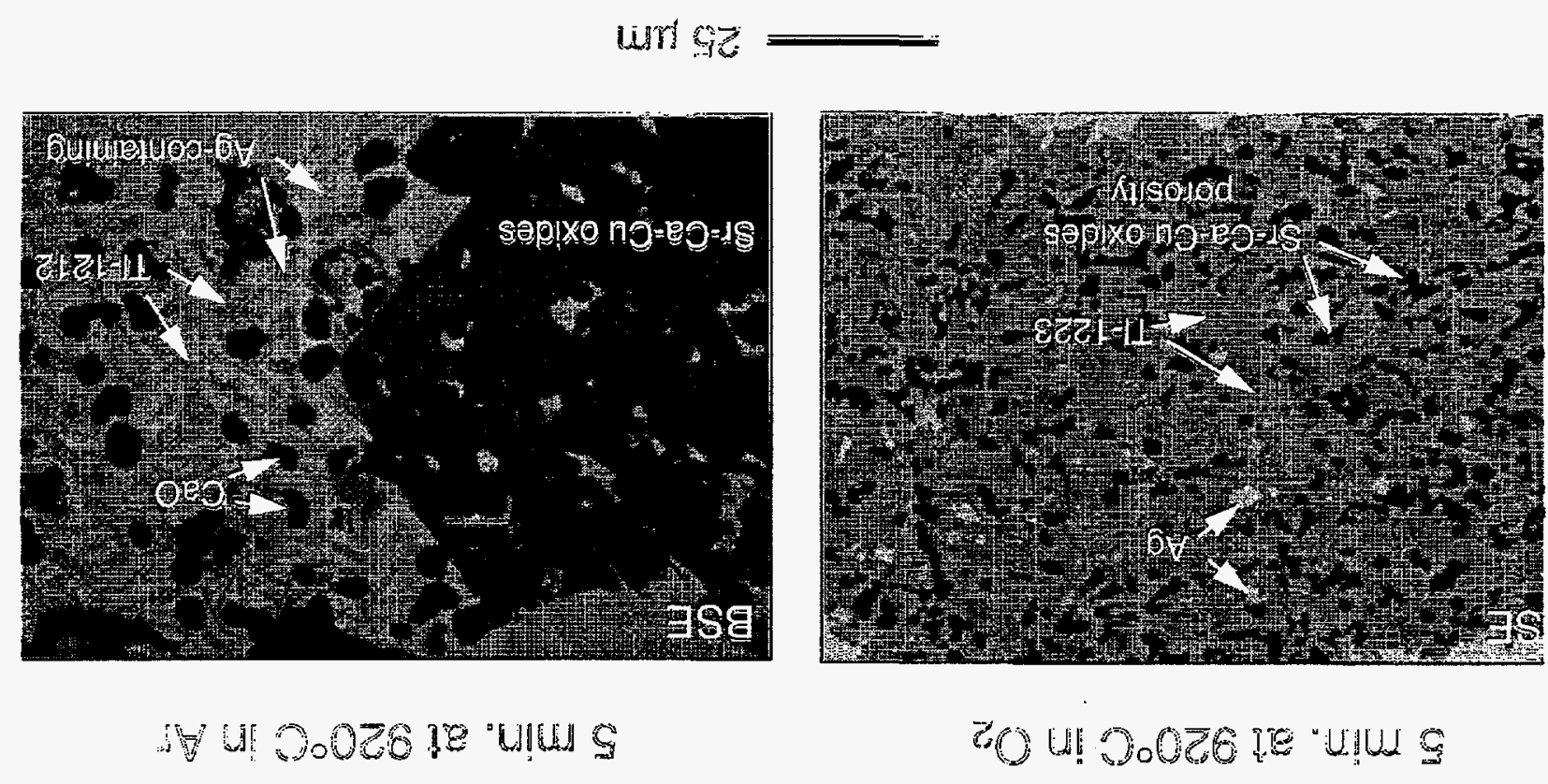


\section{$9-2$}

D.0Z6 te 'u!m s to plou

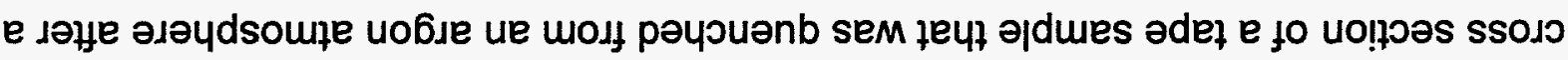

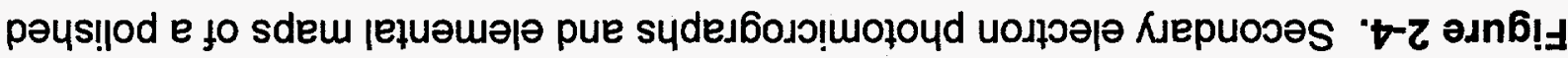
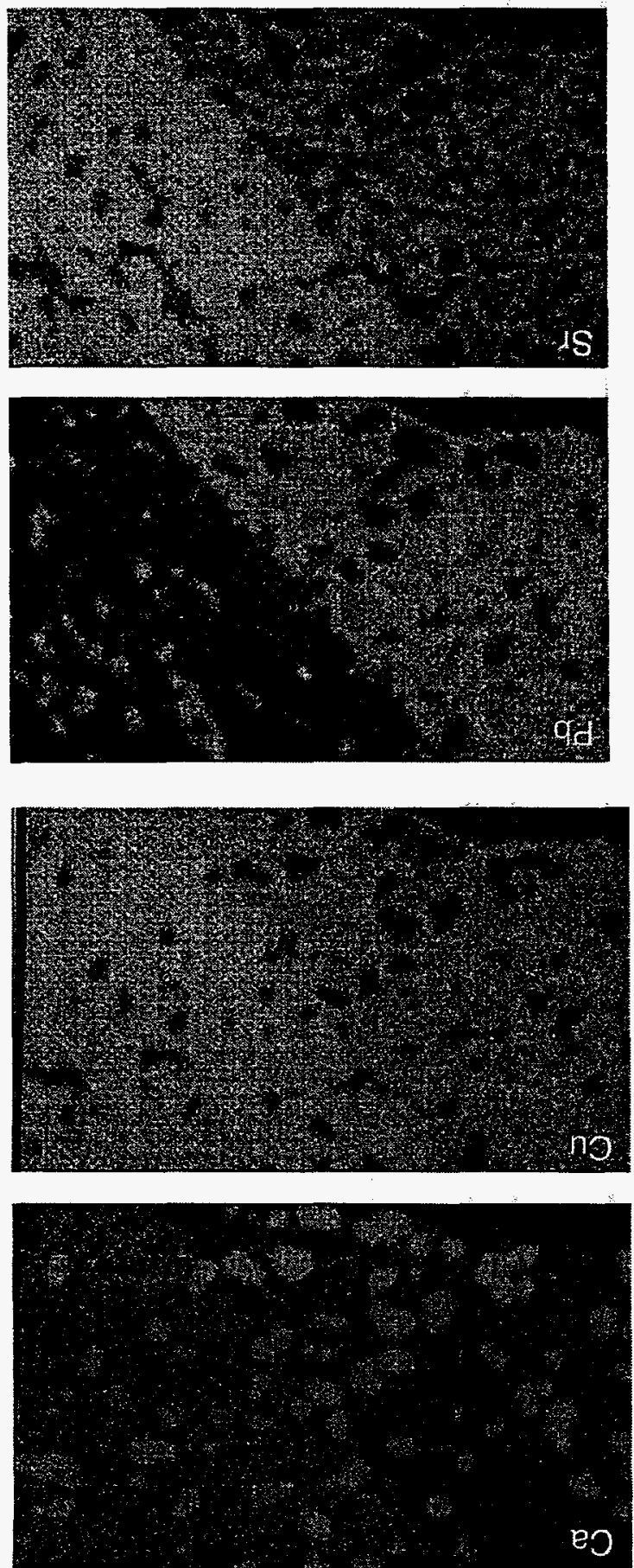

uri g己
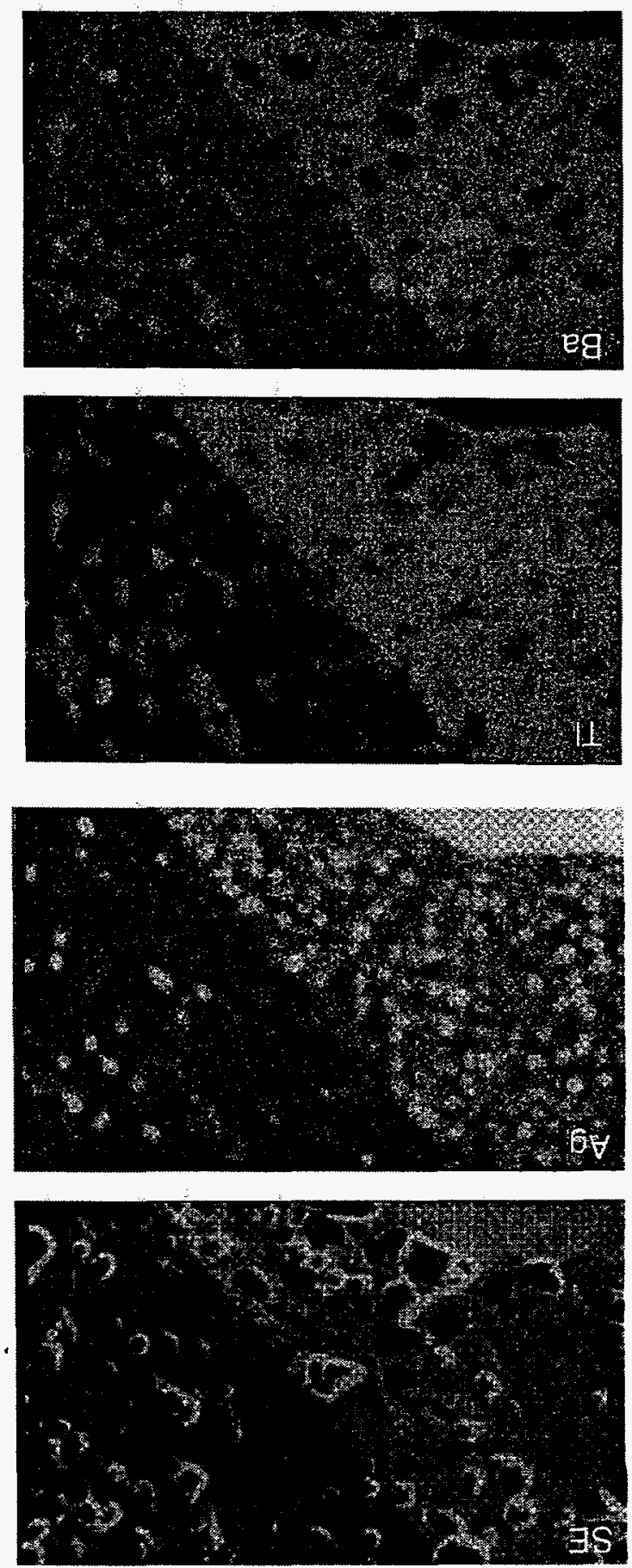

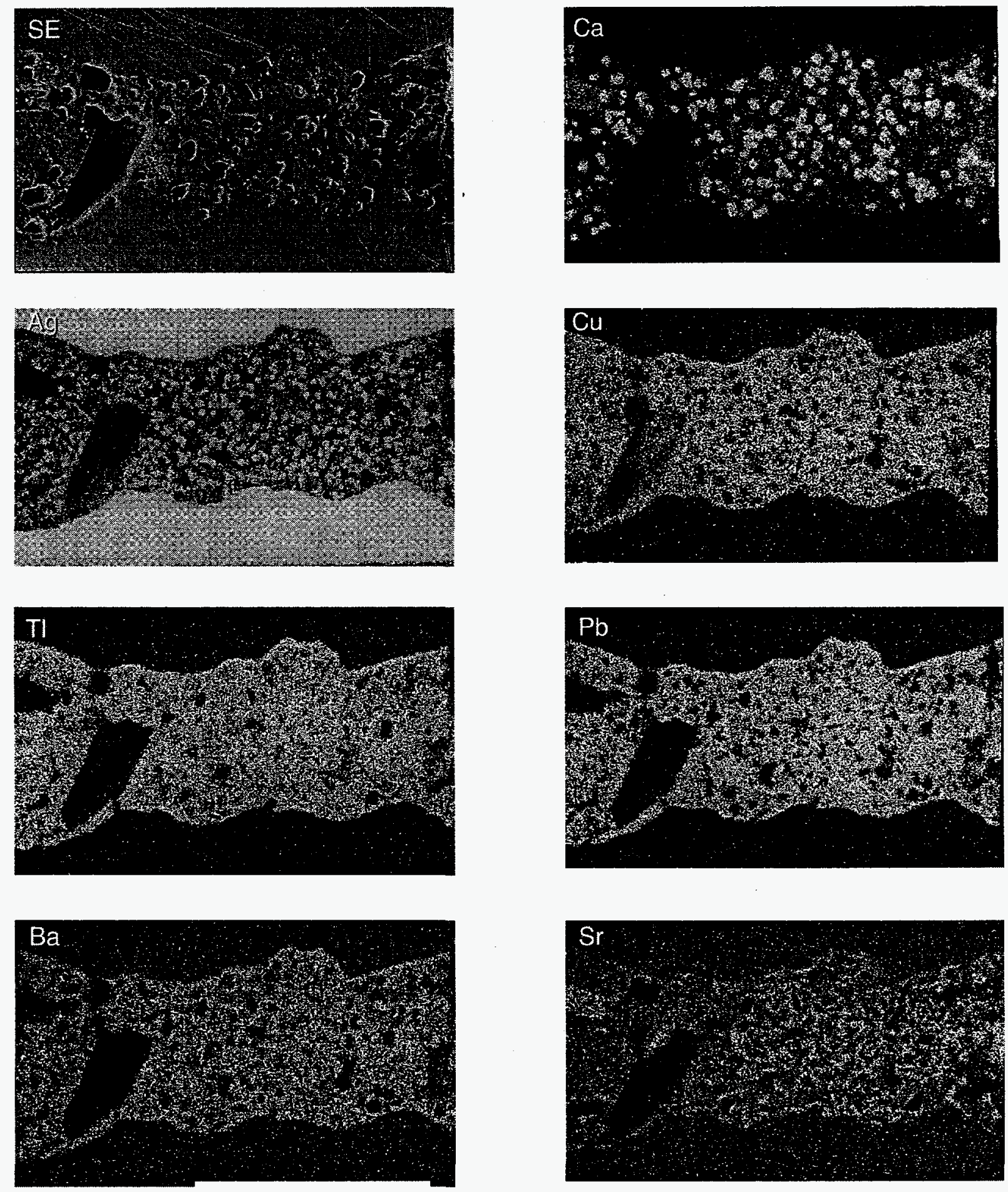

$50 \mu \mathrm{m}$

Figure 2-5. Secondary electron photomicrographs and elemental maps of a polished cross section of a tape sample that was quenched from an argon atmosphere after a hold of $10 \mathrm{~min}$. at $920^{\circ} \mathrm{C}$. 
$5 \min . \mathrm{Ar}-920^{\circ} \mathrm{C}$

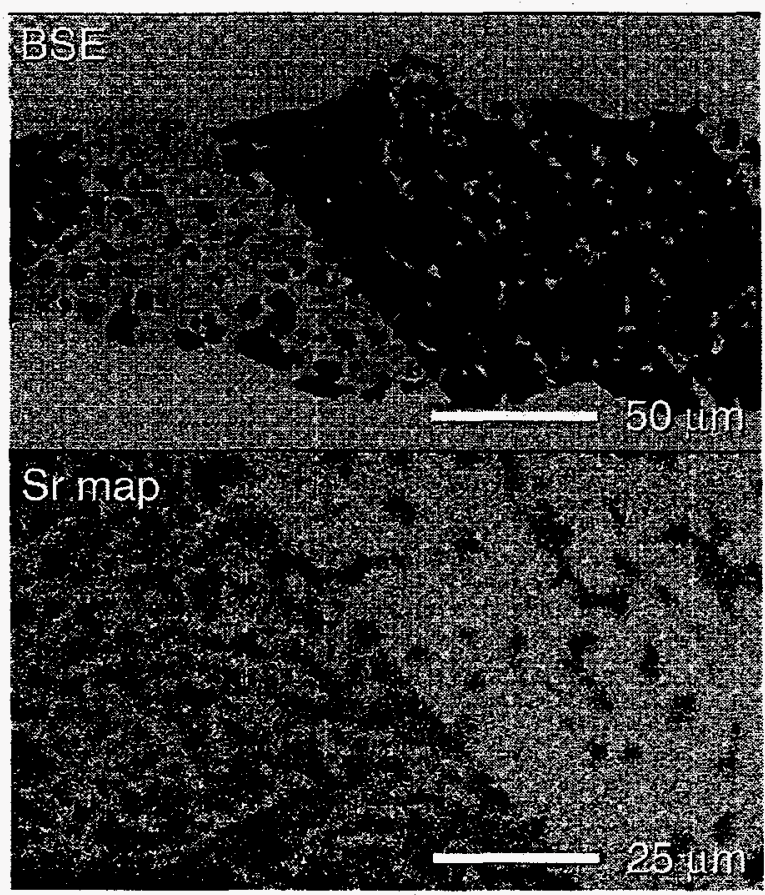

$10 \min . \mathrm{Ar}-920^{\circ} \mathrm{C}$

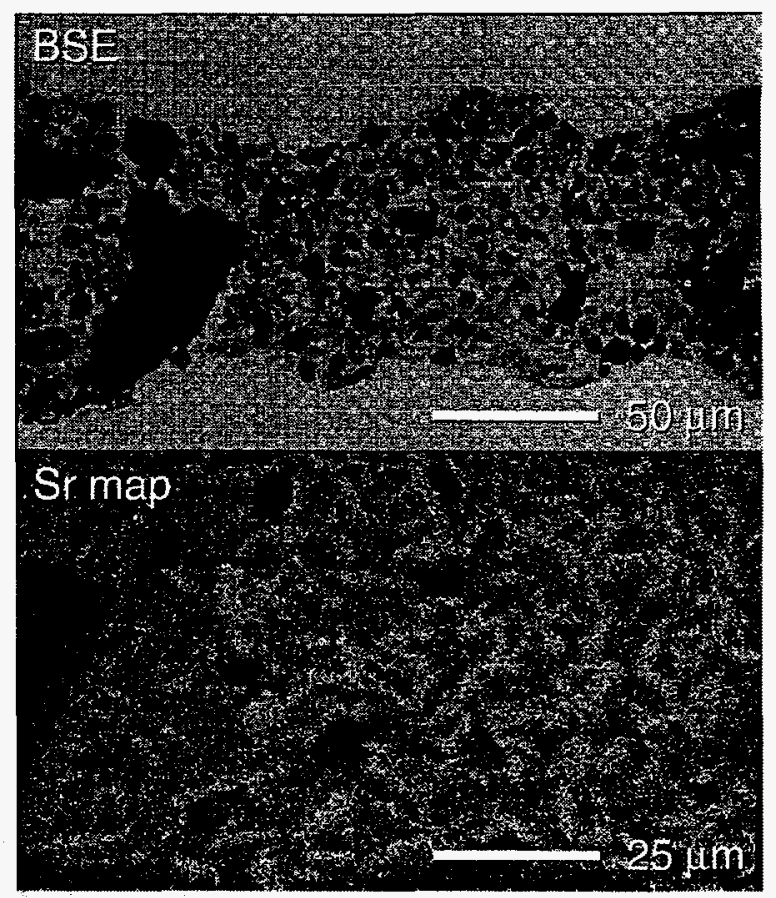

Figure 2-6. Backscattered electron photomicrographs and strontium elemental maps of polished cross sections of tape samples that were quenched from an argon atmosphere after holds of $5 \mathrm{~min}$. (left) and $10 \mathrm{~min}$. (right) at $920^{\circ} \mathrm{C}$.

\subsubsection{Quench During Controlled Cool in Oxygen}

A series of samples were quenched at different temperatures during the controlled cooling stage of the three-stage process. A cooling rate of $4^{\circ} \mathrm{C} / \mathrm{hr}$ was used after the processing atmosphere was changed from argon to oxygen at $920^{\circ} \mathrm{C}$; the samples were held for $10 \mathrm{~min}$. in argon. Samples were quenched at 915, 910, 900, 890, 880, and $870^{\circ} \mathrm{C}$. From this series of samples, the mechanism for formation of Tl-1223 from the Ag-rich liquid was determined.

The sequence of transformations that occurs is illustrated in Figure 2-7 where backscattered electron photomicrographs of polished cross sections of samples quenched at 915,910 and $870^{\circ} \mathrm{C}$ are shown. On cooling from $920^{\circ} \mathrm{C}$ to $915^{\circ} \mathrm{C}$, a significant amount of TI-1212 has been recrystallized in the form of large blocky grains with dimensions of $\approx 80 \mu \mathrm{m} \times 20 \mu \mathrm{m}$. Some of the remnants of the Ag-rich 
Cooling rate: $4^{\circ} \mathrm{C} / \mathrm{hr}$ Atmosphere: $\mathrm{O}_{2}$

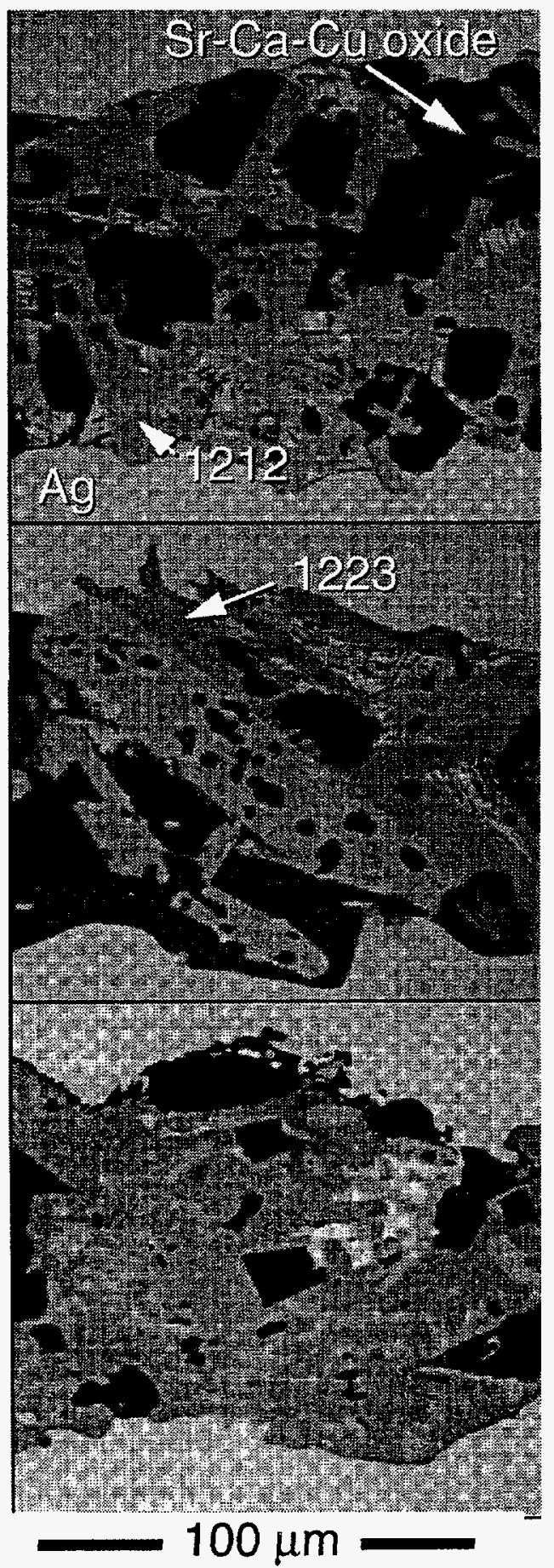

Figure 2-7. BES photomicrographs of tapes that were quenched from an oxygen atmosphere after cooling from $920^{\circ} \mathrm{C}$ to $915^{\circ} \mathrm{C}$ (top), $910^{\circ} \mathrm{C}$ (middle), and $870^{\circ} \mathrm{C}$ (bottom) at $4^{\circ} \mathrm{C} / \mathrm{min}$.; samples held for $10 \mathrm{~min}$. in argon at $920^{\circ} \mathrm{C}$ prior to cooling. 
liquid regions remain and regions of the $\mathrm{Sr}-\mathrm{Ca}-\mathrm{Cu}$ oxide have reformed. By $910^{\circ} \mathrm{C}$, the large grains of $\mathrm{Tl}-1212$ have begun to transform into $\mathrm{Tl}-1223$ by diffusion of the required $\mathrm{Ca}$ and $\mathrm{Cu}$ oxides. This process continues with further cooling (see $870^{\circ} \mathrm{C}$ micrograph) until the diffusion distance relative to the mobility of the $\mathrm{Ca}$ and $\mathrm{Cu}$ species becomes too great. As a result, small amounts of fine-grained Tl-1212 remains encapsulated within much larger TI-1223 grains.

The formation of TI-1212 and its subsequent conversion to TI-1223 can be visualized through magnetization data. The Meissner data for six samples that were quenched during the three-stage processing schedule are shown in Figure 2-8. A schematic of the schedule with the points in the schedule where samples were quenched is also shown in the figure. The data for points 1 and 2 (samples quenched after $5 \mathrm{~min}$. and $10 \mathrm{~min}$. in argon at $920^{\circ} \mathrm{C}$, respectively) are consistent with the previous discussion (Section 2.2.2). As described earlier, the argon treatment results in the decomposition of the TI-1223 to TI-1212 plus large amounts of liquid. The Meissner data indicates that there is no superconducting TI-1223 present after $5 \mathrm{~min}$. with only a small amount of superconducting TI-1212 as shown by the transition at about $55 \mathrm{~K}$. The nearly flat Meissner data for the second point indicates that much of the TI-1212 has decomposed after the longer hold of $10 \mathrm{~min}$. at $920^{\circ} \mathrm{C}$.

The Meissner data for the $4^{\circ} \mathrm{C} / \mathrm{hr}$ cooled samples in Figure 2-8 (point $3=$ quenched at $915^{\circ} \mathrm{C}$, point $4=$ quenched at $910^{\circ} \mathrm{C}$, point $5=$ quenched at $900^{\circ} \mathrm{C}$, and point $6=$ quenched at $890^{\circ} \mathrm{C}$ ) show that significant amounts of $\mathrm{TI}-1212$ has formed by the time a sample has cooled to $915^{\circ} \mathrm{C}$. By $910^{\circ} \mathrm{C}$, superconducting $\mathrm{Tl}-1223$ has begun to form as shown by the $\mathrm{TI}-1223$ transition at about $120 \mathrm{~K}$. The low-field shielding data for these samples (shown in Figure 2-9 which has the same temperature numbering convention as Figure 2-8) indicate, that during cooling at the lower temperatures (points 5 and 6 ), the TI-1223 plates continued to grow.

\subsubsection{Development of Segregated Porosity}

The development of the current-limiting regions of concentrated porosity that form as a result of the melt-regrowth process can be visualized by looking at montages of backscattered electron photomicrographs of quenched sample polished cross 

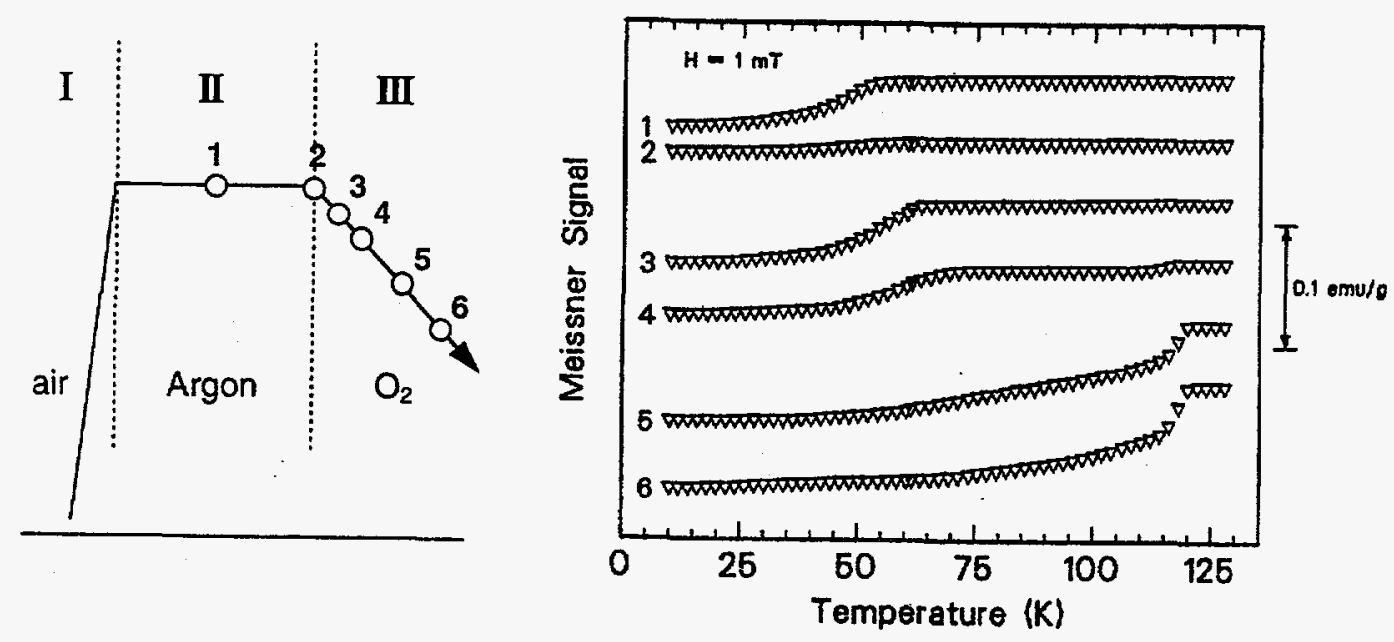

Figure 2-8. Meissner data for samples quenched during stages 2 and 3 of the processing cycle. Data for points 1 and 2 are for samples quenched after $5 \mathrm{~min}$. and $10 \mathrm{~min}$. at $920^{\circ} \mathrm{C}$ in argon, respectively, while points $3-6$ are for samples quenched after the atmosphere switch to oxygen and initiation of the controlled cool at $4^{\circ} \mathrm{C} / \mathrm{hr}$ ( point $3=$ quenched at $915^{\circ} \mathrm{C}$, point $4=$ quenched at $910^{\circ} \mathrm{C}$, point $5=$ quenched at $900^{\circ} \mathrm{C}$, and point $6=$ quenched at $890^{\circ} \mathrm{C}$ ).
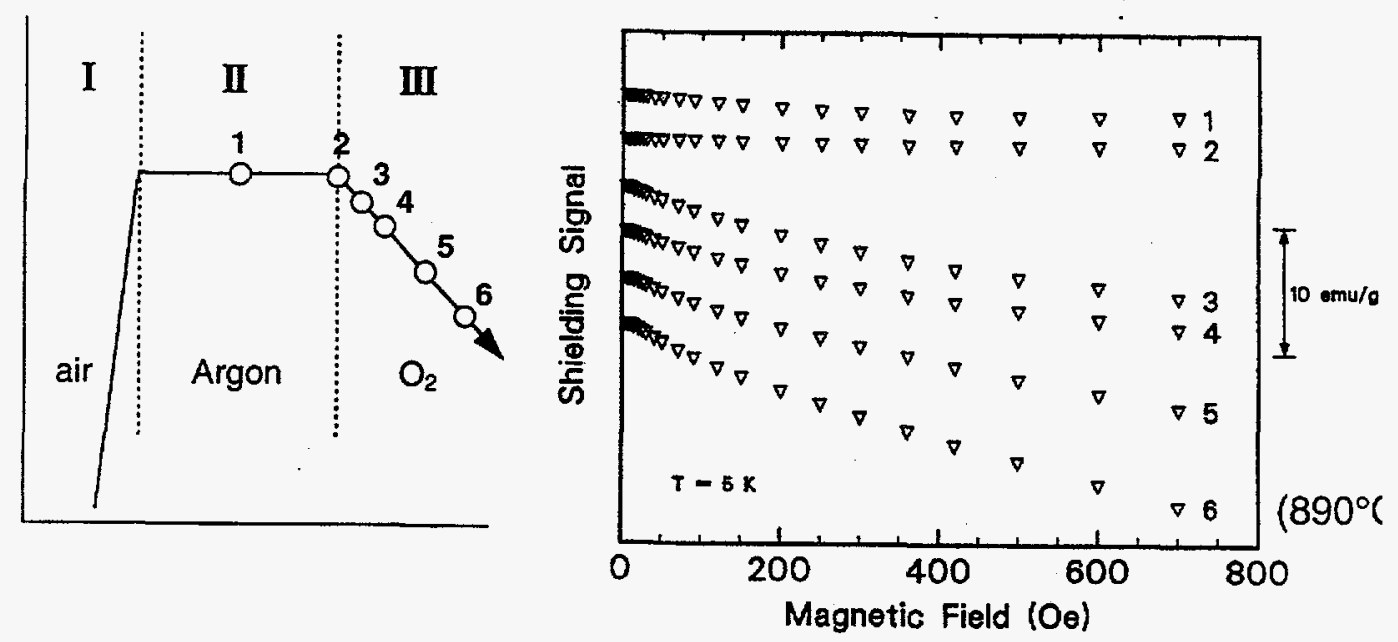

Figure 2-9. Low-field shielding data for samples quenched during stages 2 and 3 of the processing cycle. Points 1 and 2 : samples quenched after $5 \mathrm{~min}$. and $10 \mathrm{~min}$. at $920^{\circ} \mathrm{C}$ in argon, respectively; points $3-6$ : samples quenched after the atmosphere switch to oxygen and controlled cool at $4^{\circ} \mathrm{C} / \mathrm{hr}$ ( point 3: quenched at $915^{\circ} \mathrm{C}$, point 4: quenched at $910^{\circ} \mathrm{C}$, point 5 : quenched at $900^{\circ} \mathrm{C}$, and point 6: quenched at $890^{\circ} \mathrm{C}$ ). 


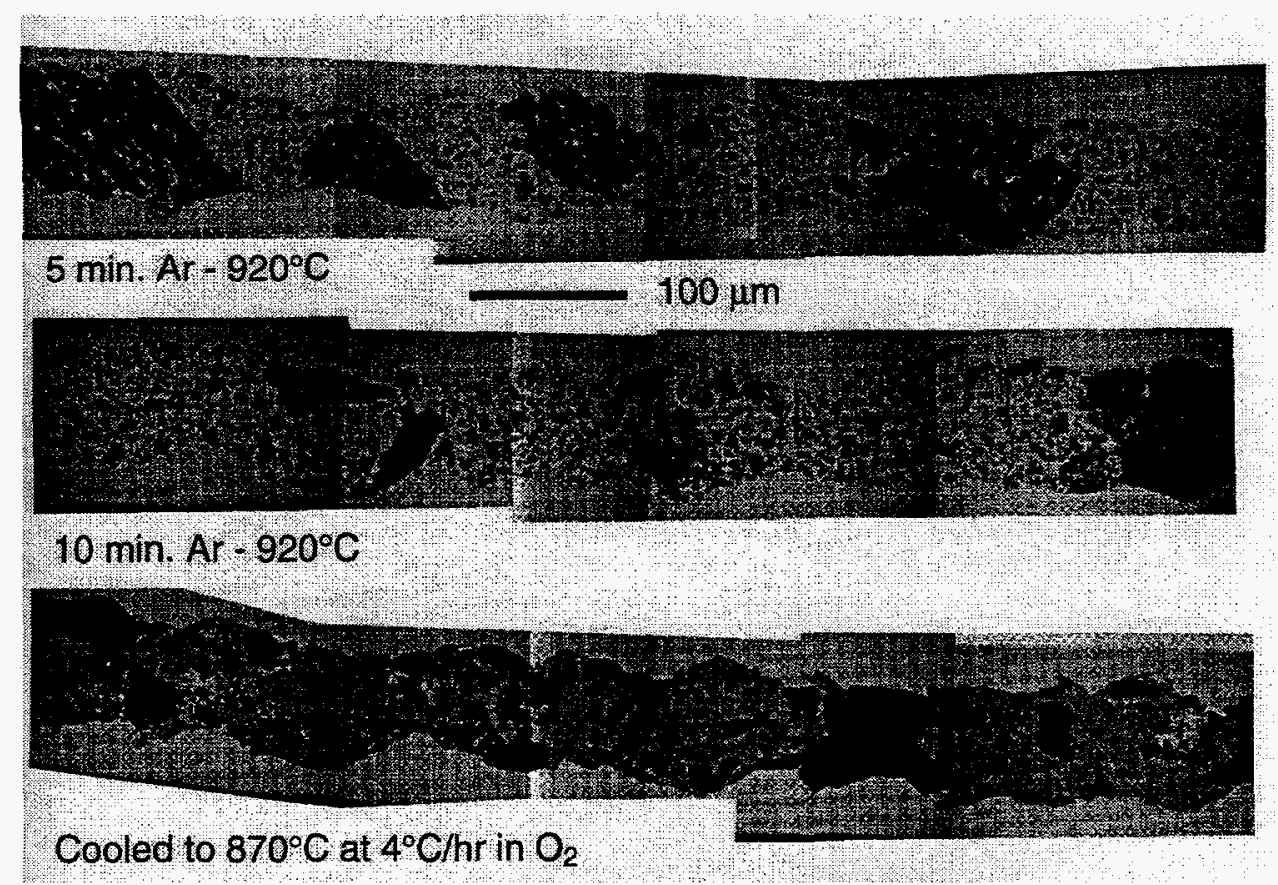

Figure 2-10. Series of backscattered electron photomicrograph montages of polished cross sections of quenched wire samples.

sections. Figure $2-10$ contains three such montages: 1) sample held at $920^{\circ} \mathrm{C}$ for 5 min. in argon and quenched; 2) sample held at $920^{\circ} \mathrm{C}$ for $10 \mathrm{~min}$. in argon and quenched; and 3) sample held at $920^{\circ} \mathrm{C}$ for $10 \mathrm{~min}$. in argon, atmosphere switched to oxygen, cooled to $870^{\circ} \mathrm{C}$, and quenched. The montage of the first sample ( $5 \mathrm{~min}$. in Ar at $920^{\circ} \mathrm{C}$ ) shows a periodic mix of quenched $\mathrm{Ag}$-rich liquid regions alternating with $\mathrm{Sr}-\mathrm{Ca}-\mathrm{Cu}$ oxide regions; the period being about a hundred micrometers. With longer heating at $920^{\circ} \mathrm{C}$ in argon (10 min. sample), the majority of the $\mathrm{Sr}-\mathrm{Ca}-\mathrm{Cu}$ oxide regions are consumed by the $\mathrm{Ag}$-rich liquid leaving behind $\mathrm{Sr}$-rich regions of concentrated porosity, again, with a periodicity of $100 \mu \mathrm{m}$. During the formation of TI1223 , the regions of high porosity remain and may in fact become larger as shown in the montage of the sample cooled to $870^{\circ} \mathrm{C}$. 


\section{$2.3 \quad$ Future Work}

The results presented here show that $\mathrm{Ag}$ and the argon processing atmosphere play critical roles in formation of the liquid from which the TI-1212 (that is converted to TI1223 ) is recrystallized. Based on this work we will attempt to devise better thermal processing strategies such as thermal or atmosphere gradient processing to enhance control of the liquid formation process and the subsequent recrystallization of large aligned TI-1212/TI-1223 microstructures.

The origin of the current-limiting porous regions appears to be related to the segregation of $\mathrm{Sr}-\mathrm{Ca}-\mathrm{Cu}$ oxide phases and the fact the strontium may not be incorporated into the Ag-rich liquid region. In an attempt to minimize this effect, compositions with reduced strontium will be prepared by our coprecipitation process, fabricated into wires, and melt processed. We also will carry out quench studies with wire samples with these compositions to determine the effect altering the strontium content has on the fundamentals of the melt-regrowth process. 
3 Two-Zone Processing of Open-System TI-Based Conductors on Metallic Substrates

\subsection{Introduction}

"Open" system conductors consist of a flexible substrate, usually metallic, on which the superconductor precursor powder is deposited, by any of a number of techniques, and then thallinated to produce the final superconducting film. We use the "two-zone" technique for thallination where the sample is maintained at one temperature while a $\mathrm{Tl}_{2} \mathrm{O}_{3}$ source is brought to a temperature sufficient to produce a $\mathrm{Tl}_{2} \mathrm{O}$ over pressure which is incorporated into the sample film. The advantage of this method is the ability to separately control sample temperature and thallium content during the critical formation stage of the superconducting grains. This method has been successful in producing aligned TI-1223 microstructures with high $\mathrm{J}_{\mathrm{c}} \mathrm{s}$ and good performance in magnetic field. The present challenge is to produce thicker films with high current carrying capacity using deposition techniques that are easily scalable to long lengths.

\subsection{Progress in FY95}

\subsubsection{Pb-.Sr-Substituted Tl-1223 Films on Ag/Pd Substrates}

The $\mathrm{Pb}$-,Sr-doped TI-based compositions have been observed to have higher magnetic irreversibiltiy behavior than seen in the undoped material. A denser, more blocky grain structure also differentiates these materials from the undoped compositions. We have processed thick films with nominal $\left(\mathrm{Tl}_{0.5} \mathrm{~Pb}_{0.5}\right)\left(\mathrm{Sr}_{0.8} \mathrm{Ba}_{0.2}\right)_{2} \mathrm{Ca}_{2} \mathrm{Cu}_{3} \mathrm{O}_{\mathrm{x}}$ composition in our flow-through two-zone furnace. Dip-coated Ag/Pd alloy substrates with a melting temperature of $1000^{\circ} \mathrm{C}$ were used at higher temperatures $\left(>930^{\circ} \mathrm{C}\right)$ to prevent melting of the coupon. These coupons were fired and uniaxially pressed before thallination in the furnace. This pressing step was necessary to densify the precursor film sufficiently to allow a textured grain structure to develop. A typical time/temperature profile is shown in Figure 3-1. The $\mathrm{Tl}_{2} \mathrm{O}_{3}$ source temperature was $760-770^{\circ} \mathrm{C}$ and the sample temperature varied from $925-940^{\circ} \mathrm{C}$. As shown by $\mathrm{X}$-ray diffraction in Figure $3-2$, a mixture of unaligned TI1212 and TI-1223 was obtained for sample temperatures of $925^{\circ} \mathrm{C}$ and below. Above 
$930^{\circ} \mathrm{C}$, a highly-aligned $\mathrm{TI}-1212$ film was obtained. SEM analysis has shown that the $\mathrm{TI}-1212$ phase results from depletion of the $\mathrm{CaCu}$ ions in the nominal TI-1223 film resulting from preferential interaction with the Pd from the substrate alloy. Figure 3-3 shows that $\mathrm{Ca}-\mathrm{Cu}-\mathrm{Pd}$ regions have formed at the substrate interface. The remaining oxides formed a thick $(72 \mu \mathrm{m})$ unaligned TI-1212 structure as shown. SEM analysis of much thinner starting films $(15 \mu \mathrm{m})$ showed that an aligned TI-1212 microstructure resulted from where the $\mathrm{Ca}-\mathrm{Cu}-\mathrm{Pd}$ interaction resulted in lenticular plates of the $\mathrm{Ca}$ Cu-Pd phase which were parallel to the substrate and resulted in alignment of the TI1212 grains. These structures are shown in Figure 3-4. This interaction can possibly be used to form a starting template for subsequent film deposition and processing in a temperature range where the $\mathrm{TI}-1223$ phase is dominant.

\subsubsection{The Effects of TI Content on Doped and Undoped Tl-1223 Films on Ag} Substrates

We have examined the effects of TI content on microstructure and resulting transport properties for films deposited on Ag substrates for both undoped and $\mathrm{Pb}$-, Sr-doped films, with and without added $\mathrm{Ag}$. TI content was determined from measured weight gains during each run and then calculated based on assumed stoichiometry. Figure 3-5 shows the transition temperatures measured for each of the various films. The data show that the maximum $\mathrm{T}_{\mathrm{c}}$ for the $\mathrm{Pb}_{0.5}$-doped composition occurs for a $\mathrm{TI}$ content of 0.5 (TI/Pb ratio of 1:1) and that the inclusion of $\mathrm{Ag}$ did not have any effect on the transition temperature. Our earlier work has shown that this is the most stable $\mathrm{TI} / \mathrm{Pb}$ ratio for this composition. However, these $\mathrm{Pb}$-, Sr-doped films have only shown transport currents of a few amps for the peak compositions. The undoped composition $\left(\mathrm{Tl}_{1} \mathrm{Ba}_{2} \mathrm{Ca}_{2} \mathrm{Cu}_{3} \mathrm{O}_{\mathrm{x}}\right.$ ) showed a much broader dependence on $\mathrm{TI}$ content with a peak occurring at a TI level of 0.85. Again, the presence of Ag did not affect the transition temperature. However, the presence of Ag was important for obtaining higher transport currents. Figure 3-6 shows the critical currents for these film compositions. Estimates of film thickness (10-100 $\mu \mathrm{m}$ ) based on calibrated areal mass density were used to calculate critical current densities and are shown in Figure 3-7. SEM analysis of the undoped films showed that these thick films consisted of unaligned grains with significant residual porosity as shown in Figure 3-8 while Figure 3-9 shows the large, blocky grain structure seen for the $\mathrm{Pb}-, \mathrm{Sr}$-doped films. 


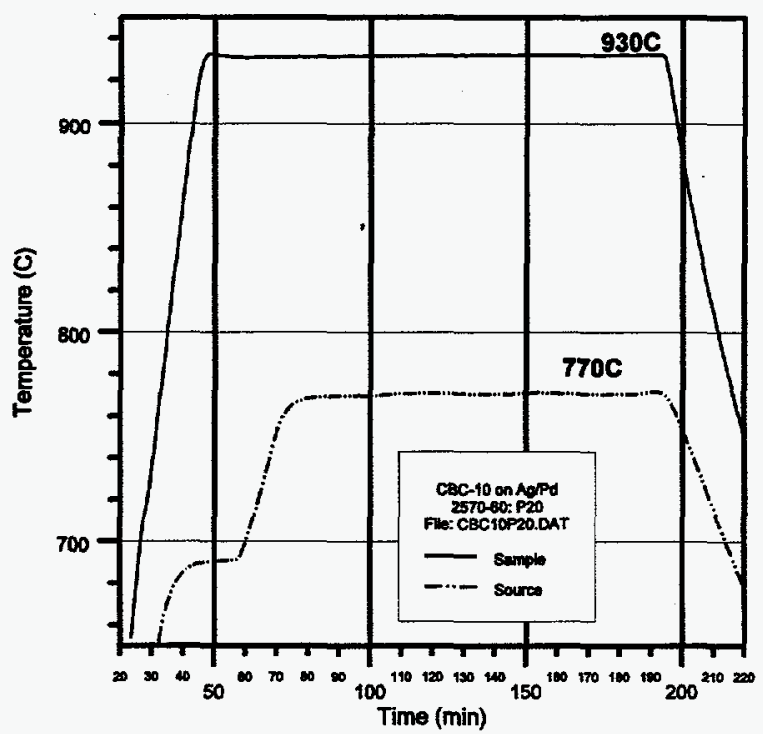

Figure 3-1. Time/Temperature profile for flow-through two-zone furnace.

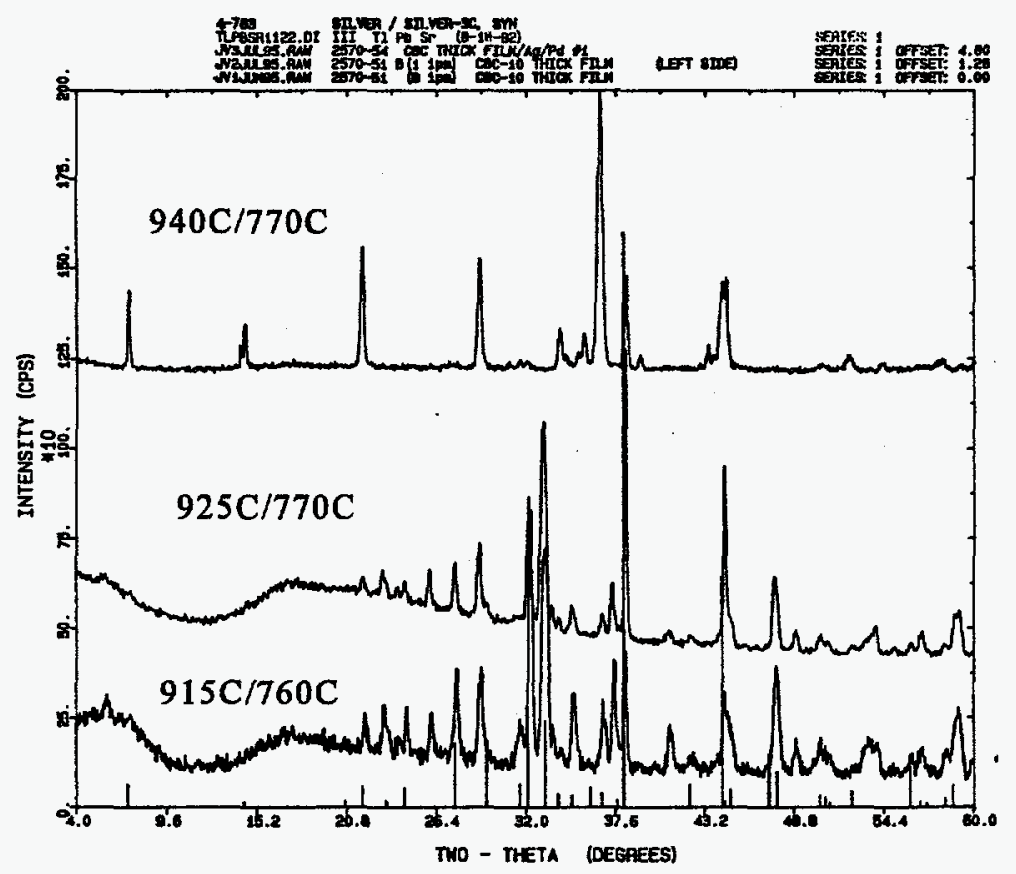

Figure 3-2 . X-ray diffraction patterns for $940^{\circ} \mathrm{C} / 770^{\circ} \mathrm{C}, 925^{\circ} \mathrm{C} / 770^{\circ} \mathrm{C}$ and $915^{\circ} \mathrm{C} / 760^{\circ} \mathrm{C}$ two-zone $\mathrm{Pb}$-, Sr-doped TI-based thick film on $\mathrm{Ag} / \mathrm{Pd}$. 


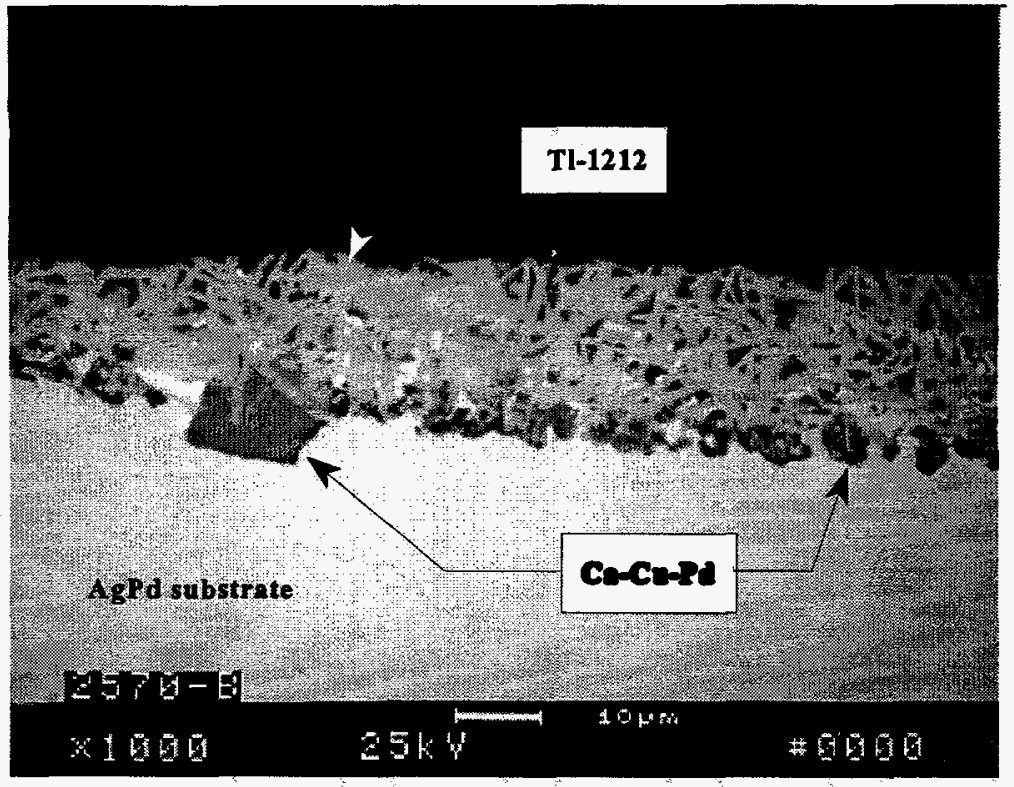

Figure 3-3. Nominal $\left(\mathrm{TI}_{0.5} \mathrm{~Pb}_{0.5}\right)\left(\mathrm{Sr}_{0.8} \mathrm{Ba}_{0.2}\right)_{2} \mathrm{Ca}_{2} \mathrm{Cu}_{3} \mathrm{O}_{x}: \mathrm{Ag}_{0.37}$ composition showing interaction with $\mathrm{AgPd}$ substrate.

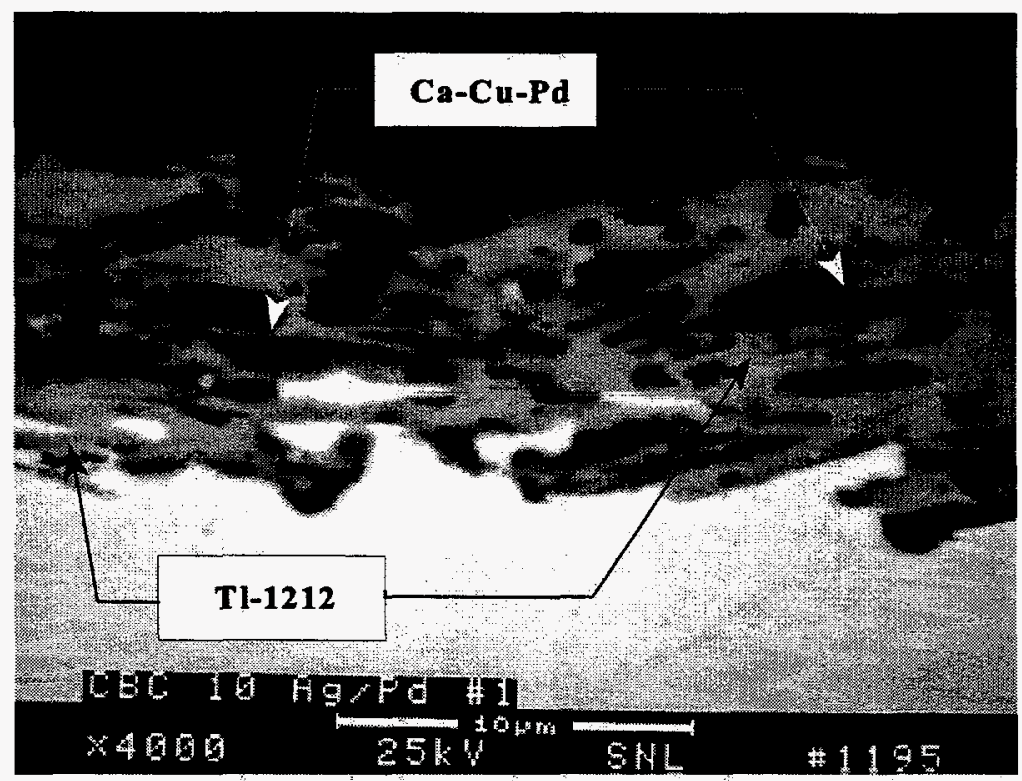

Figure 3-4. Nominal $\left(\mathrm{Tl}_{0.5} \mathrm{~Pb}_{0.5}\right)\left(\mathrm{Sr}_{0.8} \mathrm{Ba}_{0.2}\right)_{2} \mathrm{Ca}_{2} \mathrm{Cu}_{3} \mathrm{O}_{x}$ composition showing interaction with $\mathrm{AgPd}$ substrate leading to aligned grain structure. 


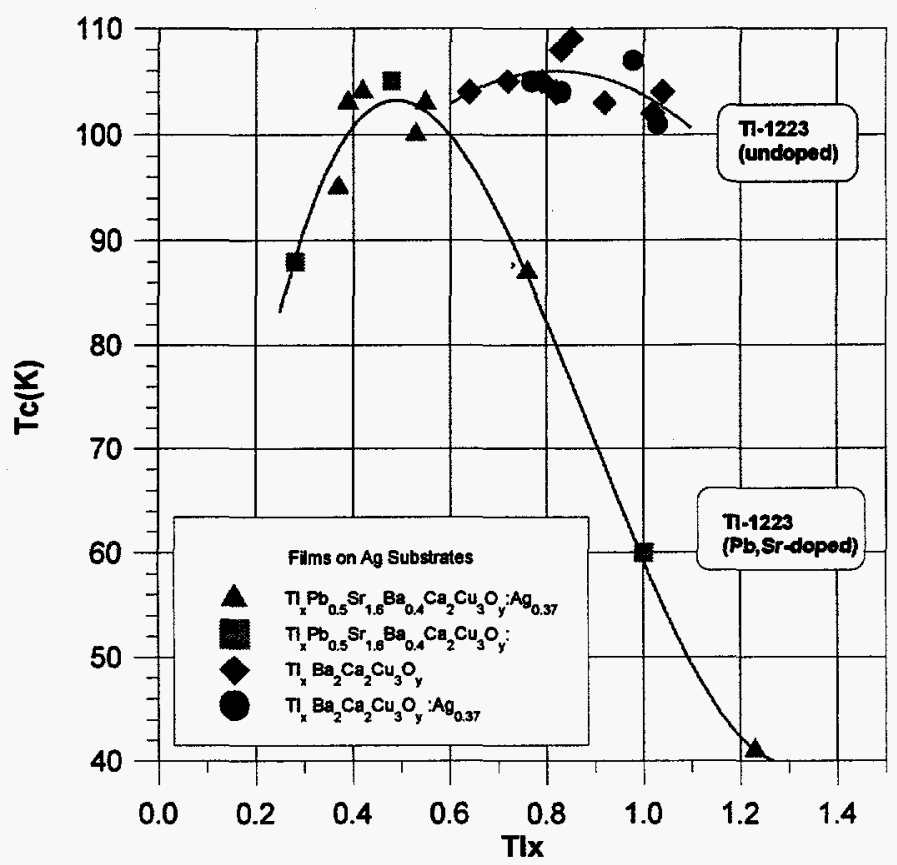

Figure 3-5. Transition temperature of TI-1223 films as a function of $\mathrm{TI}$ content.

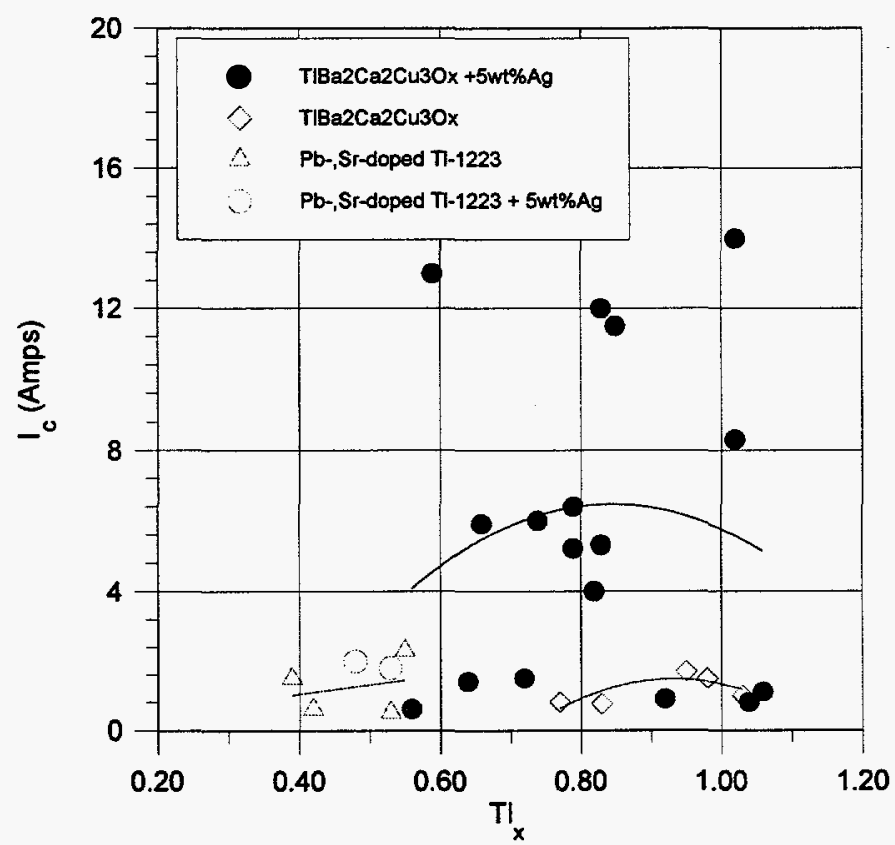

Figure 3-6. Transport currents for TBCCO TI-1223 films on Ag substrates. 


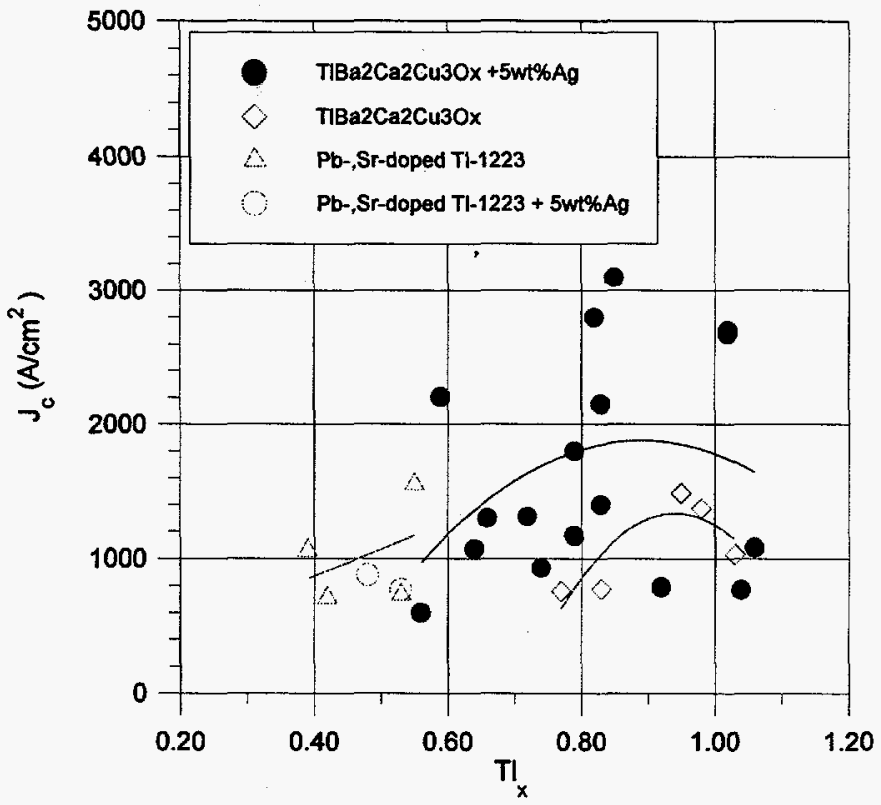

Figure 3-7. Critical current densities for TI-1223 films on Ag substrates.

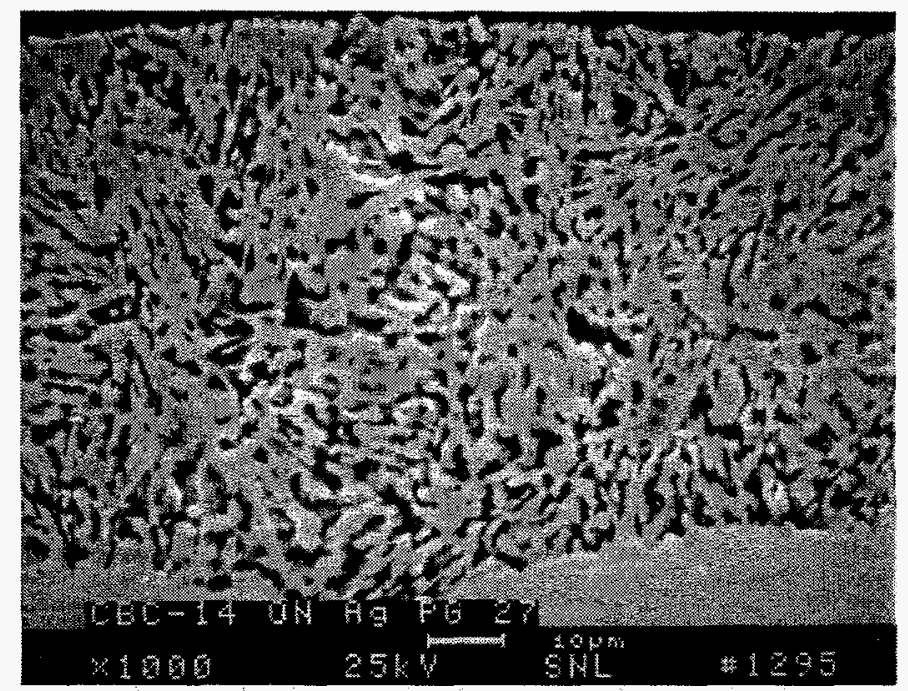

Figure 3-8. SEM micrograph of undoped TI-1223 thick film on Ag. 


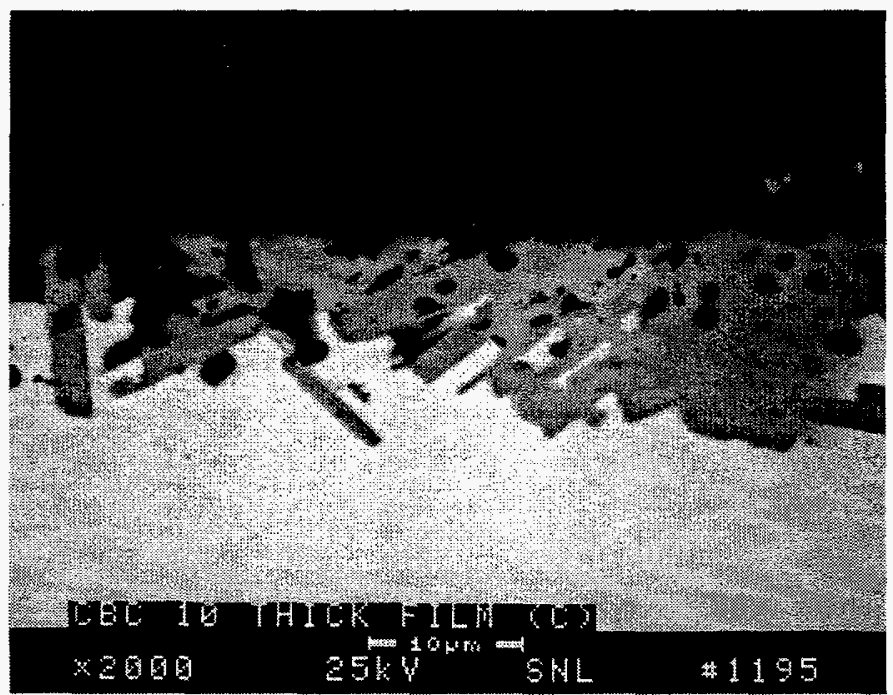

Figure 3-9. Pb-,Sr-doped Tl-1223 thick film on Ag.

\subsection{Future Work}

Work for this coming Fiscal Year will concentrate on the Pb-,Sr-doped Tl-1223 system. Dip coating of the undoped material has not achieved the degree of texture needed for high current density and strong links. The $\mathrm{Pb}$-, Sr-doped system may show superior performance if smooth interfaces can be achieved, secondary phases minimized and thicker films obtained while maintaining grain alignment. Alternate deposition techniques such as ink spray, in collaboration with NREL, will be investigated. Improvements in the precursor powders will be attempted using techniques to minimize agglomeration and thus reduce particle size. 


\section{Cryogenic Design of a High-Temperature Superconducting (HTS) Motor}

\subsection{Introduction}

Development of HTS conductors will allow increased electrical efficiency and reduced size and weight electrical devices. This will translate to a significant savings for US industry. The overall purpose of this Superconducting Partnership Initiative (SPI) project is to demonstrate a prototype $125 \mathrm{hp} \mathrm{HTS}$ motor. Our efforts in this SPI are concentrated in the heat transport aspects of the motor. Our goals for this fiscal year were to collaborate with the SPI team on the motor design. As the design progressed, heat transfer and stability analyses were conducted that were performed on geometries that evolved with the motor design.

\subsection{Progress in FY95}

Sandia provided design feedback during the motor design process. Analysis confirmed the adequacy of the design. Various instability mechanisms were investigated that could inhibit steady operation of the motor. A potentially troubling finding was parallel channel instability. SNL's analysis resulted in significant design modifications. The Reliance Electric/Sandia design team are shown in Figure 4-1 with the superconducting rotor and armature. Figure 4-2 shows a schematic of the operating motor.

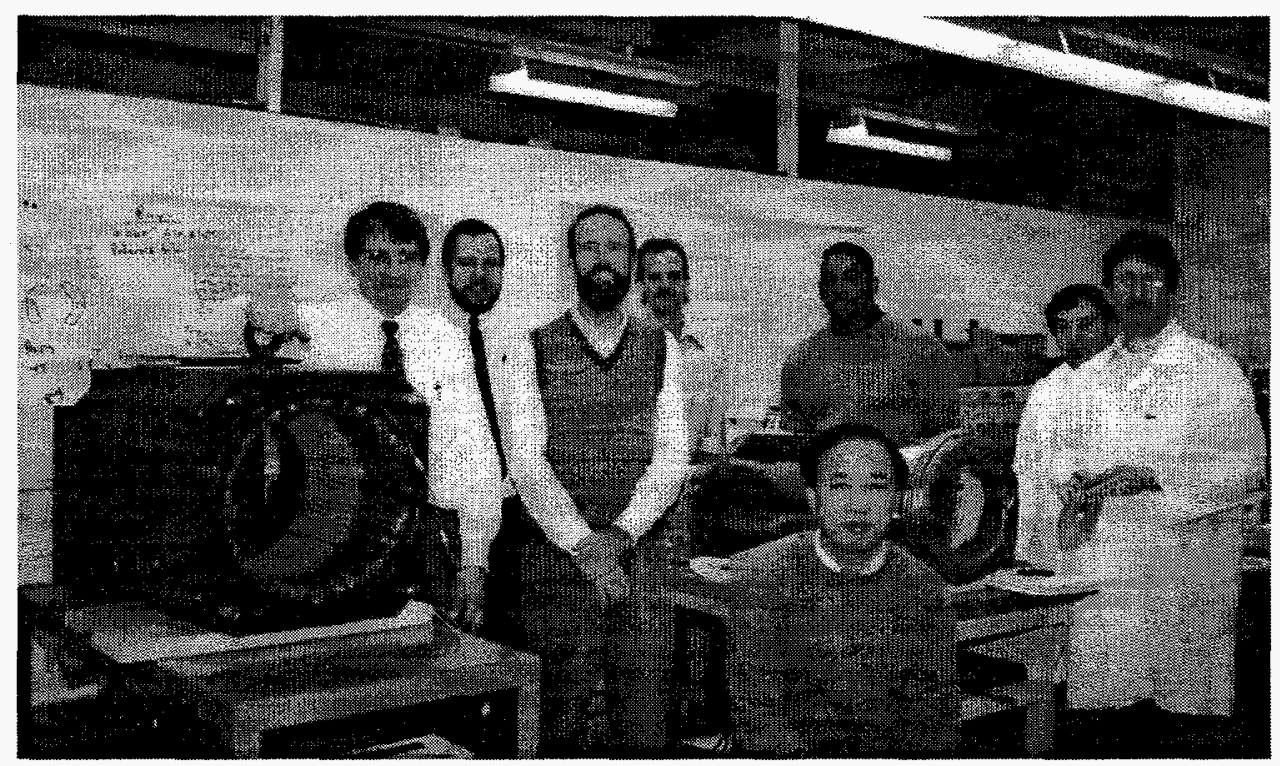

Figure 4-1. Reliance Electric/Sandia Design Team with HTS Motor. 


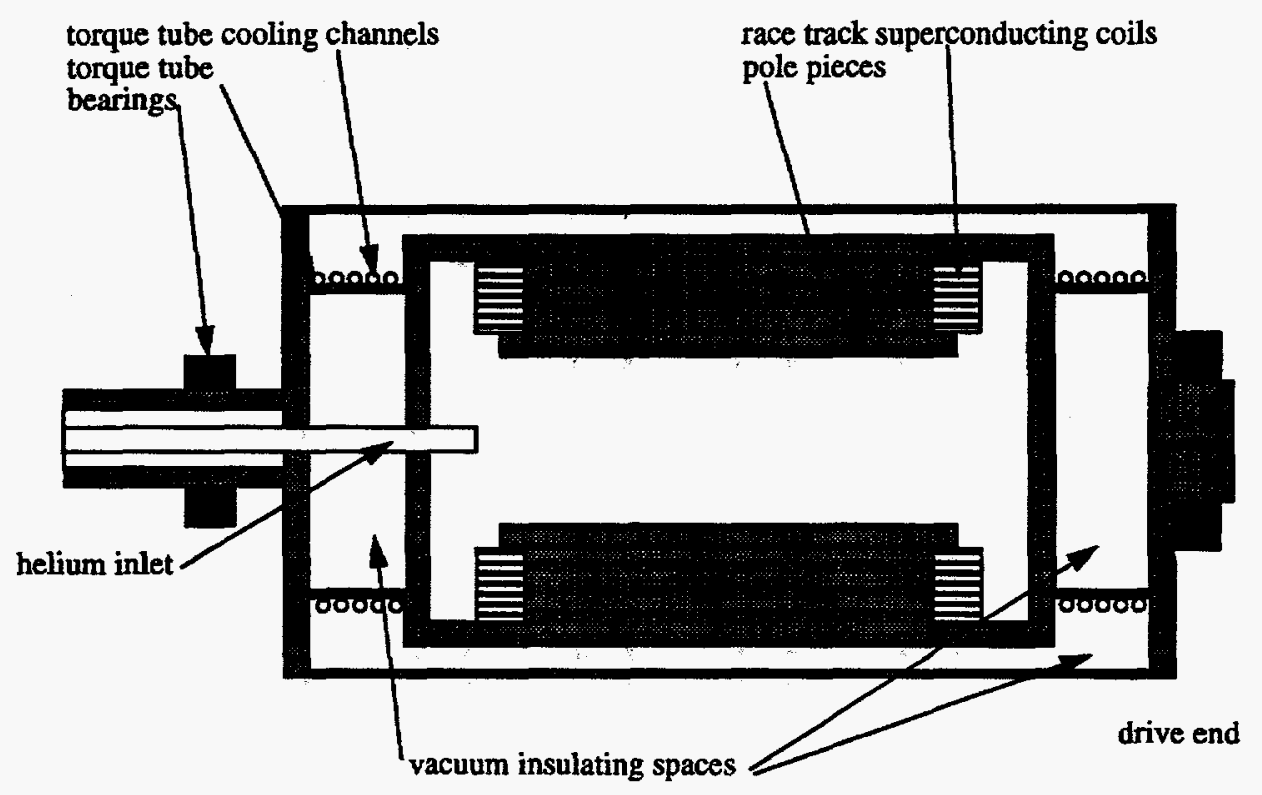

Figure 4-2. Simplified geometry of Reliance Electric cryogenic motor.

\subsection{Future Work}

In the coming fiscal year, experimental data will be coming available from the $125 \mathrm{HP}$ motor. Sandia is responsible for analyzing the experimental data for signs of flow instabilities. Sandia will also aid in the analysis of the heat transfer data to determine the effectiveness of the cooling system design. Sandia developed cooling system models will be modified to account for any unexpected results. Further analysis will suggest design improvements in the design optimization portion of the Phase $1 \mathrm{SPI}$. Also, Reliance Electric has been awarded a Phase 2 SPI where 1000 and $5000 \mathrm{HP}$ motors will be designed and built. Phase II will include development of cryogenic coolers optimized for HTS motor application. In the upcoming fiscal year, much of the design effort for Phase 2 will be accomplished. Sandia will be intimately involved in the design of the cooling system for Phase 2 in much the same manner as Sandia's involvement in Phase 1. 
Dr. James Daley

EE-14

Forrestal Building, US Department of Energy 1000 Independence Avenue, S. W.

Washington, DC 20585

Dr. Christine Platt

CE-32

Forrestal Building, US Department of Energy 1000 Independence Avenue, S. W.

Washington, DC 20585

Dr.Richard Blaugher

NREL

Branch 210, Location 16/3

1617 Cole Boulevard

Golden, CO 80401

Dr. R. A. Hawsey

Oak Ridge National Laboratory

Superconducting Technology Program

Post Office Box 2008

Oak Ridge, TN 37831-6040

Dr. David O. Welch

Brookhaven National Laboratory

Building 480

Upton, NY 11973

Mr. J. Badin

Energetics

7164 Gateway Drive

Columbia, MD 21046

Mr. Rich Schiferl

Reliance Electric

24701 Euclid Avenue

Cleveland, $\mathrm{OH} 44117$
Mr. Chris Kang

EE-14

Forrestal Building, US Department of Energy

1000 Independence Avenue, S. W.

Washington, DC 20585

Mr. Dan Eckelkamp-Baker

US Department of Energy

Kirtland AFB-East, "H" Street at Pennsylvania

Post Office Box 5400

Albuquerque, NM 87115

Dr. James Dirks

Battelle, Pacific Northwest Laboratories

Technology and Planning Center

Post Office Box 999

Richland, WA 99352

Dr. Dean E. Peterson

Los Alamos National Laboratory

MS-K763

Post Office Box 1663

Los Alamos, NM 87545

Dr. Balu Balachandran

Argonne National Laboratory, ET

Building 212

9700 South Cass Avenue

Argonne, IL 60439-4838

Mr. C. Matzdorf

Energetics

7164 Gateway Drive

Columbia, MD 21046

Dr. Susan M. Schoenung

Longitude 122 West, Inc.

1241 Hobart Street

Menlo Park, CA 94025 
Mr. James R. Gaines, Jr.

Superconductive Components, Inc.

1145 Chesapeake Avenue

Columbus, OH 43212

Mr. William T. Nachtrab

Nuclear Metals, Inc.

2229 Main Street

Concord, MA 01742

Dr. Pradeep Haldar

Intermagnetics General Corporation

Post Office Box 566

Charles Industrial Park, New Karner Road

Guilderland, NY 12084

\section{MS-0899}

Technical Library

Org. 4414 (5)

MS-0100

Document Processing for DOE/OSTI

Org. 7613-2 (2)
Dr. Nancy Levoy Nuclear Metals, Inc. 2229 Main Street

Concord, MA 01742

Mr. Marc Lemmond

MK Associates

1920 "N" Street, N. W.

Suite 750

Washington, DC 20036

MS-9018

Central Technical Files

Org. 8523-2
MS-0619

Print Media

Org. 12615

MS-0609

W. F. Hammetter
MS-0702

D. E. Arvizu
MS-0835

T. C. Bickel
MS-0752

F. D. Chavez
MS-0752

E. P. Roth 
MS-0835

R. D. Skocypec

MS-0959

F. P. Gerstle, Jr.

MS-1405

J. A. Voigt

MS-1421

E. B. Stechel

MS-1421

E. L. Venturini
MS-0835

R. C. Dykhuizen

MS-0959

S. Lockwood

MS-1405

D. Lamppa

MS-1421

B. Morosin 